Portland State University

PDXScholar

6-11-1993

\title{
Predicting Seepage of Leachate from the St. Johns Landfill to Ground and Surface Water Systems
}

Kevin A. Schock

Portland State University

Follow this and additional works at: https://pdxscholar.library.pdx.edu/open_access_etds

Part of the Civil Engineering Commons

Let us know how access to this document benefits you.

\section{Recommended Citation}

Schock, Kevin A., "Predicting Seepage of Leachate from the St. Johns Landfill to Ground and Surface Water Systems" (1993). Dissertations and Theses. Paper 4648.

https://doi.org/10.15760/etd.6532

This Thesis is brought to you for free and open access. It has been accepted for inclusion in Dissertations and Theses by an authorized administrator of PDXScholar. Please contact us if we can make this document more accessible: pdxscholar@pdx.edu. 
AN ABSTRACT OF THE THESIS OF Kevin A. Schock for the Master of Science in Civil Engineering presented June 11, 1993.

Title: Predicting Seepage of Leachate from the st. Johns Landfill to Ground and Surface water Systems.

APPROVED BY THE MEMBERS OF THE THESIS COMMITTEE:

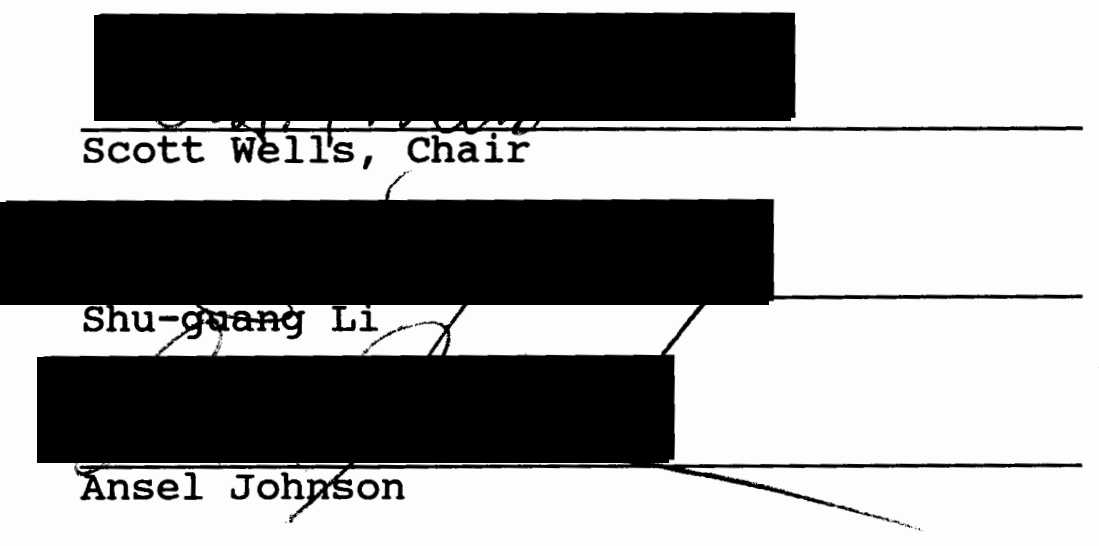

Determination of the vertical and horizontal groundwater hydraulic gradient within a landfill is the first step in determining the potential of groundwater contamination from the landfill leachate. The length of a study and the frequency at which measurements are recorded can greatly affect the description of the local groundwater environment. A more comprehensive analysis can be preformed for longer periods of study and greater measurement frequency.

The intent of this study was to install a continuous groundwater level monitoring system around the st. Johns Landfill for a minimum study length of one year. This would allow a more thorough study of the seasonal character and 
behavior of the groundwater system beneath the landfill than in previous studies. Particular interest was paid to groundwater level changes resulting from seasonal weather changes. Additional attention was paid to other forcing mechanisms which could be perturbing groundwater levels, and variations in the geochemical groundwater constituents.

Included throughout this report is a literature review of various studies pertinent to the analysis of groundwater level variations.

Seasonal variations in vertical groundwater hydraulic gradients were reviewed and time averaged vertical seepage rates were estimated. Areal plots of groundwater levels were used to view expected horizontal groundwater hydraulic gradients during seasonal maximum and minimum groundwater levels. A computer model was developed to study the effects temporal variations in slough water levels had on groundwater seepage rates through the perimeter dike separating the landfill from the sloughs. The modeling provided an estimate of the average horizontal leachate seepage rate into the sloughs.

Comparison plots of monitoring well groundwater levels were used to analyze potential swash zones beneath the landfill and potential effects of lowered water levels in Bybee Lake. Spectral analysis techniques were imployed to determine the dominant frequencies observed in the groundwater levels, allowing determination of the type of forcing 
mechanism driving the fluctuations.

Geochemical groundwater constituents were statistically analyzed to determine the significance of observed trends in the data: areal plots of chloride concentrations and electrical conductivity were made to view constituent distributions within the underlying aquifers.

Estimated vertical and horizontal groundwater seepage rates into the local waters showed that horizontal leachate seepage is insignificant compared to vertical leachate seepage. Groundwater level comparison plots indicated no significant swashing beneath the landfill occurred. The statistical studies on groundwater forcing mechanisms indicated that either the slough or the Columbia River water levels could be perturbing groundwater levels. Trend analyses on the geochemical groundwater constituents indicated significant, positive trends in chloride concentrations, and undeterminable trends in electrical conductivity. 


\title{
PREDICTING SEEPAGE OF LEACHATE FROM \\ THE ST. JOHNS LANDFILL TO \\ GROUND AND SURFACE WATER SYSTEMS
}

\author{
by \\ KEVIN A. SCHOCK
}

A thesis submitted in partial fulfillment of the requirements for the degree of

MASTER OF SCIENCE

in

CIVIL ENGINEERING

PORTLAND STATE UNIVERSITY

1993 
TO THE OFFICE OF GRADUATE STUDIES:

The members of the Committee approve the thesis of Kevin A. Schock presented June 11, 1993.
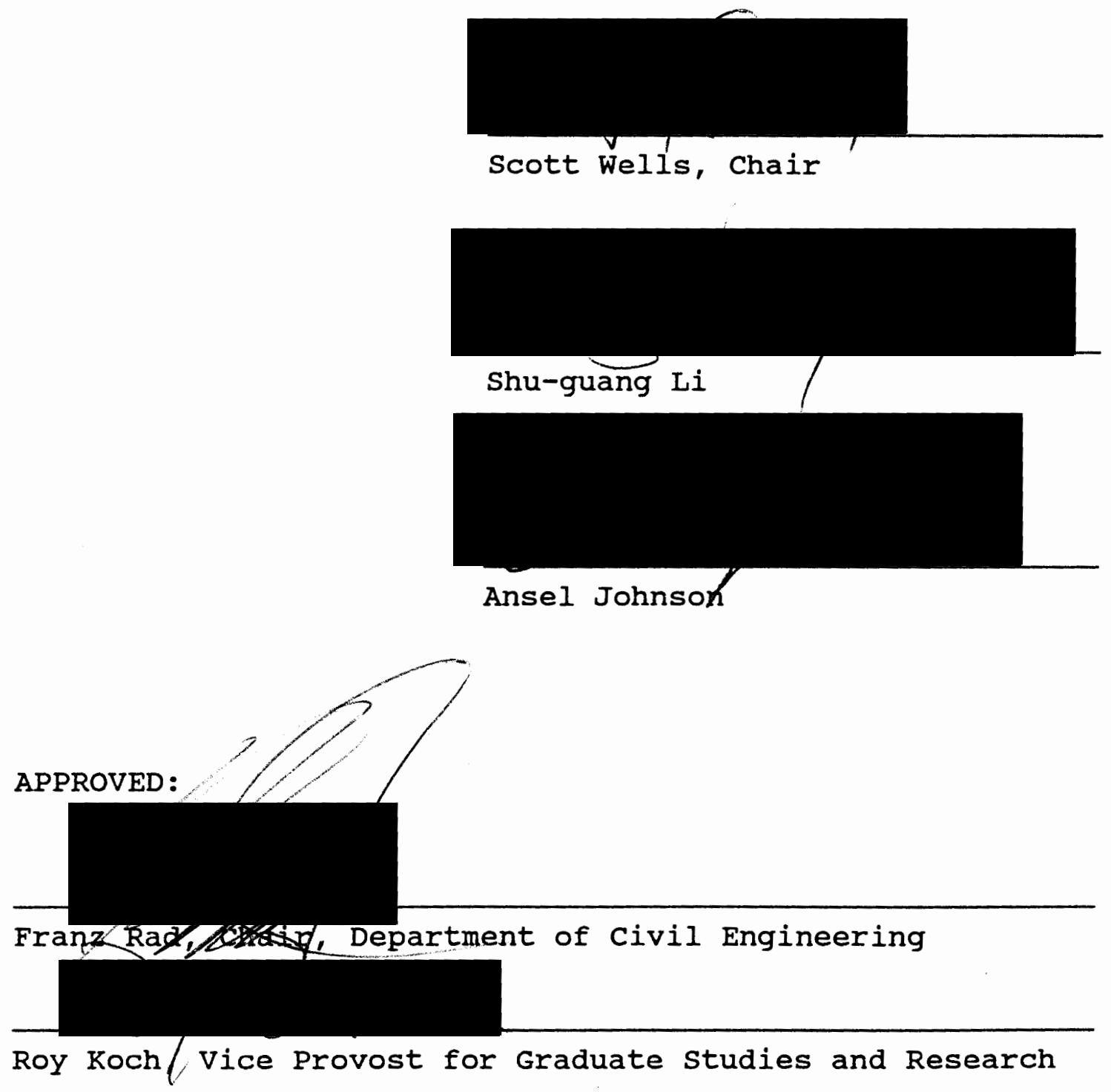
TABLE OF CONTENTS

PAGE

PAGE
$\quad \mathrm{V}$

LIST OF FIGURES .......................... vii

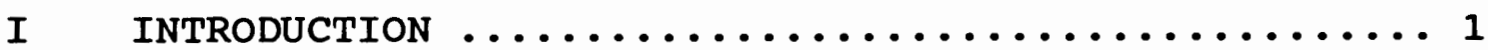

Background ........................ 1

Previous studies .....................4

II OBJECTIVES AND METHODOLOGY ................. 5

study objectives ..................... 5

Methodology ........................ 5

III FIELD STUDY RESULTS AND ANALYSES .............. 10

Investigation of the Geology Around st. Johns

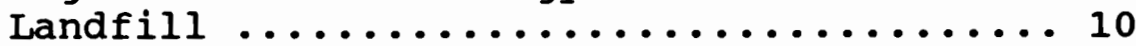

Sources of Groundwater Contamination ........ 14

Analysis of Geochemical Field Observations ... 16

Electrical Conductivity

Chloride Concentrations

Isoconcentrations for Conductivity and Chloride

Fluctuations in Groundwater Levels ........ 36

Analysis of Groundwater Level Field

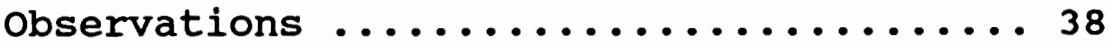

Hydraulic Gradient Analysis ............. 57

Vertical Gradients

Isocontours of Horizontal Hydraulic Head

IV COMPUTER MODEL DEVELOPMENT AND ANALYSIS ........ 71 
Dynamics of the Groundwater System Perturbed by Tidal Motions at the Beach Interface . 71

Development of the Computer Model $\ldots \ldots \ldots \ldots 73$

Governing Differential Equation

Modeling Assumptions

Model Verification

Estimation of Modeling Parameters and Boundary

set ...................... 80

Modeling Parameters

Boundary Data set

Computer Simulation Analysis .......... 85

Pre-Modeling Time Requirements

Computer Simulations

Columbia River Tidal Influences ......... 95

$\mathrm{v}$ SUMMARY AND CONCLUSIONS $\ldots \ldots \ldots \ldots \ldots \ldots \ldots \ldots$

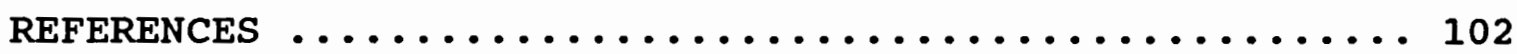

APPENDICES

A SPECIFICATIONS FOR LAB AND FIELD INSTRUMENTS • 104

B RELIABILITY OF CHLORIDE PROBE .......... 108

C SHAPIRO-WILKS TEST ON REGRESSION RESIDUALS ... 112

D BAROMETRIC PRESSURE ANALYSIS ........... 120

E SHAPIRO-WILKS TEST ON LOG TRANSFORMED

HYDRAULIC CONDUCTIVITY ........... 122

F ESTIMATION OF VERTICAL SEEPAGE $\ldots \ldots \ldots \ldots \ldots 126$ 


\section{LIST OF TABLES}

TABLE

PAGE

I Typical Chemical Concentrations in Leachate ... 15

II Typical Background Water Electrical

Conductivities for Portland Area ....... 16

III Simple Linear Regression Analysis on Trends

in Electrical Conductivity Log Transformed

Data (95\% Confidence Level).......... 24

IV Simple Linear Regression Analysis on Trends

in Chloride Concentrations Log Transformed

Data (95\% Confidence Level) .......... 27

V Mechanisms which Induce Fluctuations in

Groundwater Levels .............. 38

VI Ranges of Groundwater Levels with Periods of

14 Days and Less.................. 47

VII Groupings used in the Cross-Correlations ..... 52

VIII General Characteristics of Monitoring Wells ... 58

IX Statistics of Log Transformed Data ........83

$\mathrm{X}$ Summary of Soil Parameter Estimates and

Groundwater Level Ranges used for

the Computer simulations ........... 88

XI Observed and Calibrated Soil Parameter

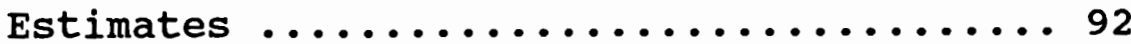


XII Comparisons the Field Estimated and Calibrated Hydraulic Conductivity .............. 94

XIII Time Averaged Groundwater Levels and Horizontal

Flow Rates from the Computer simulation .. 95

XIV Columbia River Tidal Influences on the

Groundwater Under st. Johns Landfill .... 97 
LIST OF FIGURES

FIGURE

PAGE

1. Location of the st. Johns groundwater study area relative to Portland, ore........ 2

2. Relative location of the water bodies surrounding st. Johns Landfill ....... 3

3. Relative locations of well monitoring sites and slough gaging sites ............6

4. Schematic showing the computer monitoring system used in the field ........... 8

5. Location of vertical cross-section used to describe the geologic profile ......... 11

6. Vertical profile showing the soil layers that underlie the landfill ...........11

7. Vertical profile showing the soil layers that underlie the landfill and slough through wells $G 5 b$ and $G 3$, then along the perimeter dike .................. 12

8. Vertical profile showing the soil layers that underlie the landfill and slough through wells G7, DIC, and G6 ....... 12 
9. Vertical profile showing the soil layers

that underlie the landfill and slough

through wells $G 1$ and G8b .......... 13

10. Comparisons of conductivity and chloride

for well Dla ................. 17

11. Comparisons of conductivity and chloride

for well $G 1 \ldots \ldots \ldots \ldots \ldots \ldots \ldots \ldots \ldots$

12. Comparisons of conductivity and chloride

for well G3. ............... 17

13. Comparisons of conductivity and chloride

for well Dlc ............... 17

14. Comparisons of conductivity and chloride

for well $62 . \ldots \ldots \ldots \ldots \ldots \ldots \ldots \ldots \ldots$

15. Comparisons of conductivity and chloride

for well $G 6 \ldots \ldots \ldots \ldots \ldots \ldots \ldots \ldots \ldots$

16. Comparisons of conductivity and chloride

for well G5a $\ldots \ldots \ldots \ldots \ldots \ldots \ldots \ldots \ldots$

17. Comparisons of conductivity and chloride

for well $G 7 \ldots \ldots \ldots \ldots \ldots \ldots \ldots \ldots \ldots$

18. Comparisons of conductivity and chloride

for well $G 8 b \ldots \ldots \ldots \ldots \ldots \ldots \ldots \ldots \ldots$

19. Comparisons of conductivity and chloride

for well $G 5 b \ldots \ldots \ldots \ldots \ldots \ldots \ldots \ldots$

20. Comparisons of conductivity and chloride

for well G8a $\ldots \ldots \ldots \ldots \ldots \ldots \ldots \ldots \ldots$ 
21. Comparisons of conductivity and chloride for well G8c ................. 18

22. Comparisons of conductivity and chloride for well Familian............... 19

23. Comparisons of conductivity and temperature for well Dla ................. 21

24. Comparisons of conductivity and temperature

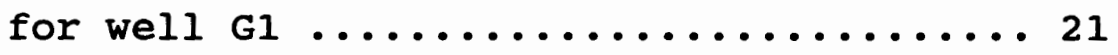

25. Comparisons of conductivity and temperature

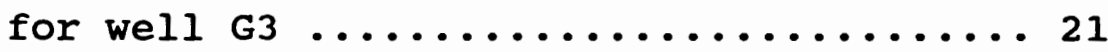

26. Comparisons of conductivity and temperature for well Dlc $\ldots \ldots \ldots \ldots \ldots \ldots \ldots \ldots \ldots . \ldots 21$

27. Comparisons of conductivity and temperature for well $62 . \ldots \ldots \ldots \ldots \ldots \ldots \ldots \ldots \ldots 21$

28. Comparisons of conductivity and temperature for well $G 6 \ldots \ldots \ldots \ldots \ldots \ldots \ldots \ldots \ldots \ldots$ 29. Comparisons of conductivity and temperature for well G5a $\ldots \ldots \ldots \ldots \ldots \ldots \ldots \ldots \ldots 22$ 30. Comparisons of conductivity and temperature for well $G 7 \ldots \ldots \ldots \ldots \ldots \ldots \ldots \ldots \ldots 22$

31. Comparisons of conductivity and temperature for well $G 8 b \ldots \ldots \ldots \ldots \ldots \ldots \ldots \ldots 22$

32. Comparisons of conductivity and temperature for well $G 5 b \ldots \ldots \ldots \ldots \ldots \ldots \ldots \ldots 22$ 
33. Comparisons of conductivity and temperature for well G8a ................. 22

34. Comparisons of conductivity and temperature for well $G 8 \mathrm{c} \ldots \ldots \ldots \ldots \ldots \ldots \ldots \ldots \ldots 22$

35. Comparisons of conductivity and temperature for well Familian............... 23

36. Electrical conductivity for multiple completion well G5ab ............. 25

37. Electrical conductivity for multiple completion well G8abc ............ 26

38. Electrical conductivity for multiple completion well Dlac $\ldots \ldots \ldots \ldots \ldots \ldots 26$

39. Chloride concentration for multiple completion well G5ab ............ 28

40. Chloride concentration for multiple completion well G8abc ............ 29

41. Chloride concentration for multiple completion well Dlac ............. 29

42. Isoconcentrations of chloride distributions in the silt aquitard, $(1 / 16 / 91) \ldots \ldots .32$

43. Isoconcentrations of chloride distributions in the silt aquitard, $(4 / 24 / 92) \ldots \ldots \ldots 32$ 44. Isoconcentrations of chloride distributions in the sandy/gravel aquifer, (1/14/91) . 32 
45. Isoconcentrations of chloride distributions in the sandy/gravel aquifer, (4/24/92) .. 32

46. Superimposed chloride concentration time series for monitoring wells G5, G6 and $\mathrm{G} 8 \mathrm{~b} \ldots \ldots \ldots \ldots \ldots \ldots \ldots \ldots \ldots \ldots . \ldots \ldots$

47. Superimposed chloride concentration time series for monitoring wells G2, G3 and $\mathrm{Dlc} \ldots \ldots \ldots \ldots \ldots \ldots \ldots \ldots \ldots \ldots \ldots \ldots . \ldots \ldots$

48. Isoconcentrations of electrical conductivity distributions in the silt aquitard,

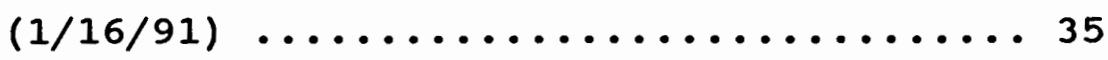

49. Isoconcentrations of electrical conductivity distributions in the silt aquitard,

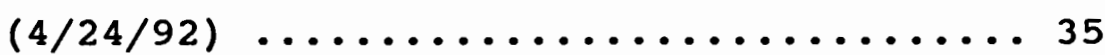

50. Isoconcentrations of electrical conductivity distributions in the sandy/gravel aquifer,

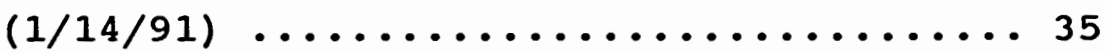

51. Isoconcentrations of electrical conductivity distributions in the sandy/gravel aquifer,

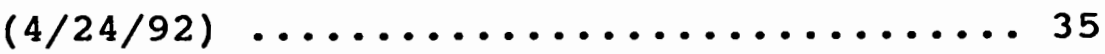

52. Superimposed electrical conductivity concentration time series for monitoring wells $G 5, G 6$ and $G 8 b \ldots \ldots \ldots \ldots$ 
53. Superimposed electrical conductivity concentration time series for monitoring wells $G 2, G 3$ and $D 1 C \ldots \ldots \ldots \ldots \ldots$

54. Observed groundwater levels at field monitor sites: (a) $G 1$, (b) $G 2$, (c) $G 3 \ldots . . . . .40$

55. Observed groundwater levels at field monitor sites: (a) G5a, (b) G5b, (c) G6 ....... 40

56. Observed groundwater levels at field monitor sites (a) G8a, (b) G8b, (c) G8C ........4 41

57. Observed groundwater levels at field monitor sites (a) Dla, (b) Dlc, (c) Familian ....4 41 58. Observed precipitation events for Julian year 1991 displayed as: (a) hourly precipitation (water equivalent in inches), (b) cumulative rainfall depth (Julian day 1 is January 1 ,

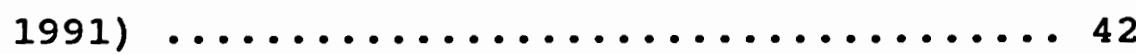

59. Power spectrum showing the amount of variance per interval of frequency for groundwater level time series: (a) G1, (b) G2, (c) $\mathrm{G} 3$ 44

60. Power spectrum showing the amount of variance per interval of frequency for groundwater level time series: (a) G6, (b) Dla, (c) $\mathrm{D} 1 \mathrm{c} \ldots \ldots \ldots \ldots \ldots \ldots \ldots \ldots \ldots \ldots \ldots \ldots . \ldots . \ldots 44$ 
61. Power spectrum showing the amount of variance per interval of frequency time series: (a) N. Slough, (b) Rainfall ..........44 62. Groundwater level time series for monitoring well Gl each series being: (a) observed, (b) 14 day smoothed, (c) differenced .... 46 63. Groundwater level time series for monitoring well G2 each series being: (a) observed, (b) 14 day smoothed, (c) differenced .... 46 64. Groundwater level time series for monitoring well G3 each series being: (a) observed, (b) 14 day smoothed, (c) differenced ....4 48 65. Groundwater level time series for monitoring well G5a each series being: (a) observed, (b) 14 day smoothed, (c) differenced .... 48 66. Groundwater level time series for monitoring well G6 each series being: (a) observed, (b) 14 day smoothed, (c) differenced .... 49 67. Groundwater level time series for monitoring well G5b each series being: (a) observed, (b) 14 day smoothed, (c) differenced .... 49 68. Groundwater level time series for monitoring well G8b each series being: (a) observed, (b) 14 day smoothed, (c) differenced .... 50 
69. Groundwater level time series for monitoring well G8a each series being: (a) observed, (b) 14 day smoothed, (c) differenced ..... 50 70. Groundwater level time series for monitoring well G8C each series being: (a) observed, (b) 14 day smoothed, (c) differenced .... 51

71. Groundwater level time series for monitoring well Dla ,each series being: (a) observed, (b) 14 day smoothed, (c) differenced .... 51

72. Groundwater level time series for monitoring well Dlc each series being: (a) observed, (b) 14 day smoothed, (c) differenced .... 52 73. Cross-correlation matrix between the slough and groundwater monitoring sites: (a) GI, (b) $G 2$, (c) $G 3 \ldots \ldots \ldots \ldots \ldots \ldots \ldots \ldots \ldots \ldots \ldots \ldots \ldots \ldots$

74. Cross-correlation matrix between the slough and groundwater monitoring sites: (a) G5a, (b) $G 5 b$, (c) $G 6 \ldots \ldots \ldots \ldots \ldots \ldots \ldots \ldots \ldots \ldots \ldots \ldots$

75. Cross-correlation matrix between the slough and groundwater monitoring sites: (a) G8a, (b) G8b, (c) G8c $\ldots \ldots \ldots \ldots \ldots \ldots \ldots \ldots \ldots$

76. Cross-correlation matrix between the slough and groundwater monitoring sites: Dla,c .. 54 
77. Vertical cross-sections showing soil types at each screened interval and distances between intervals for multiple completion wells used in the vertical gradient analysis .....................6 60

78. Vertical hydraulic gradient at monitoring well G5ab ......................60

79. Comparisons between the water level time series at monitor well G5ab and near by Bybee Lake $\ldots \ldots \ldots \ldots \ldots \ldots \ldots \ldots \ldots 61$

80. Comparisons between the water level time series at monitor well G5ab and water levels in the North Slough ..........61

81. Vertical hydraulic gradient at monitor well

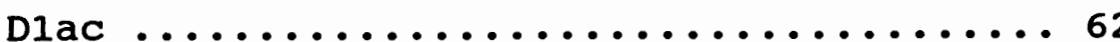

82. Vertical hydraulic gradient at monitor well G8abc 64

83. Isocontours of the hydraulic head in the upper silt aquitard, day $170(5 / 19 / 91) \ldots 66$

84. Isocontours of the hydraulic head in the upper silt aquitard, day $310(11 / 16 / 91) \ldots 66$ 85. Comparison plot of the groundwater level time series for monitoring wells completed in the upper silt aquitard ....6 67 
86. Isocontours of the hydraulic head in the lower sandy/gravel aquifer, day 170

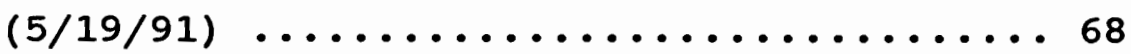

87. Isocontours of the hydraulic head in the

lower sandy/gravel aquifer, day 310

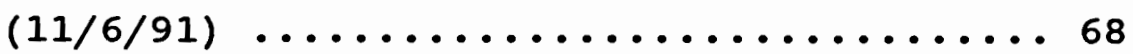

88. Comparison plot of groundwater level time series for monitoring wells completed in the lower sandy/gravel aquifer ........ 69

89. Physical representation of the computer

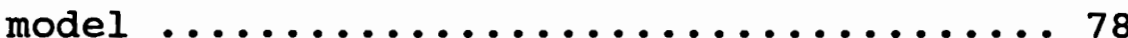

90. The hydraulic head predicted by the computer model for a vertically stratified, unconfined aquifer ................ 81

91. Mirrored USGS Lombard and monitoring well G1 water level time series: (a) observed, smoothed, (c) differenced ............ 85

92. Computed head envelops after pre-modeling run times: (a) 5 yrs, (b) 25 yrs,

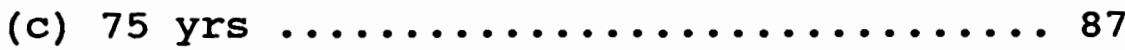

93. Head envelope from storativity calibration, SI is assumed constant along ' $\mathrm{x}$ '........ 90 94. Head envelope from storativity calibration, S1 is assumed constant along ' $\mathrm{x}$ '........990 
95. Head envelope from storativity calibration,

s1 is assumed constant along ' $\mathrm{x}$ '........ 90

96. Head envelope using the field estimated soil parameters ...................... 90

97. Head envelope using the field estimated soil

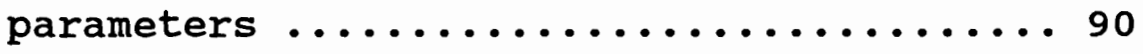

98. Head envelope using the field estimated soil parameters ...................... 90 


\section{CHAPTER I}

\section{INTRODUCTION}

\section{BACKGROUND}

The St. Johns Landfill is located north-west of Portland, Oregon in the st. Johns/Rivergate industrial district, see Figure 1. Prior to the development of the industrial park, the area was an extensive network of interconnected lakes, marshes, wetlands, and sloughs. The industrial park is bounded on the north and south by the columbia and willamette Rivers respectively, the confluence of the two rivers forms the eastern boundary.

Landfilling of the dump site began in the early 1930's and continued until its closing in late 1991, the filling is composed of both industrial and municipal waste. The landfill itself lies atop an unnamed lake, its boundaries formed by a system of natural levees which are now the perimeter dike system separating the landfill from the adjacent sloughs. The Columbia Slough borders the south and the North Slough borders the north, see Figure 2 .

The general stratigraphy of the geology underlying the landfill consists of, from top to bottom, flood plain silt, river sand, and sandy/gravel. The depth and areal extent of each stratum changes quite dramatically in space. A more 


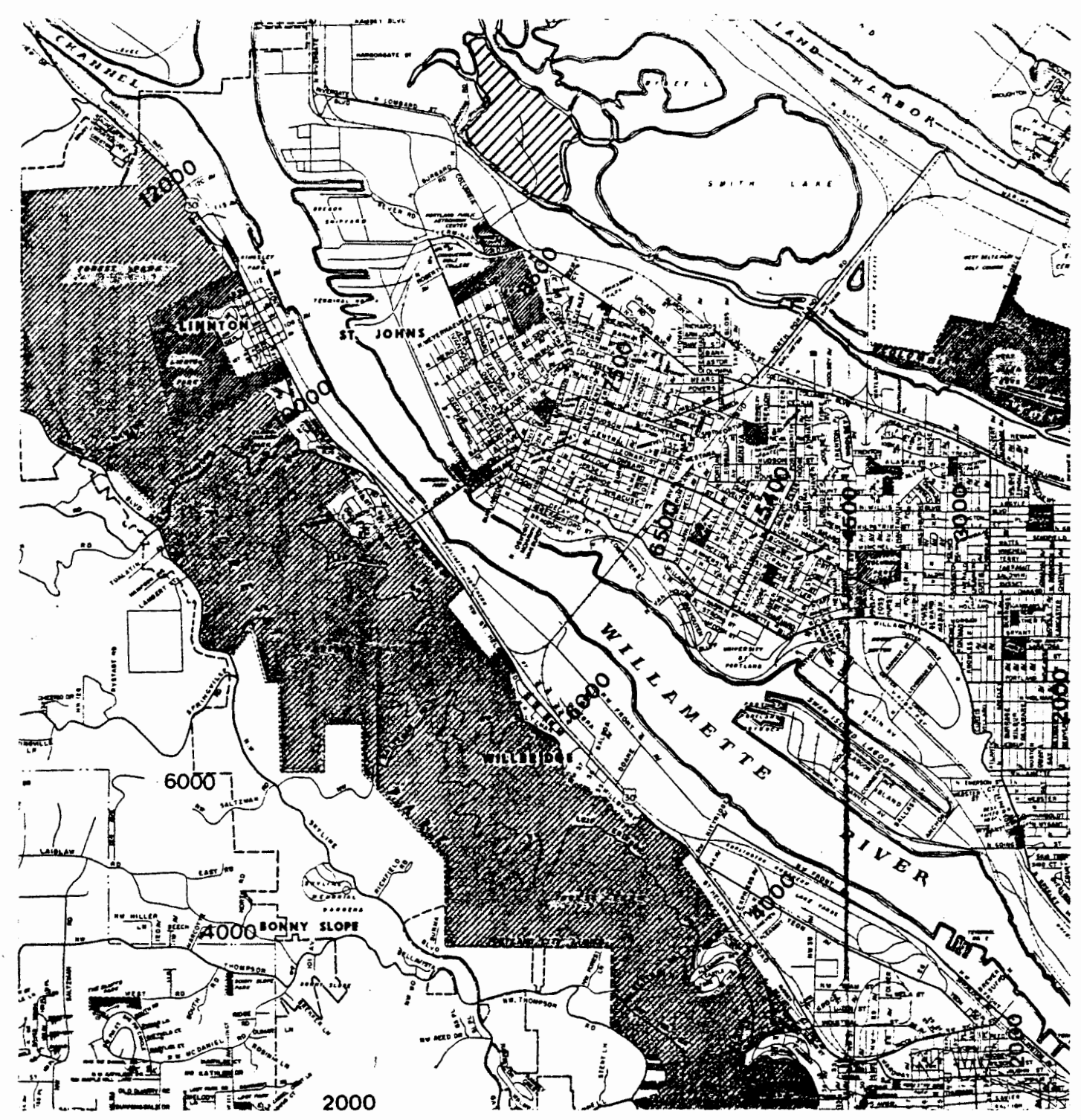

Figure 1. Location of the st. Johns groundwater study area relative to Portland, Oregon.

detailed investigation of the stratigraphy is presented in subsequent chapters.

The area surrounding the landfill is heavily used by industry and the City of Portland Municipal Wastewater 


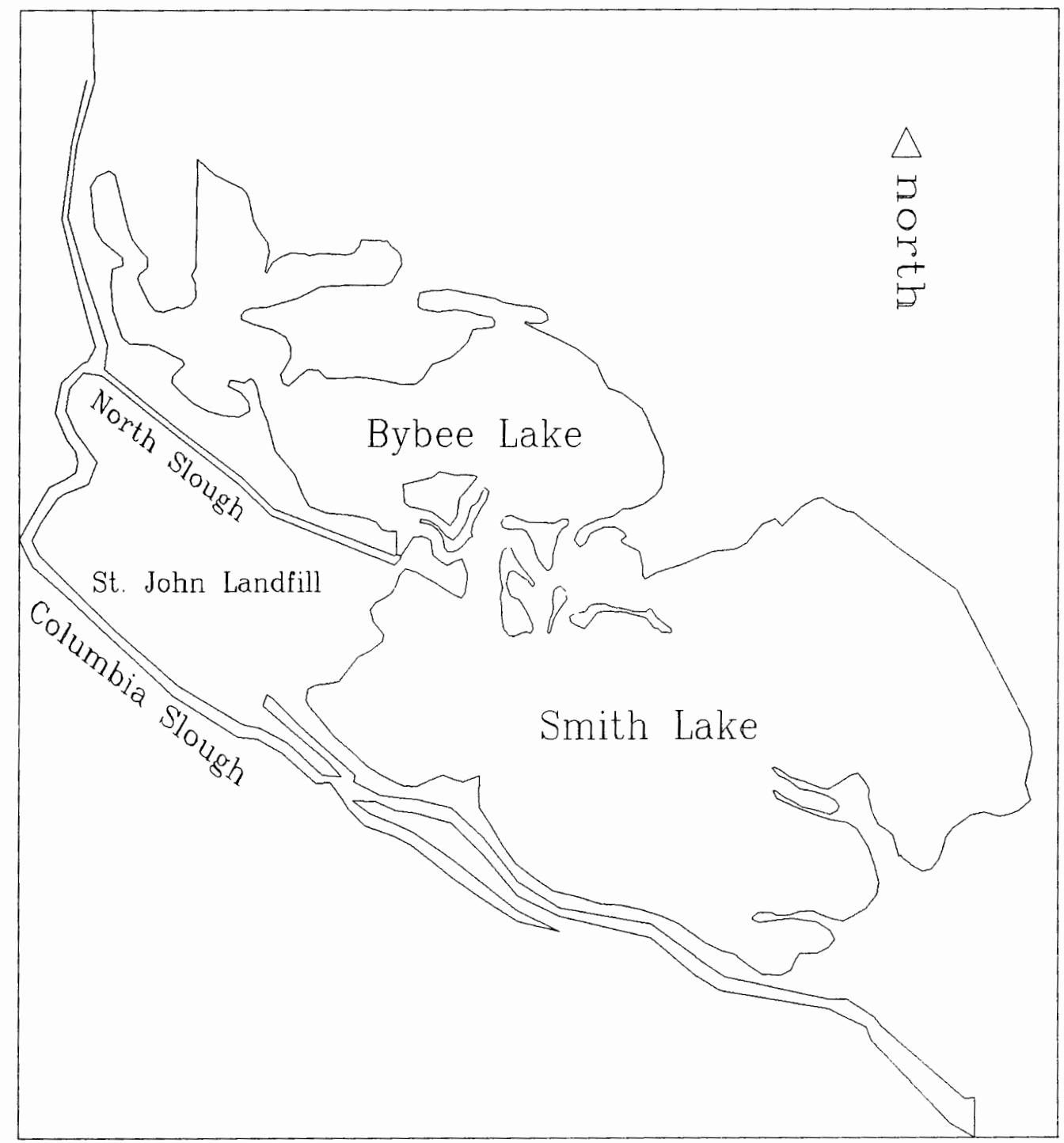

Figure 2. Relative location of the water bodies surrounding $S t$. Johns Landfill.

Treatment Plant is nearby. In addition, several combined sewer outflows discharge directly into the columbia slough during heavy rains. Thus, there are many sites which have the potential to contaminate the local groundwater besides the landfill. A comprehensive list of possible industrial contamination sites and types can be found in sweet 
Edwards/EMCON (1989) report.

\section{PREVIOUS STUDIES}

The most extensive studies regarding the st. Johns Landfill to date, were prepared by Sweet Edwards/EMCON (1989) and Fishman Environmental Services (1986) for the Metropolitan Services District of Portland (METRO). Fishman Environmental Services reported that leachate from st. Johns Landfill had penetrated the flood plain silts and was seeping into the underlying sandy/gravel aquifer, and that the areal horizontal groundwater gradient direction was towards the Columbia River. The Sweet Edwards/EMCON study reported general horizontal groundwater gradients in a north to northwesterly direction, and once during the period of study reversing to southerly direction. Both studies suggested that the groundwater around the landfill was influenced by tidal and flooding events that occur in the surrounding surface waters. Neither of the two studies implemented a continuous groundwater monitoring program of significant length, the studies could not adequately discuss seasonal groundwater changes. A continuous monitoring system of at least one year in length would allow a more thorough study of the character and behavior of the groundwater system. 
CHAPTER II

OBJECTIVES AND METHODOLOGY

\author{
STUDY OBJECTIVES
}

The intent of this study was to understand how the physical and chemical character or behavior of the groundwater beneath St. Johns Landfill changed temporally and spatially over the seasons. This information would then be used to predict the magnitude and extent of leachate migration through the landfill into neighboring surface and ground water systems. In order to understand the groundwater flow dynamics, the following programs were initiated:

(1) Installation of a continuous groundwater level monitoring system operating for a minimum of 12 months to capture the seasonal variations in groundwater levels. This would allow a thorough analysis of the seasonal variations in the vertical and horizontal hydraulic gradients, and the influence tidal motions in surrounding surface waters have on groundwater within the landfill.

(2) Record various groundwater chemical constituents (specifically chloride, electrical conductance, and groundwater temperature) at monthly intervals to determine if groundwater quality is changing due to leachate seepage from st. Johns Landfill.

\title{
METHODOLOGY
}

A total of thirteen existing wells were selected for the groundwater monitoring program. The relative locations of 


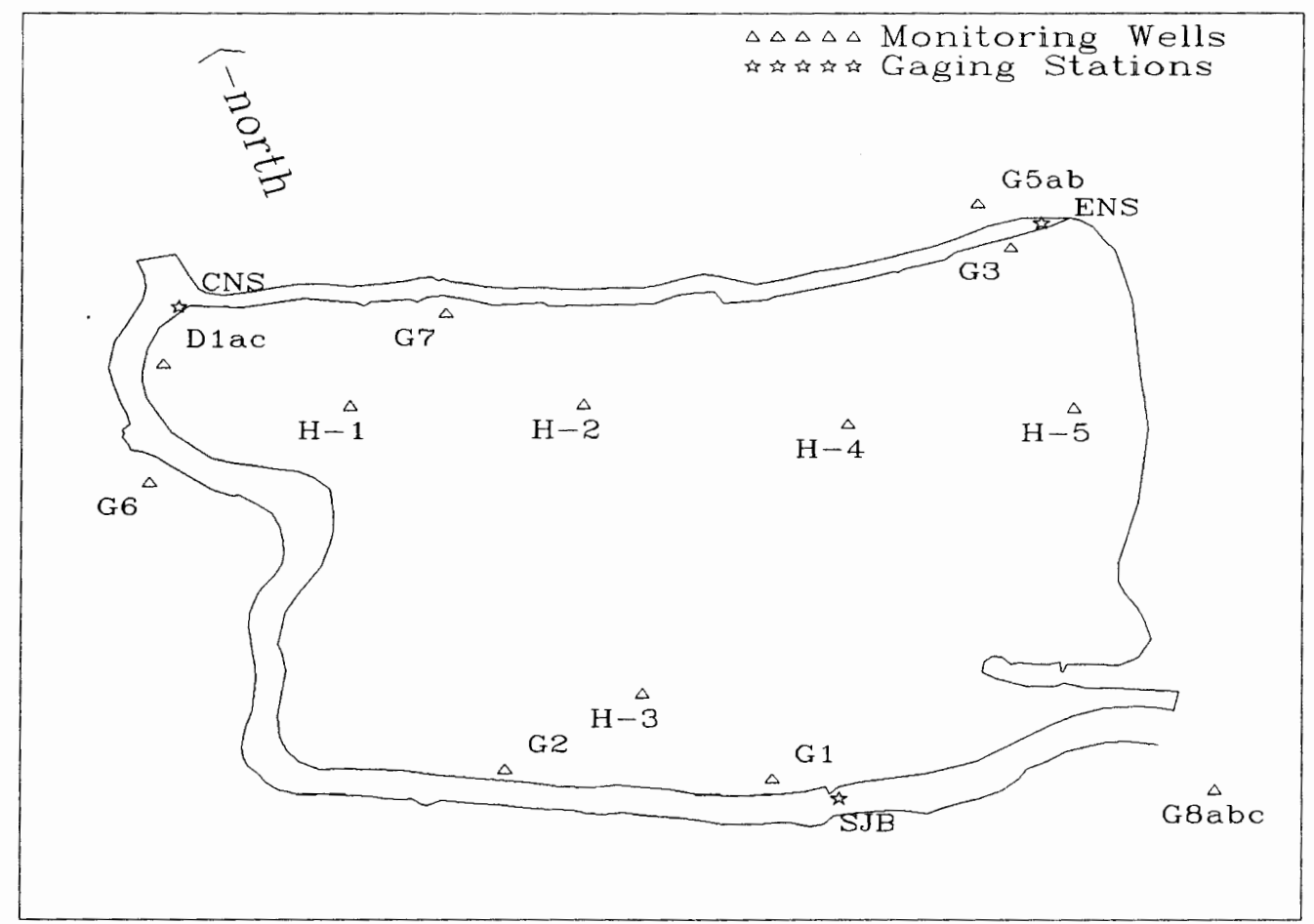

Figure 3. Relative locations of well monitor sites and slough gaging sites.

these wells around st. Johns Landfill are shown in Figure 3 . Six of the wells are located along the landfill perimeter dike (G1, G2, G3, G7, and Dlac) the remaining seven wells were located outside the landfill (G5ab, G6, G8abc, and Familian). The Familian well is not shown, although data for it was collected, no well bore log records were available to identify the screened depth, nor in what type(s) of soil it was completed. In addition to the thirteen wells, five wells located interior of the perimeter dike (the $\mathrm{H}$ wells) were monitored by Parametrix Inc. and CH2MHiIl for METRO on a monthly basis. Data from this study was included in this report. 
Concomitant to the continuous groundwater monitoring program, a separate study under the direction of Dr. Scott A. Wells, Portland state University, was initiated in which slough water levels that circumscribe the landfill were monitored. The gaging station locations are shown in Figure 3 (gaging station CNS was dismantled mid-year, 1991). Information from this program was used to study the interaction between the slough and groundwater system.

For the thirteen monitoring wells operated in this study, groundwater levels were monitored using Unidata portable computer data loggers (PDL) with electronic piezometer, see Figure 4 showing the field installation. The PDLs' were initially programmed to record the average water level every fifteen minutes. Review of the recorded outputs showed such a slow change in groundwater levels over time that the recording period was reprogrammed to log every thirty minutes.

Two different types of piezometer were used. For wells less than $30 \mathrm{ft}$ to the water table, 5 meter probes with 9 meter cables were installed. For wells greater than $30 \mathrm{ft}$ to the water table, 10 meter probes with 20 meter cables were installed. The 5 meter probe can measure a 5 meter change in water level with a resolution of $20 \mathrm{~mm}$, and the 10 meter probe has a 10 meter range with a resolution of $40 \mathrm{~mm}$.

For the chemical constituents, conductivity and temperature measurements were determined in the field using a Orion model 140 conductivity/temperature probe. The probe was 


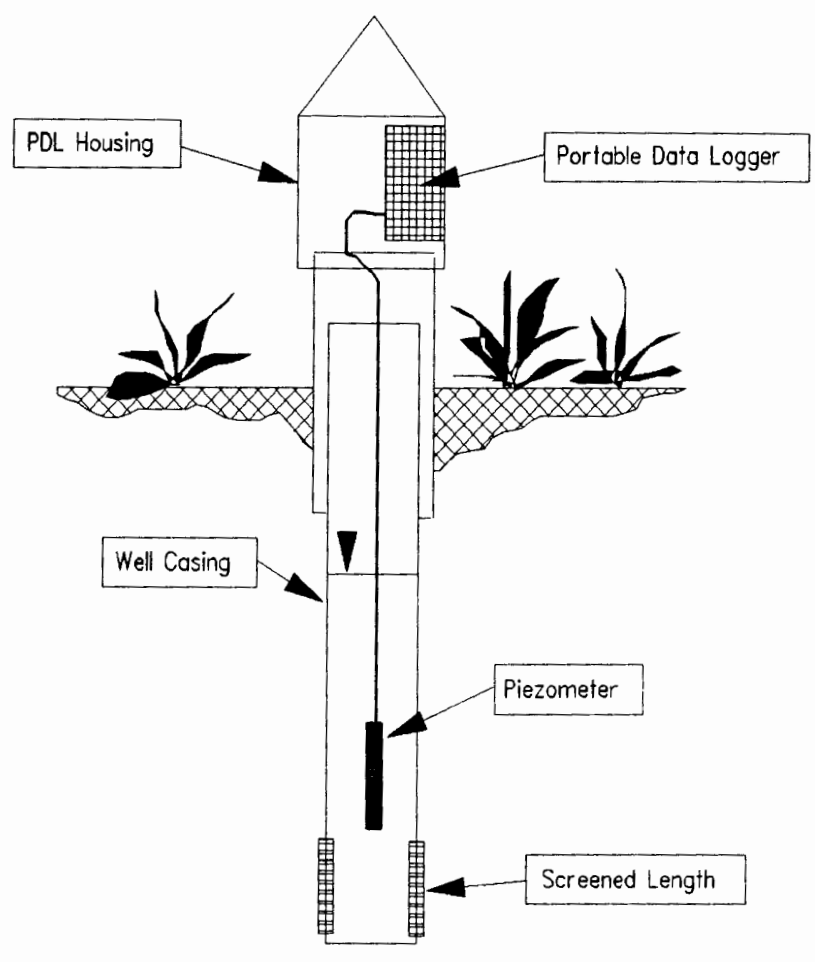

Figure 4. Schematic showing the computer monitoring system used in the field.

internally calibrated for "natural waters", i.e., natural unpolluted ground or surface waters, automatically compensating for temperatures deviating from the $25^{\circ} \mathrm{C}$ calibration temperature.

Chloride ion concentrations were determined in the laboratory from water samples drawn in the field. An Omega chloride ion selective measuring electrode, used in conjunction with a $\mathrm{pH}$ or $\mathrm{mV}$ meter, was used for the laboratory analysis. The probe was calibrated in the laboratory at the start of each analysis, and was recalibrated approximately every two hours thereafter. Standard solutions for the calibration were prepared fresh each day. The operational 
concentration range is 1.8 to $35,000 \mathrm{ppm}$. Low level concentrations calibration procedures were followed after initial laboratory analyses indicated typical sample concentration levels between 1 and $100 \mathrm{mg} / \mathrm{l}$. Experience indicated that probe accuracy decreased at lower concentration levels (1-10 ppm), and that readings tended to drift upwards with increasing time of laboratory analysis. Additional instrument specifications can be found in appendix $A$.

Field monitoring procedures were as follows: (1) data loggers were downloaded, (2) the well was purged and water samples were drawn for subsequent chloride analysis, then temperature and conductivity readings were taken.

Chloride sampling, temperature, and conductivity readings for the circumscribing sloughs' was started during the later part of calendar year 1991. For the five interior H-wells only water levels and chloride concentration data were obtained. 
CHAPTER III

\section{FIELD STUDY RESULTS AND ANALYSES}

\section{INVESTIGATION OF THE GEOLOGY AROUND ST. JOHNS LANDFILL}

In chapter I, a short summary describing the geology around the st. Johns Landfill area was presented. In this section a description of the underlying geology near the monitor wells around the perimeter of the st. Johns Landfill will be developed. This will help in the analysis of field data and in the development of a computer model to predict the groundwater flow between the landfill and the surrounding slough waters. The vertical soil profiles were developed from the 13 well logs used in this study and others from previous studies, Sweet Edwards/EMCON (1986). A perimeter vertical profile was constructed from well logs which follow the perimeter dike. Additional vertical profiles were developed which transect the landfill and sloughs. The location of the vertical-cross sections through the monitoring wells can be seen in Figure 5.

The geological stratums were grouped into the four basic types: clay, silt, sand, and gravel. More complex geologic types were identified where and when the profiles did not become too cluttered. The vertical profile around the 


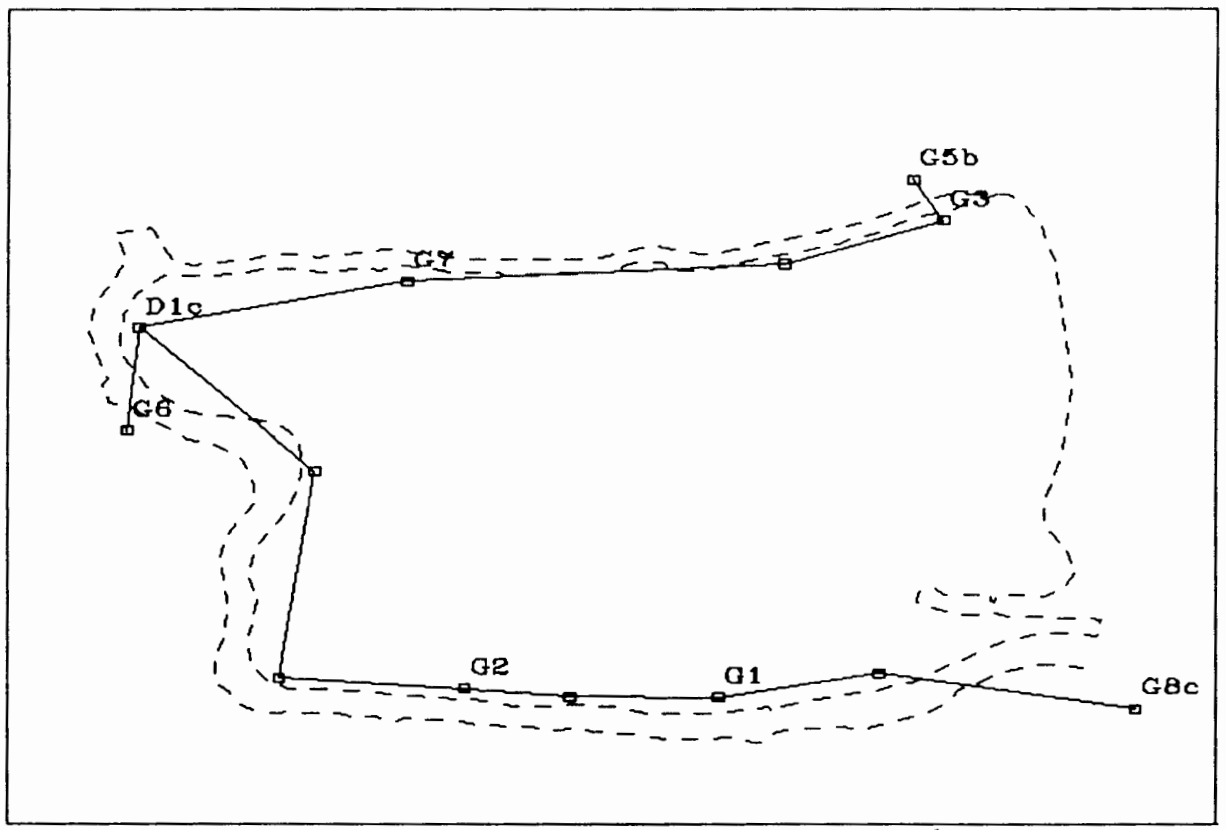

Figure 5. Location of vertical cross-section used to describe the geologic profile.

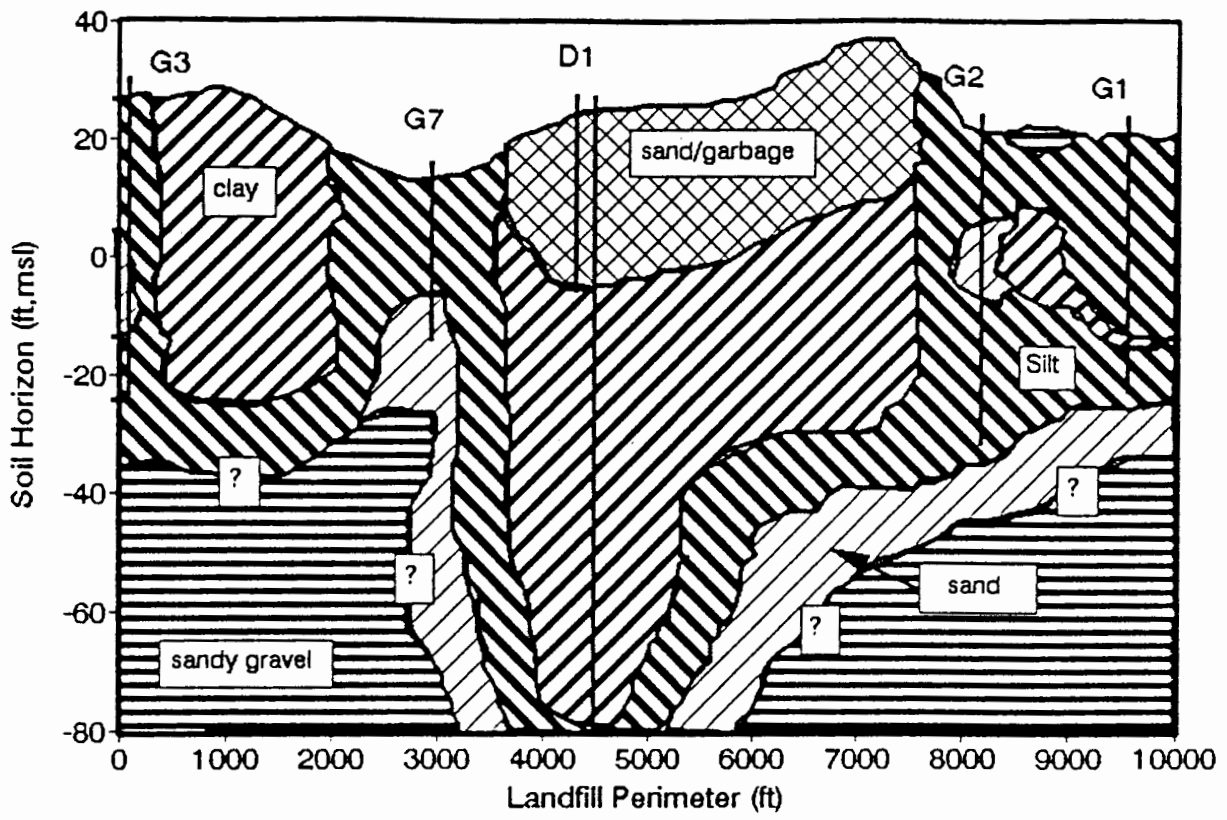

Figure 6. Vertical profile showing the soil layers that underlie the landfill. The section cuts through wells G3, G7, D1C, G2, G1, and G8c. 


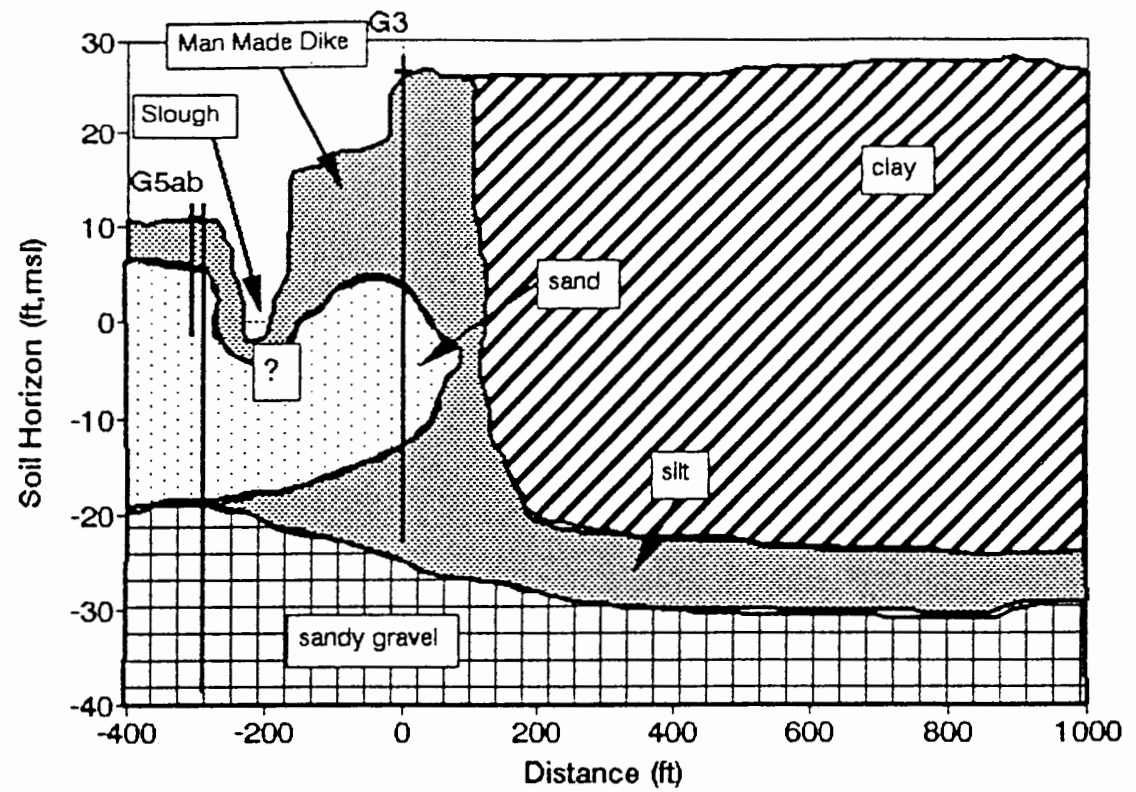

Figure 7. Vertical profile showing the soil layers that underlie the landfill and slough through wells G5b and G3, then along the perimeter dike.

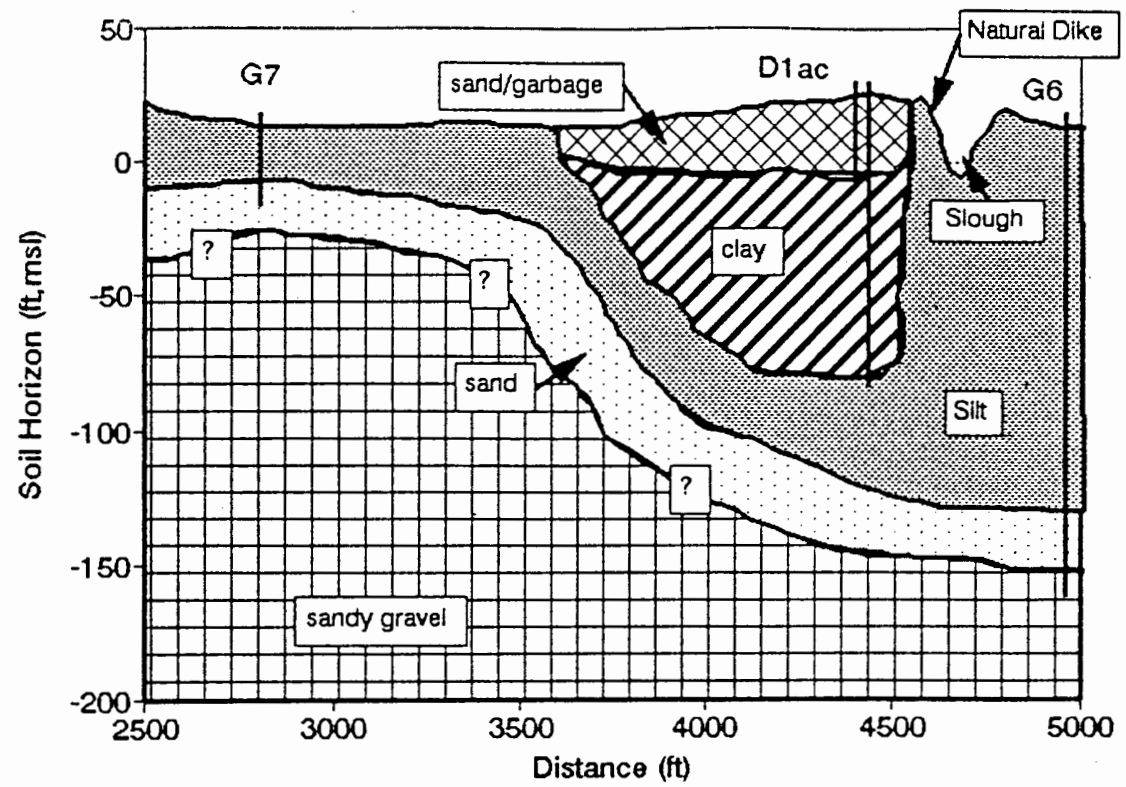

Figure 8. Vertical profile showing the soil layers that underlie the landfill and slough through wells G7, D1C, and G6. 


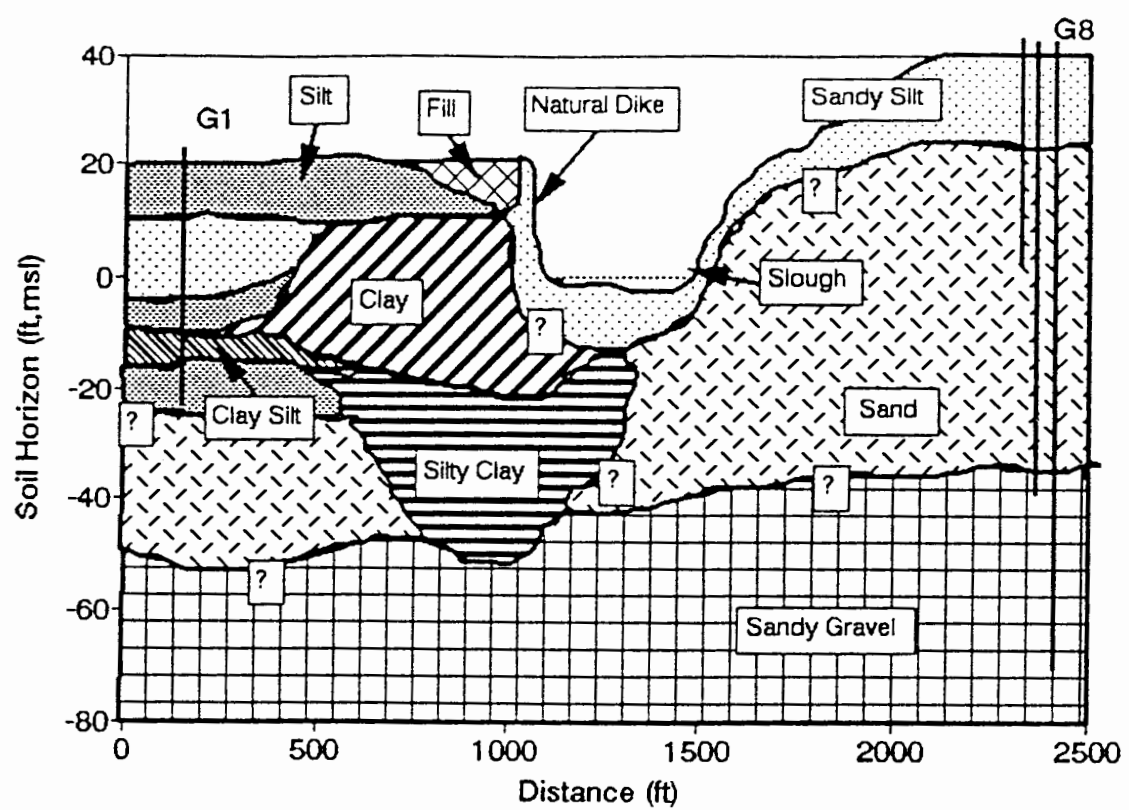

Figure 9. Vertical profile showing the soil layers that underlie the landfill and slough through wells G1 and G8b.

perimeter of the landfill is shown in Figure 6. Except for monitoring well G7, the profile shows the geological stratums which lie just inside the perimeter dike. It is evident that even using the general soil classifications, the geological stratigraphy is fairly complex.

Vertical soil profiles for wells G5ab, G6, and G8abc showing the separation of the landfill from the sloughs by the perimeter dike are shown in Figures $7-9$. The bottom of the slough channel was approximated at $-1 \mathrm{ft}$, MSL. The vertical profile for monitor well G5ab, Figure 7 , shows that the sandy aquifer might surface at the bottom of the North slough channel. Figure 8 also indicates that the sandy aquifer rises to within 5 feet of the slough channel bottom near monitoring 
well G7. The sandy aquifer may or may not surface near monitoring well G8abc, Figure 9, but it is apparent that the aquifer rises significantly above the slough channel bottom

\section{SOURCES OF GROUNDWATER CONTAMINATION}

As groundwater moves through the subsurface, its chemical composition is altered by a variety of geochemical processes. In fact, the geochemical structure of the geologic matrix can be determined through chemical analyses of the insitu groundwater (Freeze and Cherry 1979). The chemical composition of the local groundwater can change over time due to either natural or anthropogenic events. The ability to identify the natural 'background' chemical composition is important when trying to determine anthropogenic causes. Monitoring of just a few chemical constituents can be useful in identifying changes in groundwater quality due to human activities. The appropriate chemical constituents to use depends on the source of the contaminates. Freeze and Cherry (1979), suggest that chloride (conservative substance) and total dissolved solids (TDS) are good chemical indicators when the suspected contaminate source is a landfill, as the leachate within landfills contain high concentrations of inorganic compounds and total dissolved solids. Typical ranges of chloride and TDS concentrations for leachate are shown in Table I (Freeze and Cherry 1979). Increases in chloride or TDS levels over the background indicate possible groundwater contamination from 
the landfill.

TABLE I

TYPICAL CHEMICAL CONCENTRATIONS IN LEACHATE

\begin{tabular}{|c|c|}
\hline Parameter & Range (mg/l) \\
\hline \hline Chloride $\left(\mathrm{Cl}^{-}\right)$ & $300-3000$ \\
\hline Total Dissolved Solids & $5000-40,0000$ \\
\hline
\end{tabular}

Source: Freeze and Cherry 1979

A similar measurement of TDS is the electrical conductance or conductivity of the groundwater (Freeze and Cherry 1979). High TDS concentrations imply high electrical conductivity values and visa-versa for low levels. Typical background electrical conductance values for the Portland area are given in Table II (Fishman 1986).

TABLE II

TYPICAL BACKGROUND WATER ELECTRICAL CONDUCTIVITIES FOR PORTIAND AREA

\begin{tabular}{|c|c|}
\hline & $\begin{array}{c}\text { Electrical conductance } \\
\left(\mu \mathrm{mhos} / \mathrm{cm} \text { a } 25^{\circ} \mathrm{C}\right) \\
\end{array}$ \\
\hline willamette River & 70 \\
\hline Columbia River & 160 \\
\hline Fresh groundwater & 300 \\
\hline St. Johns leachate & $1000-12000$ \\
\hline
\end{tabular}

Source: Fishman 1989

Groundwater temperature can also be used as a contamination indicator, the biological decay of the waste increases ground and water temperatures. The two previous 
studies by Fishman (1986) and Sweet Edwards/EMCON (1989) monitored groundwater temperatures using increased temperatures above background as an indication of possible contamination.

\section{ANALYSIS OF GEOCHEMICAL FIELD OBSERVATIONS}

As mentioned earlier, conductivity and temperature readings were recorded in the field, and chloride levels were determined in the laboratory from water samples drawn in the field. Reliability of the instrumentation used for the chloride analysis is discussed in appendix B. It was assumed in this study that the instrumentation can satisfactorily predict trends in chloride levels.

Results from the field investigation are graphically summarized in comparison plots of chloride concentrations and conductivity, Figures $10-22$, and in comparison plots of conductivity and temperature, Figures $23-35$.

Chloride concentrations in monitoring wells Dla (5623 $\mathrm{mg} / \mathrm{l})$ and $\mathrm{G7}(22387 \mathrm{mg} / \mathrm{l})$, Figures 10 and 17 respectively, were noticeably higher than those in the other wells. This may have been due, in part, to the methods used to compute the concentrations from the calibration curves. The emv values determined in the laboratory analysis were outside the range of emv values used in the calibration curves. Therefore, chloride values had to be interpolated from the calibration 


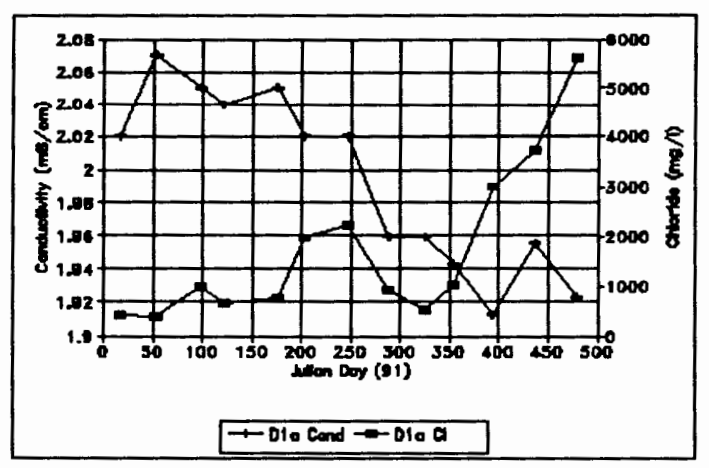

Figure 10. Comparisons of conductivity and chloride for well Dla.

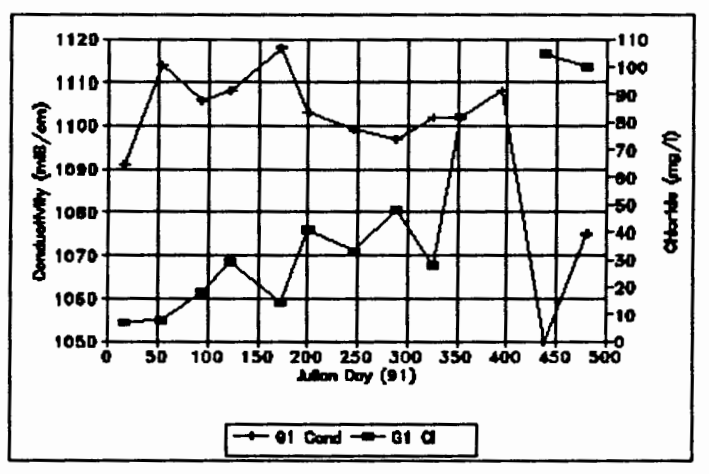

Figure 11. Comparisons of conductivity and chloride for well GI.

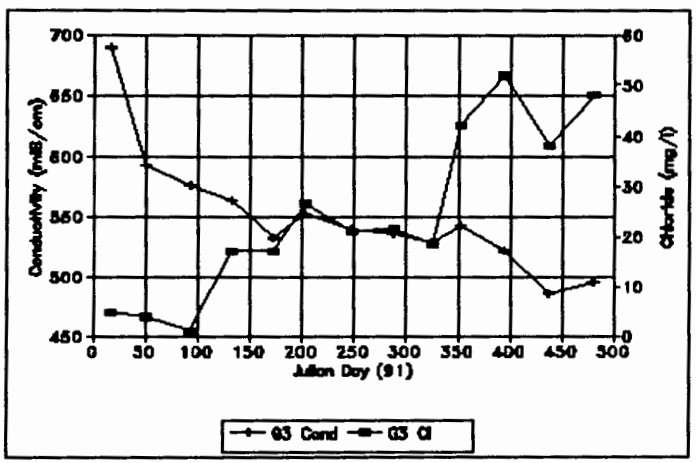

Figure 12. Comparisons of conductivity and chloride for well G3.

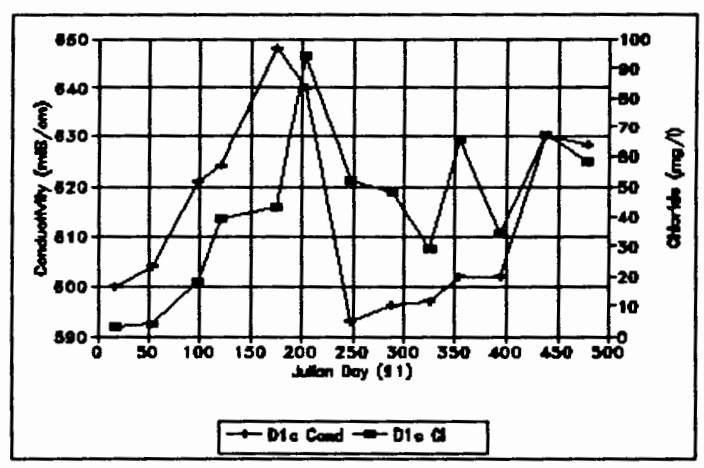

Figure 13. Comparisons of conductivity and chloride for well Dlc.

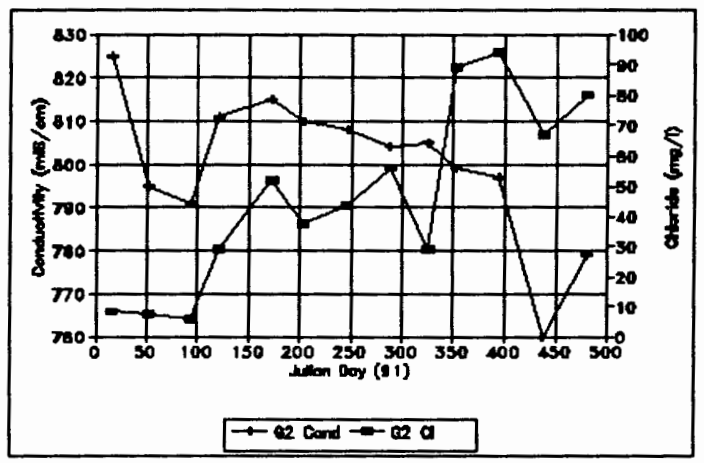

Figure 14. Comparisons of conductivity and chloride for well G2.

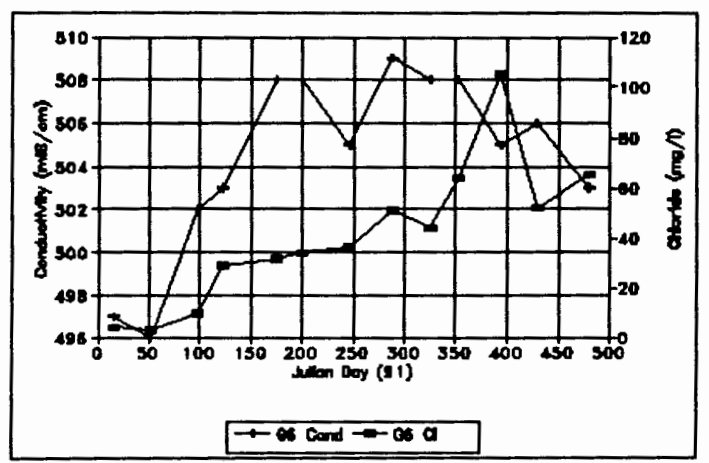

Figure 15. Comparisons of conductivity and chloride for well G6. 


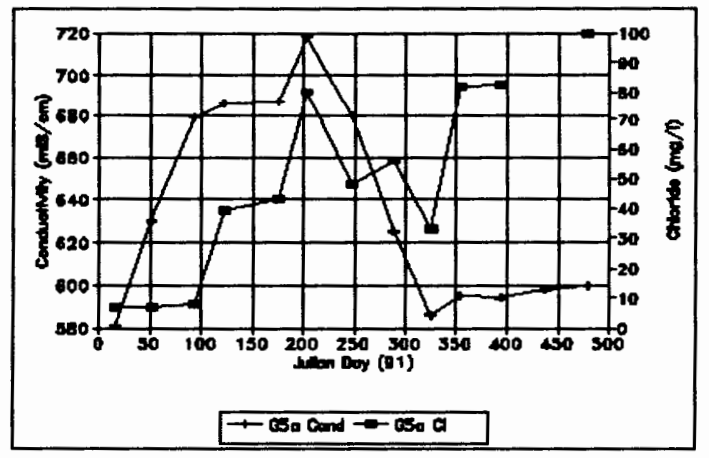

Figure 16. Comparisons of conductivity and chloride for well G5a.

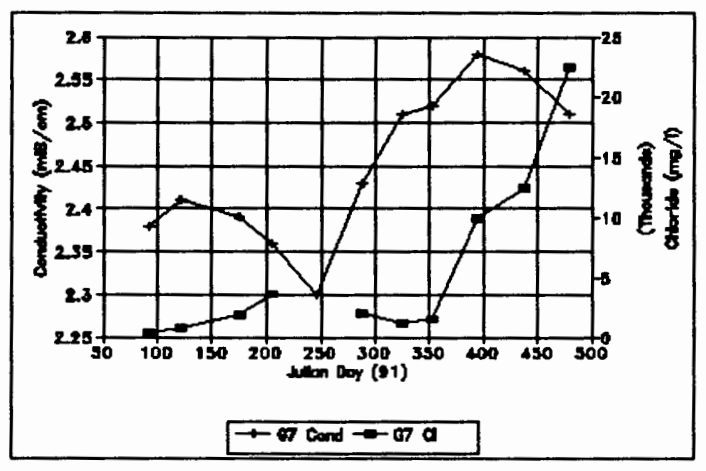

Figure 17. Comparisons of conductivity and chloride for well G7.

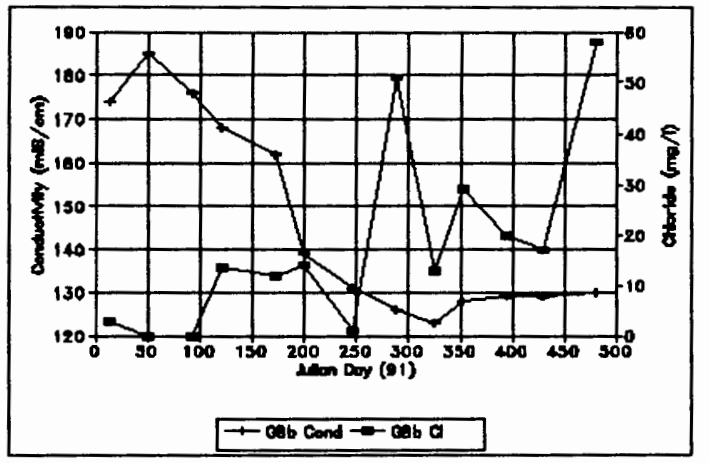

Figure 18. Comparisons of conductivity and chloride for well G8b.

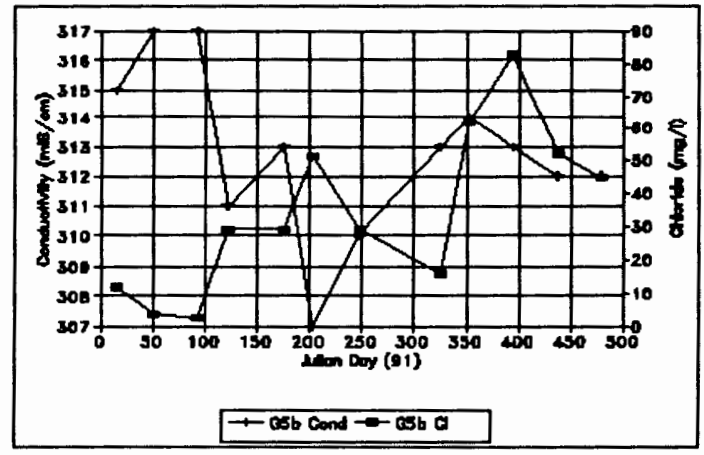

Figure 19. Comparisons of conductivity and chloride for well $G 5 b$.

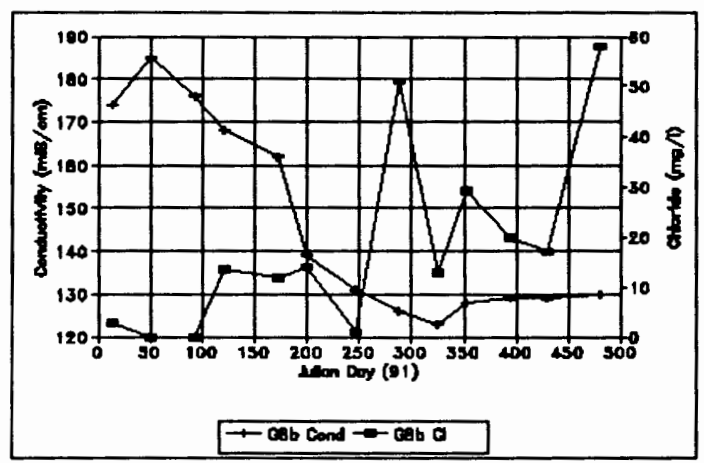

Figure 20. Comparisons of conductivity and chloride for well G8a.

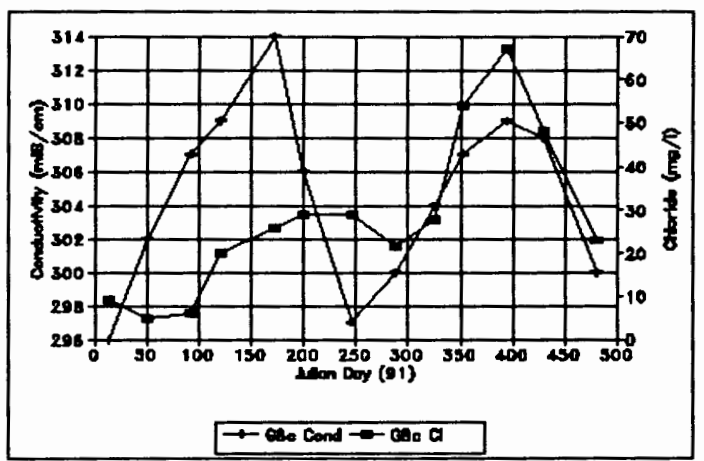

Figure 21. Comparisons of conductivity and chloride for well G8C. 


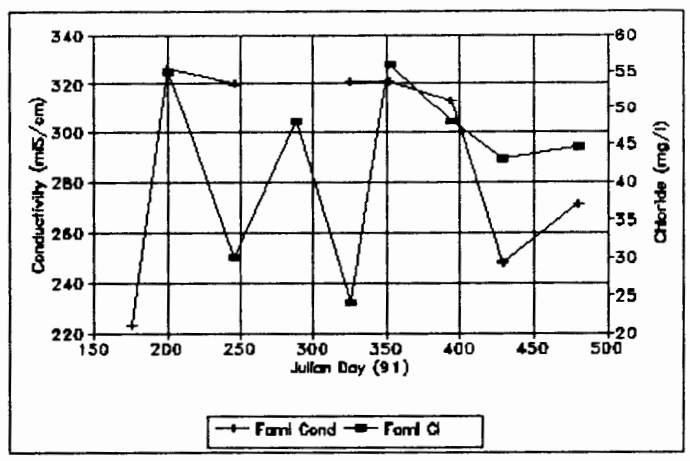

Figure 22. Comparisons of conductivity and chloride for well Familian.

curves. At chloride concentrations greater than $10 \mathrm{ppm}$, the calibration curve for the $\log _{10}(\mathrm{emV})$ verses concentration becomes linear (according to the instrument manual). The error in the interpolation was dependent on the accuracy of the best-fit line through the calibration points. Since the line placement was visually interpolated it is difficult to quantify the error in each calibration curve. Examples of the calibration curves used in the chloride analysis are given in appendix $B$.

Concurrent and previous studies indicate maximum chloride concentrations in and around st. Johns landfill to be: 2020 $\mathrm{mg} / 1$ for well D8a (Fishman 1986); $636 \mathrm{mg} / \mathrm{l}$ for well G7 (Sweet Edwards/EMCON 1989); and $3800 \mathrm{mg} / \mathrm{l}$ for well H3 (Parametrix 1991). Representative chloride concentrations for sea water are around $18000-21000 \mathrm{mg} / \mathrm{l}$, International Hydrology Program (1987). Even though the chloride concentrations for monitor 
wells Dla and G7 are high, they are not physically unreasonable.

Close inspection of the comparison plots of electrical conductivity and chloride concentration revealed that trends in the data existed for most of the wells. The significance of the trends were tested using simple linear regression. Prior to any statistical analysis all data were $\log$ transformed. The reason for using this transformation was that most hydrological parameters and characteristics are log-normally distributed, they are bounded on the left by zero and are positively skewed. Transforming the data sets into the lognormal space better assured a normal distribution of the simple linear regression residuals.

It should be noted at this point that simple linear regression analysis can not distinguish between trend or long term variation. To distinguish between the two, considerably longer periods of record would be required. Simple linear regression is the best test, however, for trends if the data is normally distributed and nonseasonal (the more skewed the data, the less powerful regression becomes), Hirsch et al (1982). Best, when other statistical tests such as the Seasonal Kendall and Seasonal Linear Regression are considered. Due to the short time frame of the study, statitical adjustments for seasonality in the data were not possible. The best non-parametric test to use for data trends 


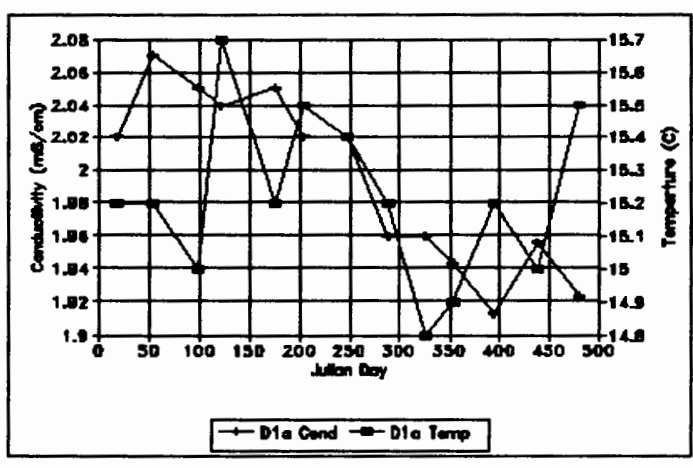

Fiqure 23. Comparisons of conductivity and temperature for well Dla.

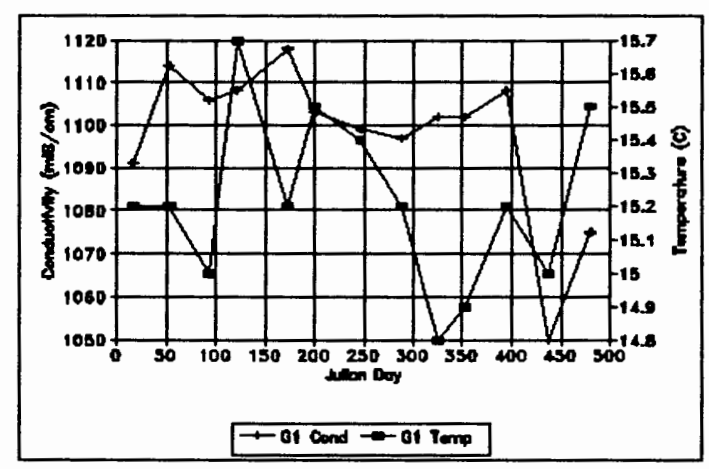

Figure 24. Comparisons of conductivity and temperature for well Gl.

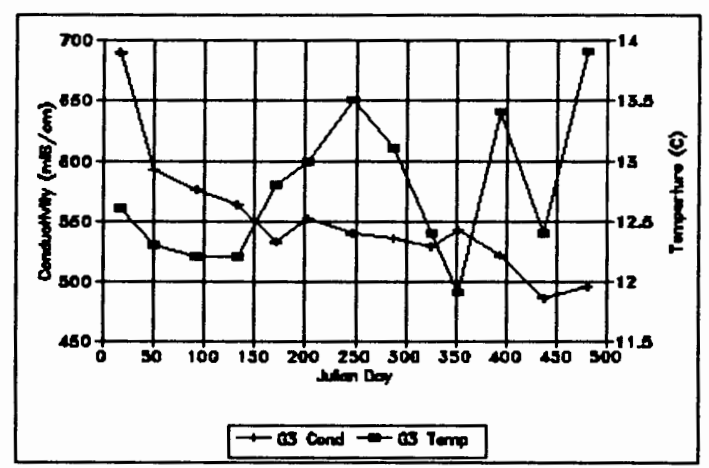

Figure 25. Comparisons of conductivity and temperature for well G3.

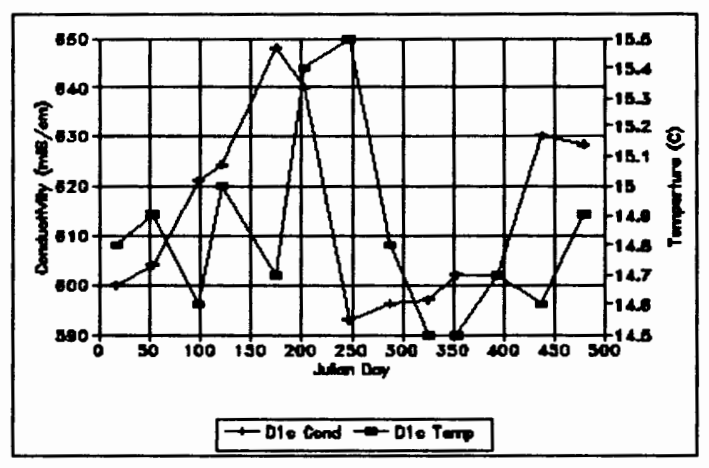

Figure 26. Comparisons of conductivity and temperature for well Dlc.

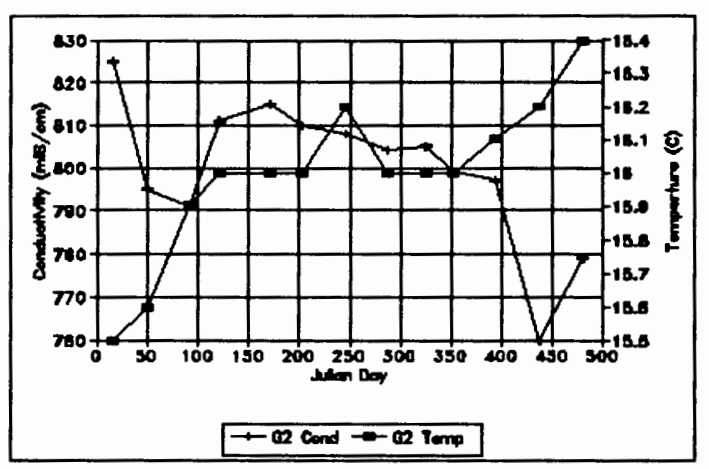

Figure 27. Comparisons of conductivity and temperature for well G2.

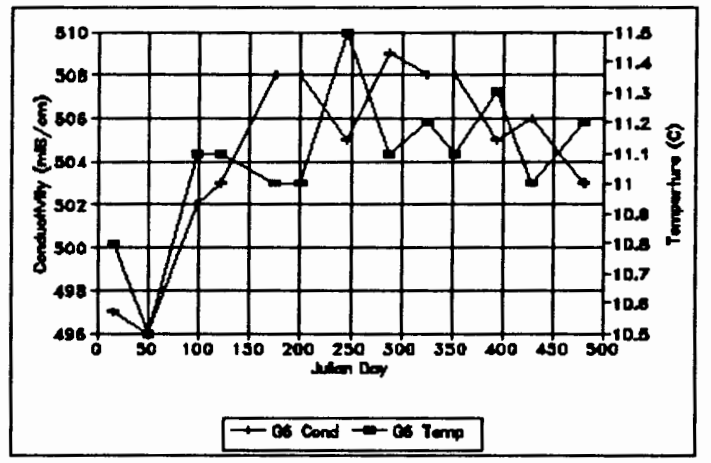

Figure 28. Comparisons of conductivity and temperature for well G6. 


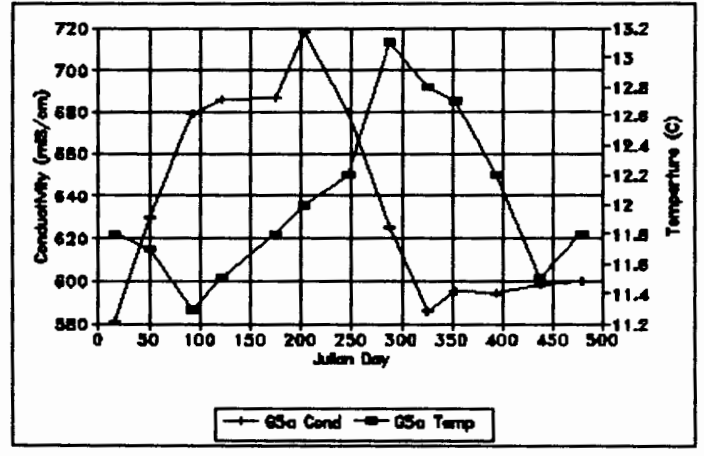

Figure 29. Comparisons of conductivity and temperature for well G5a.

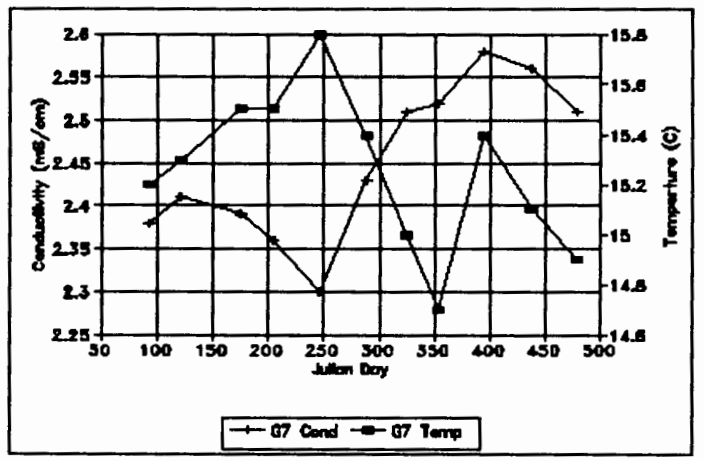

Figure 30 . Comparisons of conductivity and temperature for well G7.

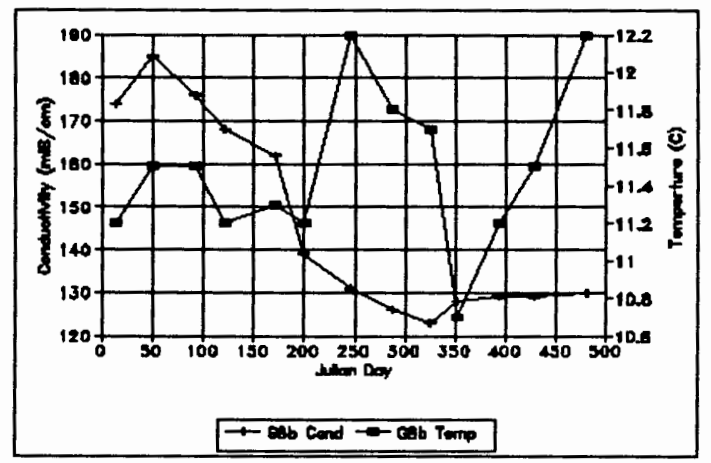

Figure 31. Comparisons of conductivity and temperature for well G8b.

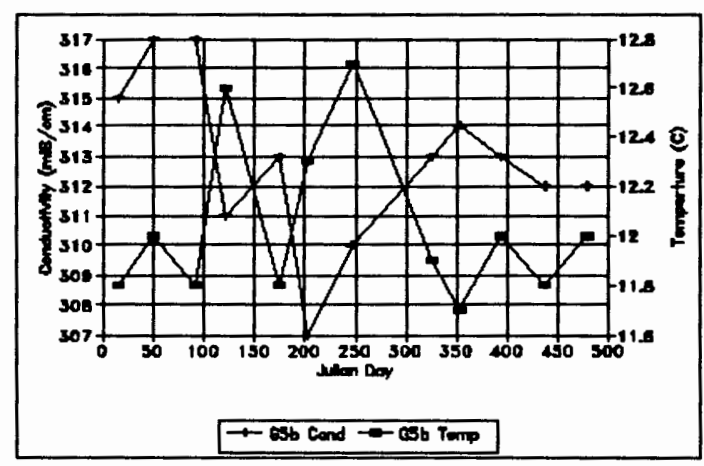

Figure 32. Comparisons of conductivity and temperature for well G5b.

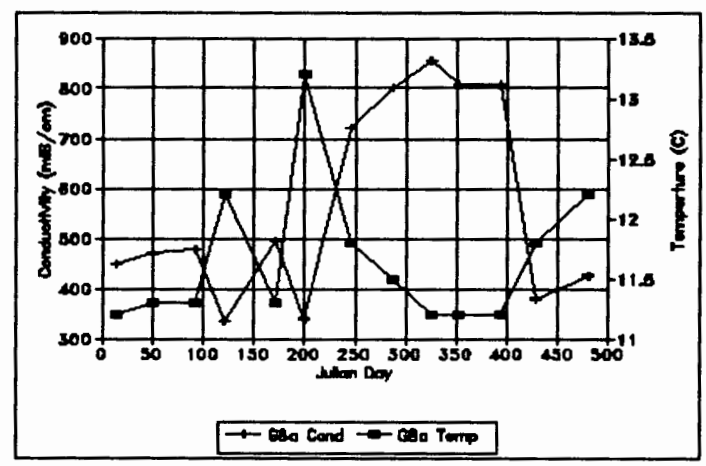

Figure 33. Comparisons of conductivity and temperature for well G8a.

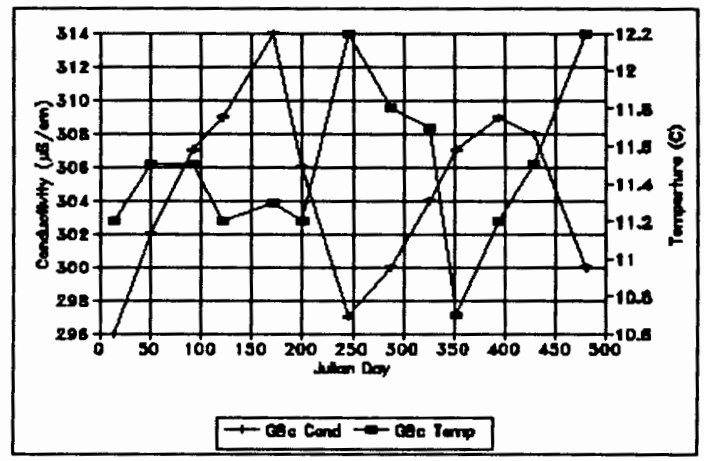

Figure 34. Comparisons of conductivity and temperature for well G8C. 


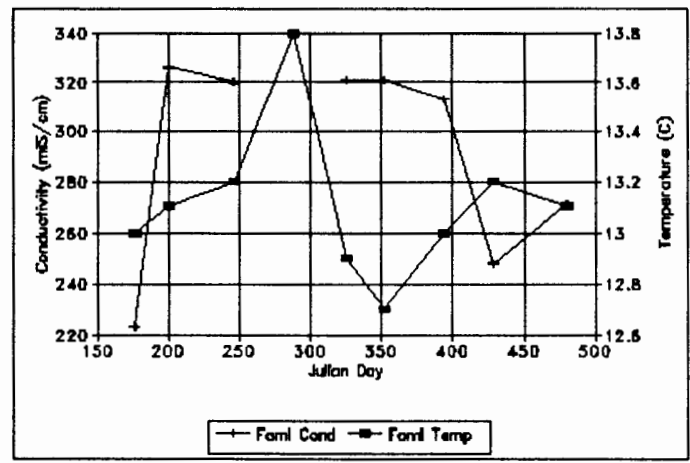

Fiqure 35. Comparisons of conductivity and temperature for well Familian.

having seasonal variations was the Kendall test. However, inclusion of the Kendall test was beyond the scope of this report, it is suggested that the Kendall test be investigated for use in future studies.

All residuals for each regression analysis were tested for conformity to a normal distribution using the shapiroWilks test, see appendix c. Parameter estimates whose residuals were normally distributed were tested at the 100(1$\alpha), \alpha=0.05$, confidence level for statistical significance, Tables III and IV summarizes the statistical analyses. Trends were statistically significant at: $\alpha \leq 0.05$, and positive values imply increasing concentrations.

\section{Electrical Conductivity}

The Shapiro-Wilks test indicated that the residuals for monitoring wells G1, G2, and Familian do not conform to a 
TABLE III

SIMPLE LINEAR REGRESSION ANALYSIS ON

TRENDS IN ELECTRICAL CONDUCTIVITY, LOG TRANSFORMED DATA

( $95 \%$ CONFIDENCE LEVEL )

\begin{tabular}{|c|c|c|c|c|}
\hline Well & $\begin{array}{l}\text { Squared } \\
\text { Regression } \\
\text { Coefficient }\end{array}$ & $\begin{array}{l}\text { Trend } \\
\text { Coefficient } \\
(1 / \text { day })\end{array}$ & $\begin{array}{c}\text { Alpha } \\
(2 \text { tail })\end{array}$ & $\begin{array}{l}\text { Normality } \\
\text { of } \\
\text { Residuals }\end{array}$ \\
\hline G1 & 0.313 & -0.00006 & 0.047 & No \\
\hline G2 & 0.394 & -0.00009 & 0.0217 & No \\
\hline G3 & 0.749 & -0.00051 & 0.00013 & Yes \\
\hline G5a & 0.183 & -0.00021 & 0.145 & Yes \\
\hline G5b & 0.118 & -0.00002 & 0.274 & Yes \\
\hline G6 & 0.342 & 0.00003 & 0.0359 & Yes \\
\hline G7 & 0.59 & 0.00022 & 0.00579 & Yes \\
\hline G8a & 0.104 & 0.00079 & 0.306 & Yes \\
\hline G8b & 0.758 & -0.00086 & 0.00023 & Yes \\
\hline G8C & 0.018 & 0.00002 & 0.678 & Yes \\
\hline Dla & 0.796 & -0.00016 & 0.00004 & Yes \\
\hline Dlc & 0.000 & 0.000 & 0.962 & Yes \\
\hline Familian & 0.000 & -0.00002 & 0.966 & No \\
\hline
\end{tabular}

normal distribution, Table III. of the remaining monitoring wells, 5 out of 10 indicate a statistically significant trend (see shaded areas). For the 5 statistically significant wells, three indicated a decreasing trend and two an increasing trend, making it difficult to determine condutivity trends within the group.

Plots of electrical conductivities for each multiple 
completion well in Figures $36-38$ indicate that conductivity generally decreases with depth. This is consistent with Fishman's (1986) report. The conductivity levels in monitoring well G8b were much lower than levels in companion wells G8a and G8C see Figure 37. Values in G8b were similar to levels found in the Columbia River see Table II. Multiple completion well G5ab in Figure 36 showed that conductivity levels in the gravel aquifer (G5b). Conductivity values in multiple completion wells Dlac in Figure 38 were well above normal groundwater levels. Well Dla showed conductivity values consistent with leachate found in the landfill see Table II. upper sand aquifer (G5a) were about twice that in the lower

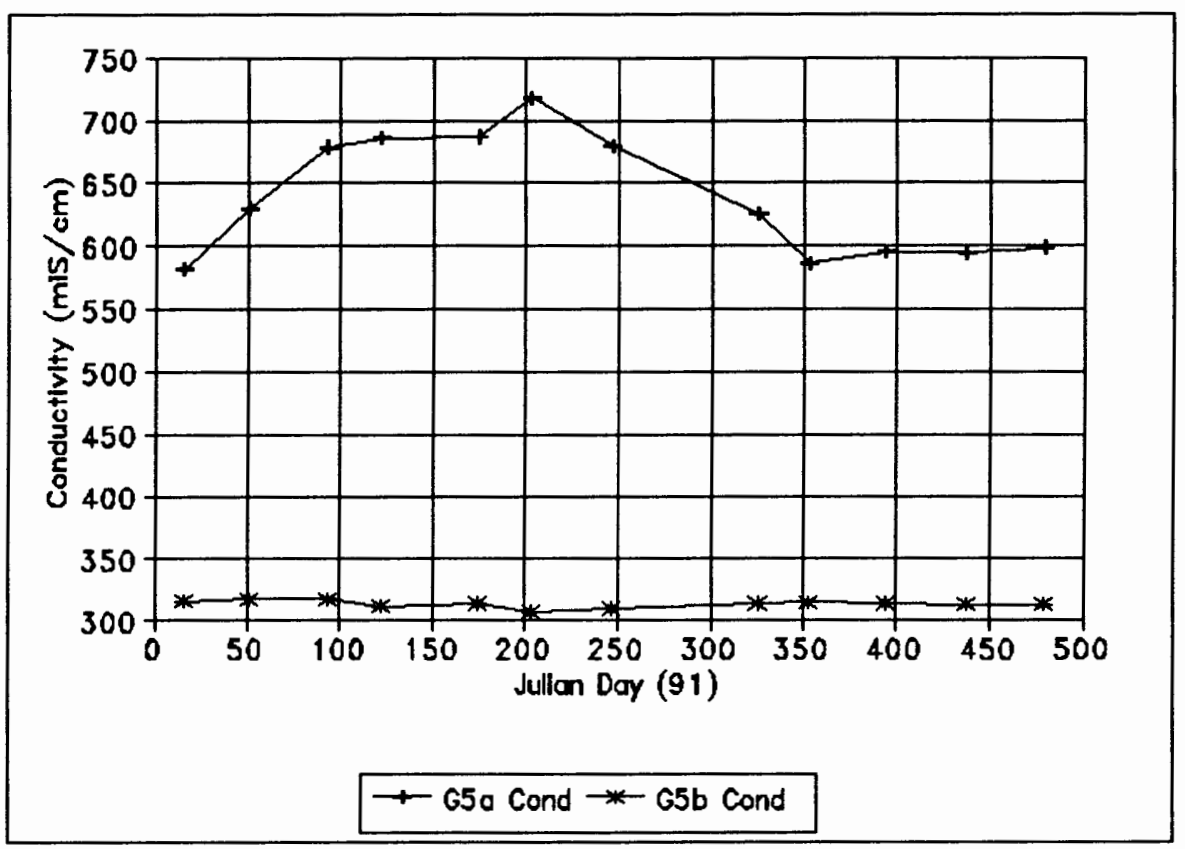

Figure 36. Electrical conductivity for multiple completion well G5ab. 


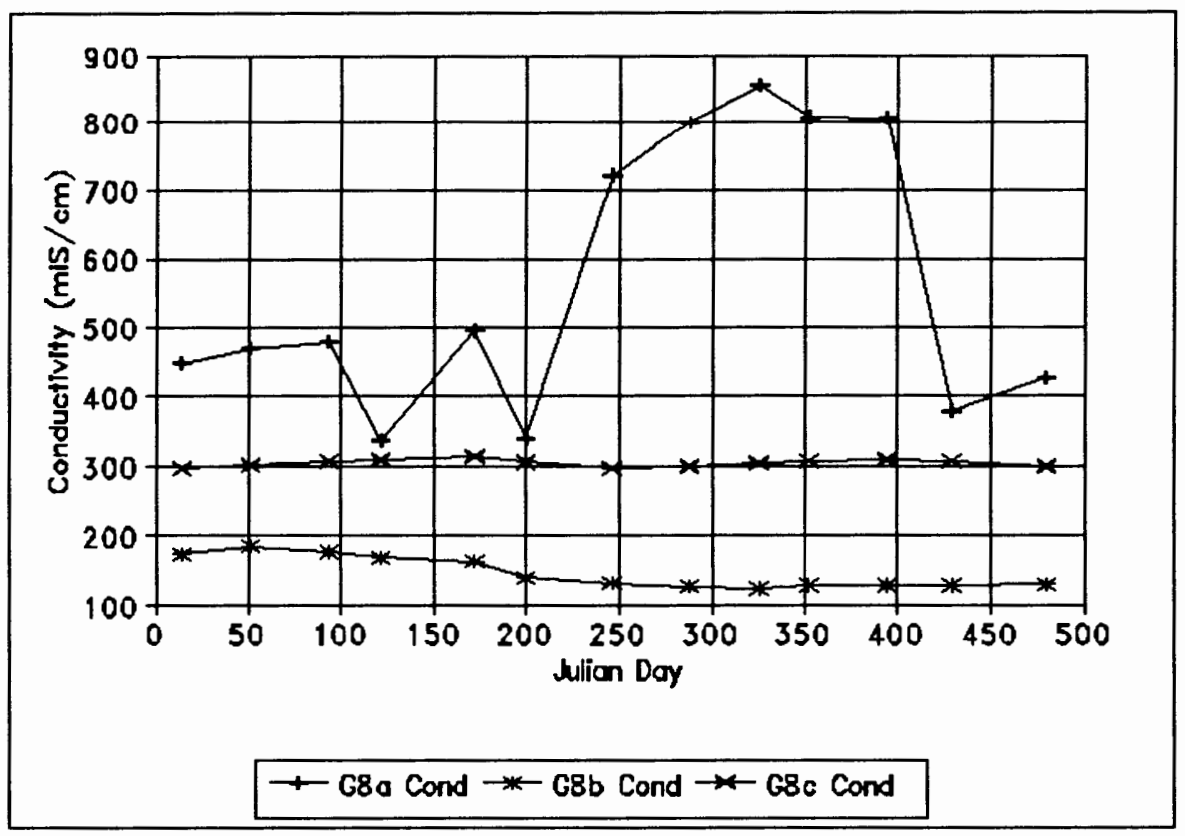

Figure 37. Electrical conductivity for multiple completion well G8abc.

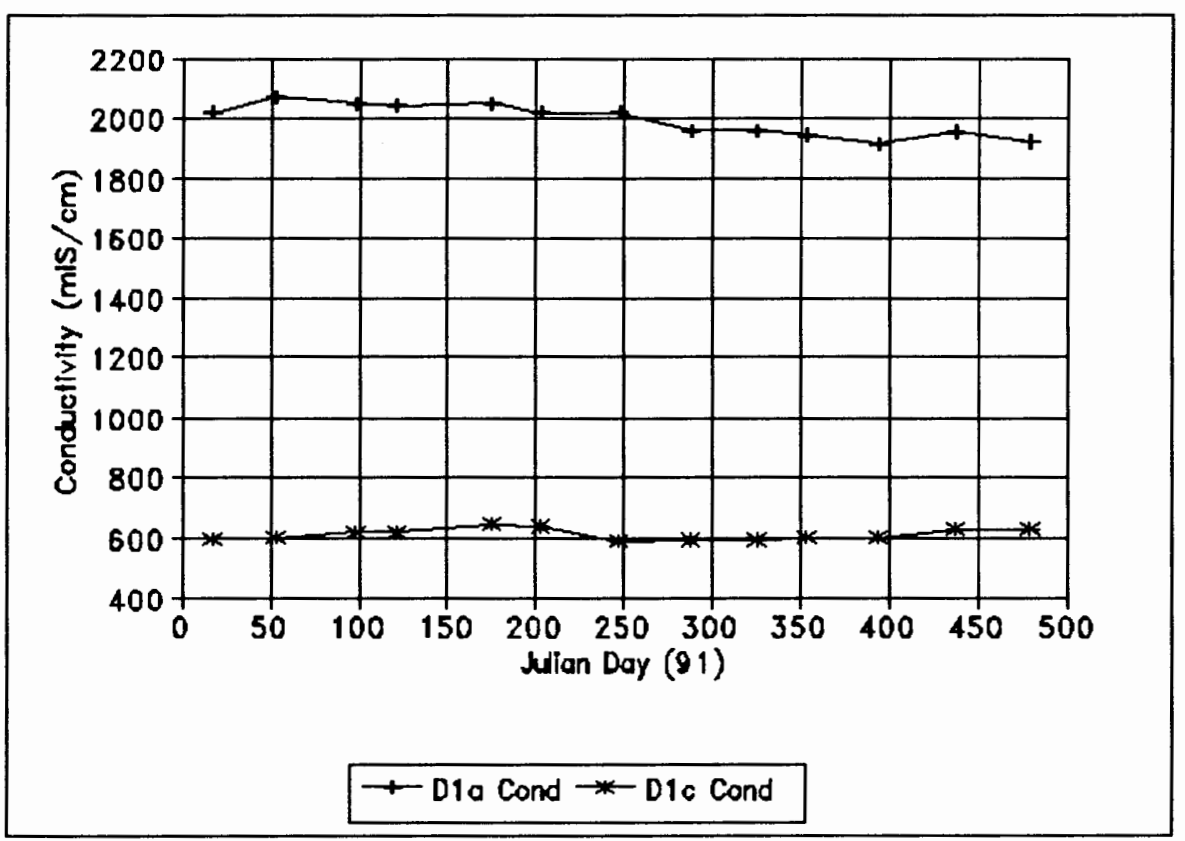

Figure 38. Electrical conductivity for multiple completion well Dlac. 
TABLE IV

SIMPLE LINEAR REGRESSION ANALYSIS ON

TRENDS IN CHLORIDE CONCENTRATIONS, LOG TRANSFORMED DATA

( $95 \%$ CONFIDENCE LEVEL )

\begin{tabular}{|c|c|c|c|c|}
\hline Well & $\begin{array}{l}\text { Squared } \\
\text { Regression } \\
\text { Coefficient }\end{array}$ & $\begin{array}{l}\text { Trend } \\
\text { Coefficient } \\
(1 / \text { day }) \\
\end{array}$ & $\begin{array}{c}\text { Alpha } \\
(2 \text { tail) }\end{array}$ & $\begin{array}{l}\text { Normality } \\
\text { of } \\
\text { Residuals } \\
\end{array}$ \\
\hline G1 & 0.833 & 0.00563 & 0.00003 & Yes \\
\hline G2 & 0.719 & 0.00541 & 0.00025 & Yes \\
\hline G3 & 0.658 & 0.00625 & 0.00077 & No \\
\hline G5a & 0.698 & 0.00585 & 0.00072 & Yes \\
\hline G5b & 0.486 & 0.00494 & 0.0118 & Yes \\
\hline G6 & 0.748 & 0.00631 & 0.00013 & Yes \\
\hline G7 & 0.697 & 0.00812 & 0.00266 & Yes \\
\hline G8a & 0.772 & 0.00763 & 0.00017 & Yes \\
\hline $\mathrm{G} 8 \mathrm{~b}$ & 0.320 & 0.00472 & 0.06954 & Yes \\
\hline G8C & 0.606 & 0.00418 & 0.00173 & No \\
\hline Dla & 0.601 & 0.00447 & 0.00184 & Yes \\
\hline Dlc & 0.484 & 0.00492 & 0.00830 & Yes \\
\hline amilian & 0.003 & 0.00011 & 0.906 & No \\
\hline
\end{tabular}

\section{Chloride Concentrations}

The results of the Shapiro-Wilks test in Table IV showed that for monitoring wells G3, G8C, and Familian the residuals do not conform to a normal distribution. Of the remaining monitoring wells, 9 out of the 10 indicate statistically significant trends in chloride concentrations (see shaded areas). Only monitoring well $\mathrm{G} 8 \mathrm{~b}$ indicates no significant 
trend in chloride levels. All of the trends are positive, implying increasing levels of chloride over time in all wells. In the previous conductivity analysis it could not be determined whether a general trend (increase or decrease) in conductivity levels existed when the wells were considered as a group. One would expect that increasing chloride levels would cause the electrical conductivity levels to increase also, as chloride is an ionic species.

Plots of chloride concentrations for each multiple completion well are shown in Figures $39-41$. The plots indicate that chloride levels decreased with increasing depth. In Figure 40 the chloride levels in monitoring well G8b are generally lower than those of companion wells G8a and G8c. The

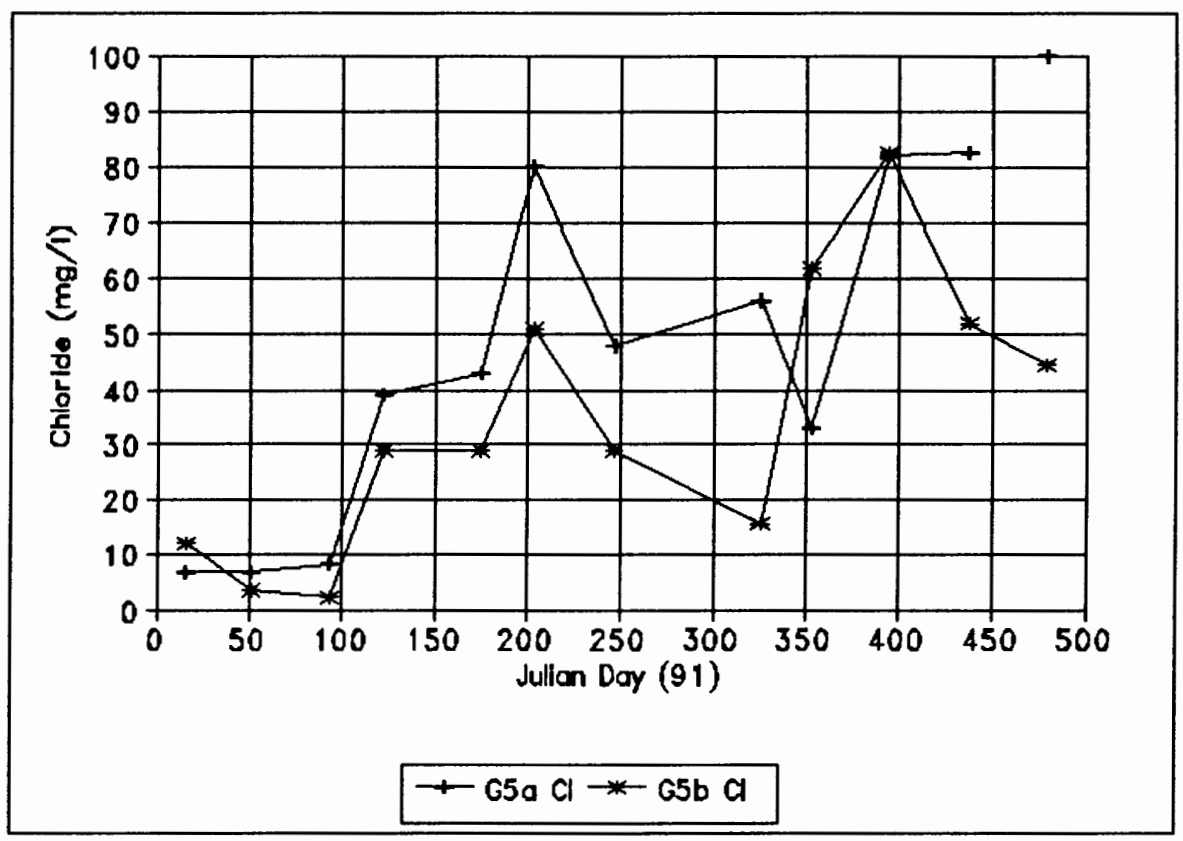

Figure 39. Chloride concentrations for multiple completion well G5ab. 


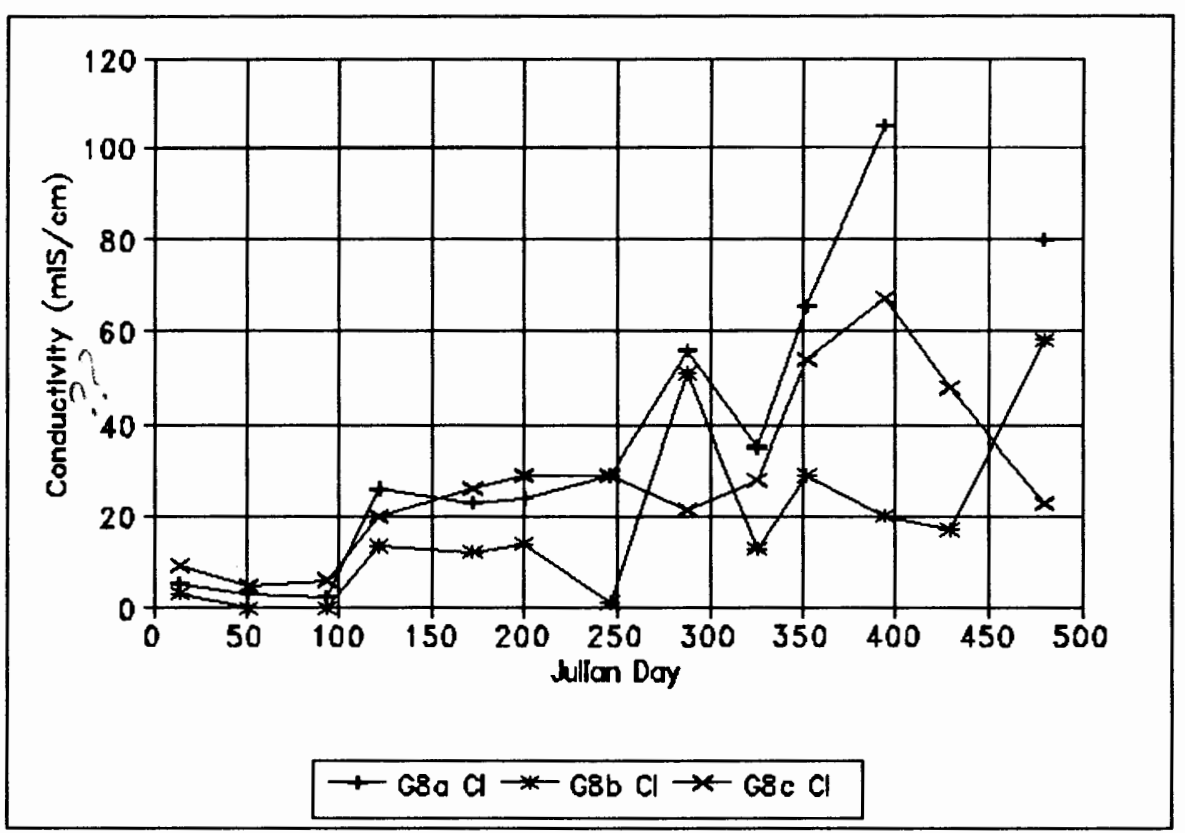

Figure 40. Chloride concentrations for multiple completion well G8abc.

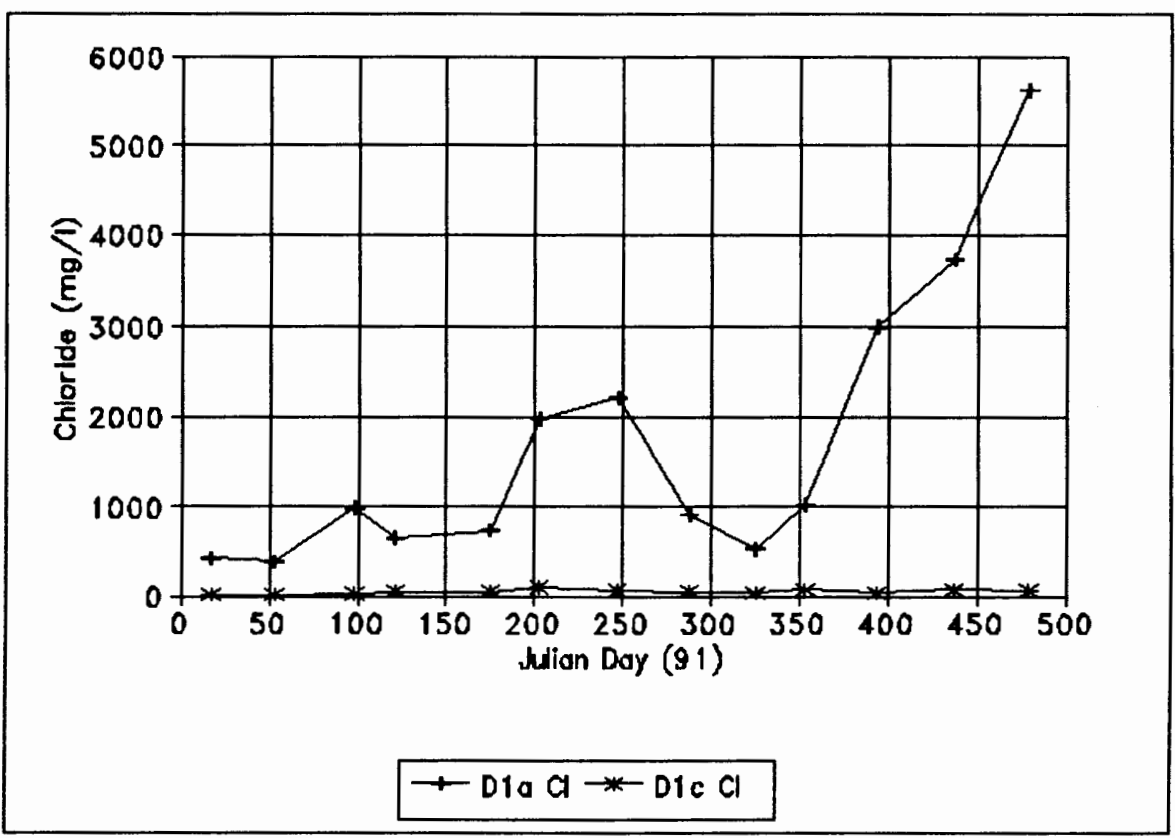

Figure 41. Chloride concentrations for multiple completion well Dlac. 
statistical analysis also indicated that the apparent trend in chloride levels for well $G 8 b$ was not statistically significant. When the depth and geological stratigraphy of well G8b is reviewed relative to companion wells G8a and G8b, the results of the conductivity and chloride studies showed unexpected behavior. It would seem more likely that conductivity and chloride values in well G8b would lie some where between companions values $\mathrm{G} 8 \mathrm{a}$ and $\mathrm{G8C}$, rather than outside the two.

\section{Isoconcentrations for Conductivity and Chloride}

As shown earlier, the geologic stratigraphy around st. Johns Landfill is very complicated, even when presented in a simplified format as in Figures 6 - 9. Because of the spatial variability in the geologic units, it was difficult to develop gradient maps using wells completed at different depths and within different aquifers. In this study, isoconcentration plots were developed for each aquifer/aquitard using only those wells which were completed in the specified aquifer/aquitard. Erroneous results can occur if wells completed in one aquifer type are included in a different aquifer type when developing gradient maps Bear (1976). While the advective transport of contaminates in the silts and sands may be equivalent (similar hydraulic conductivities), the dispersion and absorption characteristics for each type may be quite different.

Estimates for the hydraulic conductivities in the silt 
and sandy/gravel aquifers are 0.042 ( $\mathrm{ft} /$ day) and 335 (ft/day) respectively Sweet Edwards/EMCON (1989). Hydraulic conductivities for the sandy aquifer are on the same order of magnitude as the silts, 0.14 (ft/day).

The hydraulic conductivity of the sandy/gravel aquifer is four orders of magnitude larger than the silty or sandy aquifers. For aquifer-aquitard systems with hydraulic conductivity contrast of two orders of magnitude or more, flow lines tend to become almost vertical in the aquitard and horizontal in the aquifer Freeze and Cherry (1979). It could therefore be assumed that in the st. Johns Landfill the groundwater flow is primarily vertical in the slits or sands, and horizontal in the sandy/gravel aquifer. Since the hydraulic conductivity in both the silt and sand aquifers are the same order of magnitude, the two aquifers could be combined when developing hydraulic gradient maps.

Chloride concentrations. Isoconcentrations for the silts a the start of this study are shown in Figure 42 , Figure 43 shows the isoconcentrations at the finish. The Figures indicate that at the higher chloride levels exist along the south-west border of the landfill adjacent to the columbia slough.

If chloride levels for monitoring wells G7 and Dla had been included higher levels would exist at the north-west tip of the landfill, near the confluence of the Columbia and North Sloughs. However, monitoring well $\mathrm{G7}$ is completed in the 


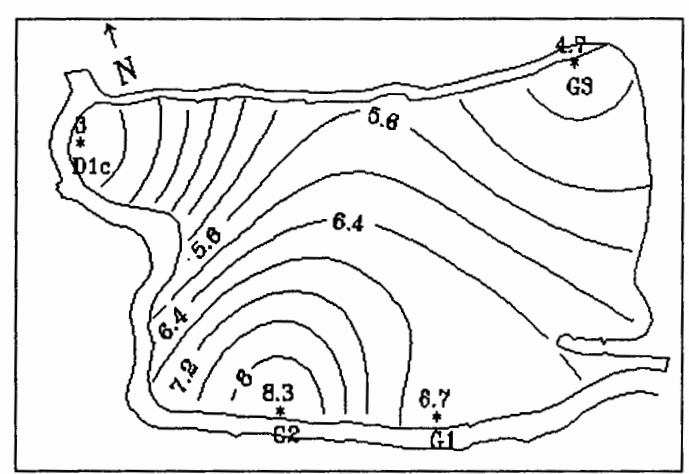

Figure 42. Isoconcentrations of chloride distributions in the silt aquitard, $(1 / 16 / 91)$. only four interpolation points were used.

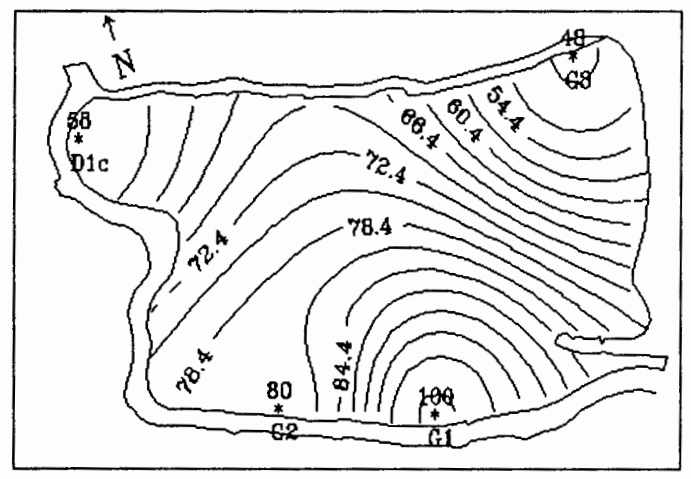

Figure 43 . Isoconcentrations of chloride distributions in the silt aquitard, (4/24/92). only four interpolation points were used.

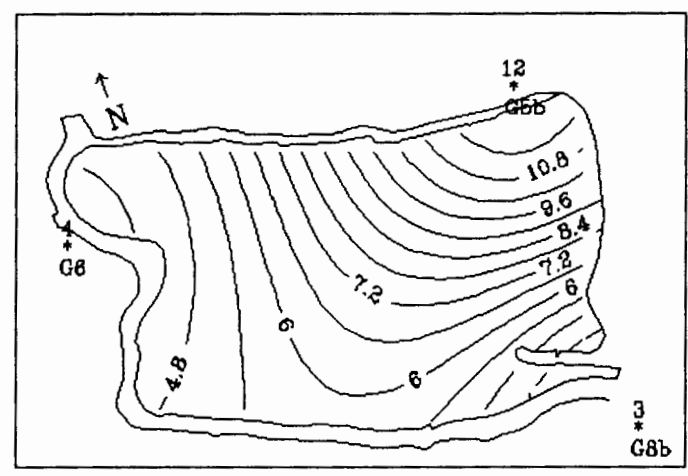

Figure 44. Isoconcentrations of chloride distributions in the sandy/gravel aquifer, $(1 / 14 / 91)$. only three interpolation points were used.

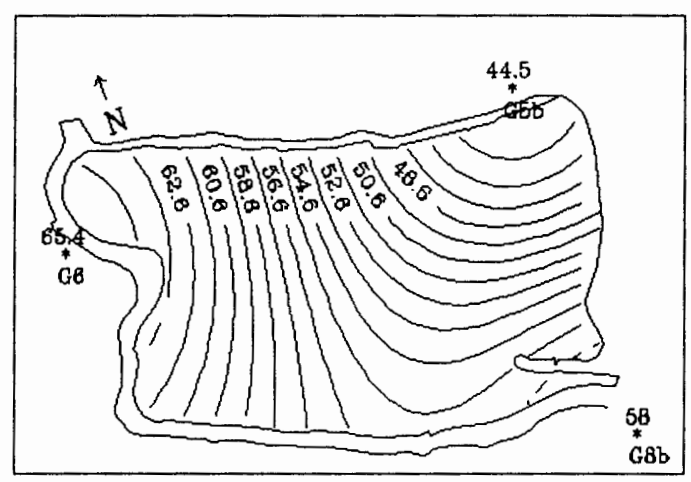

Figure 45. Isoconcentrations of chloride distributions in the sandy/gravel aquifer, $(4 / 24 / 93)$. Only three interpolation points were used.

underlying sandy aquifer, and Dla is at the interface of the landfill bottom and clay stratum, see Figure 6. If only advective transport is considered, monitoring well G7 could be included in the isoconcentration plot, as it is assumed that groundwater flow is primarily vertical in both the silts and 
sands. Monitoring well Dla is separated from the underlying silts by some 80 feet of clay. Including well Dla in the isoconcentration plots would results in spurious conclusions regarding contamination in the silts.

Isoconcentrations showing the chloride concentrations in the sandy/gravel aquifer at the start and finish of this study are shown in Figures 44 and 45 respectively. Comparison of the two Figures shows a complete reversal in the chloride gradient. Chloride concentration time series for wells G5b, G6, and G8b are superimposed in Figure 46, the plot shows several instances where the chloride levels in one of the wells exceeds the others. The same comparison is made with wells G1, G2, G3 and D1C, Figure 47, this plot shows similar results to Figure 46 . The oscillations can probably be attributed to natural variation in chloride levels and measurement errors.

Electrical conductivity. Isoconcentrations in the silt aquitard at the start and finish of this study are shown in Figures 48 and 49 respectively. The conductivity distributions appear to coincide with the chloride distributions shown in Figures 42 and 43.

For the underlying sandy/gravel aquifer, the electrical conductivity isoconcentrations at the start and finish are shown in Figures 50 and 51 respectively. The average electrical conductivity gradient in the sandy/gravel aquifer 


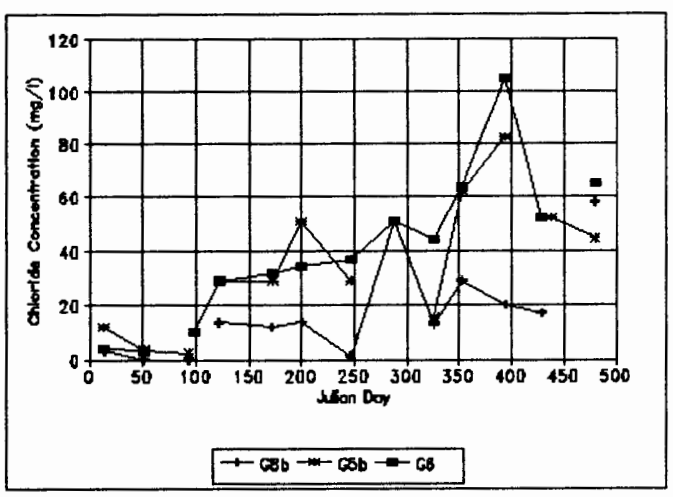

Figure 46. Superimposed chloride concentration time series for monitor wells $\mathrm{G} 5 \mathrm{~b}, \mathrm{G} 6$ and G8b.

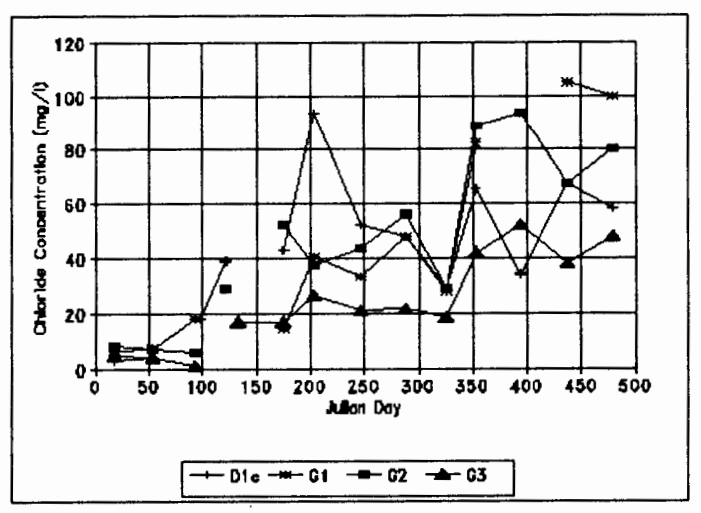

Figure 47. Superimposed chloride concentration time series for monitor wells G1, $\mathrm{G} 2$, G3, and D1c.

was orthogonal to the silty aquitard.

Superimposed electrical conductivity time series comparison plots for monitoring well groups G5b, G6, G8b and G1, G2, G3 and D1C are shown in Figures 52 and 53, respectively. The comparison plots show that the electrical conductivity time series is fairly stable leading to the assumption that gradient directions remain constant with time.

If the groundwater flow in the silty aquitard and sandy aquifer is primarily vertical, then changes in the areal distributions of the chemical indicators would be due to changes in source strength of the leachate, and less, perhaps, than to horizontal advective transport.

The isoconcentrations for the electrical conductivity in the sandy/gravel aquifer are generally in agreement with isoconcentrations developed by Fishman (1986). Their isoconcentration plots, however, include wells which were 


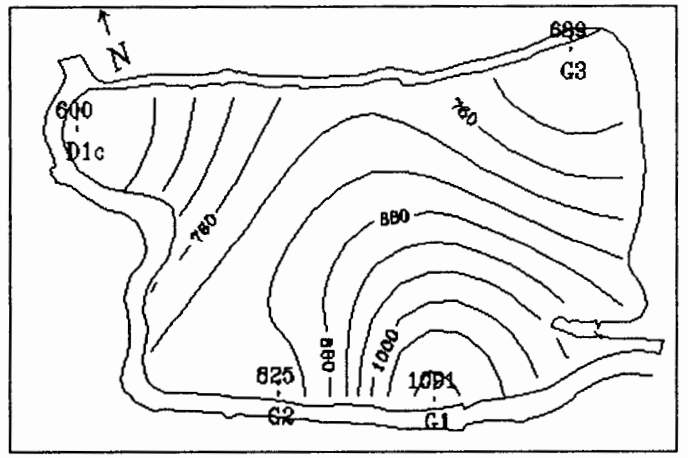

Figure 48. Isoconcentrations of electrical conductivity distributions in the silt aquitard,(1/16/91). Only four interpolation points were used.

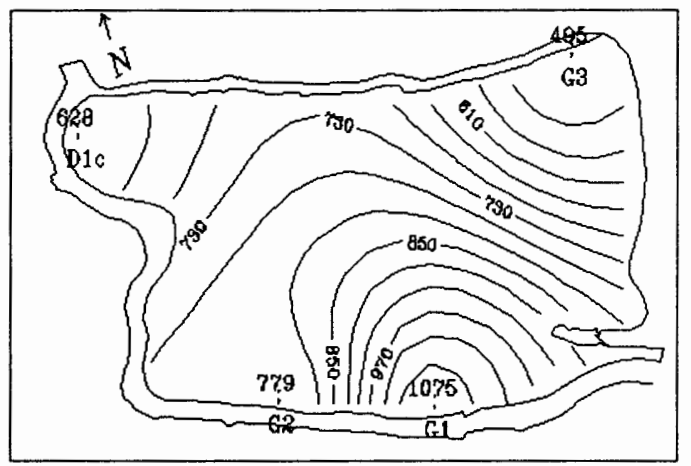

Figure 49. Isoconcentrations of electrical conductivity distributions in the silt aquitard, (4/24/92). Only four interpolation points were used.

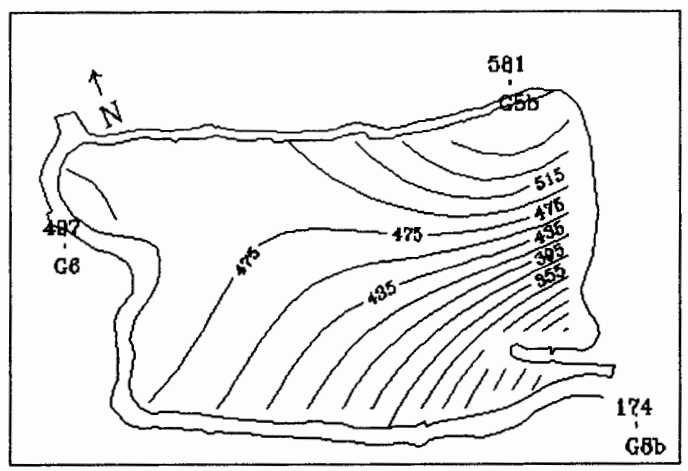

Figure 50. Isoconcentrations of electrical conductivity distributions in the sandy/gravel aquifer, $(1 / 14 / 91)$. Only three interpolation points were used.

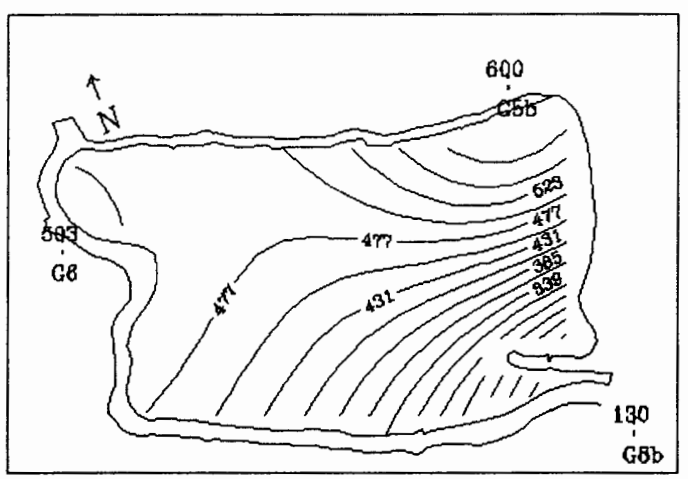

Figure 51. Isoconcentrations of electrical conductivity distributions in the sandy/gravel aquifer, $(4 / 24 / 92)$. Only three interpolation points were used.

completed just above the silt aquitard at the base of the landfill. Thus, higher electrical conductivity values interior of the perimeter dike are noted in the Fishman (1986) and 


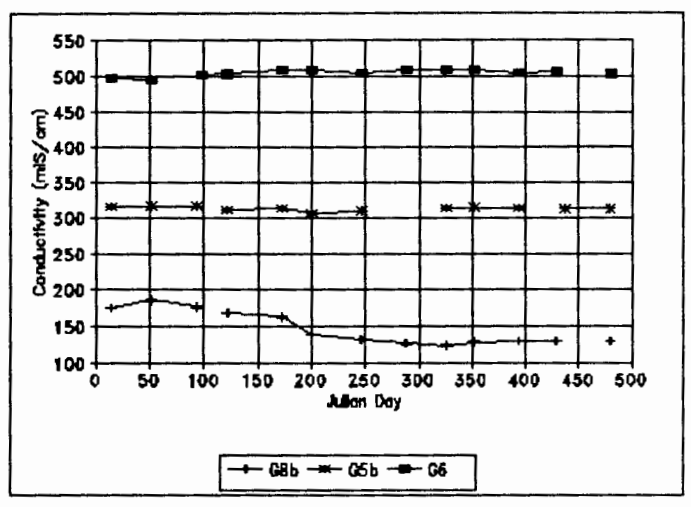

Figure 52. Superimposed electrical conductivity time series for monitor wells G5b, G6 and G8b.

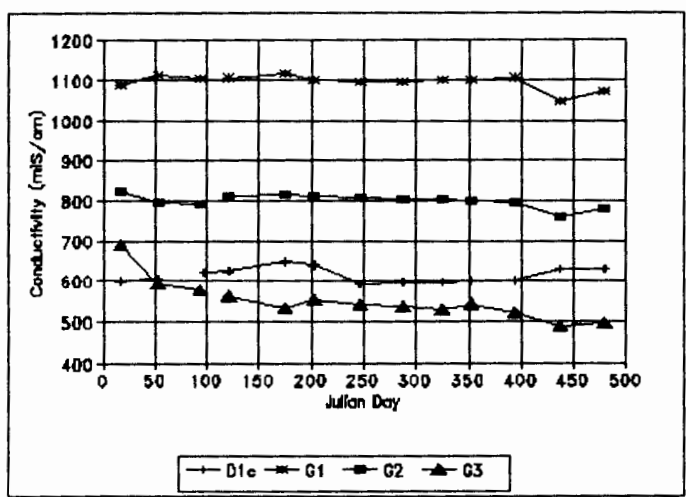

Figure 53. Superimposed electrical conductivity time series for monitor wells G1, $\mathrm{G} 2, \mathrm{G} 3$, and $\mathrm{D} 1 \mathrm{C}$.

Sweet Edwards/EMCON (1989). The wells in this study are completed in the silt and sandy/gravel aquifers located on or outside the landfill perimeter dike. Thus, the isoconcentration plots generated in this study do not accurately represent the values of chloride or conductivity in the silt or sandy/gravel aquifers interior of the perimeter dike. It would be expected that much higher values do exist in the landfill interior, but as yet, the actual concentration of chloride and conductivity levels in the underlying aquifers interior of the perimeter dike are unknown.

\section{FLUCTUATIONS IN GROUNDWATER LEVELS}

Fluctuations in groundwater levels can be caused by either natural or anthropogenic mechanisms. Freeze and cherry, (1979) have compiled a fairly extensive list identifying those mechanisms which most commonly cause groundwater level fluctuations (see Table V). Added to the list in Table V are 
fluctuations (see Table V). Added to the list in Table $\mathrm{V}$ are the effects of earth tides (John Bredehoeft (1966)) which are associated with strains in the earths crust due to the heavenly bodies. The most obvious mechanisms that could influence groundwater levels in the st. Johns Landfill monitoring well system are: (1) recharge, (2) atmospheric, (3) tidal, (4) evapotranspiration, and (5) external loading. If the aquifers which the monitoring wells tap are either semiconfined or confined, the rise and fall of the slough waters could be considered to act as a dynamic external load (D.K. Todd (1980)). Of the mechanisms listed in Table $V$, only the influence of tidal motions in the sloughs on the phreatic surface within the perimeter dike will be investigated. Atmospheric effects can produce spurious fluctuations within groundwater monitoring wells, i.e., an increase in atmospheric pressure causes water levels in the well to decrease, and visa-versa. The total change in head (pressure) in the well can equal the change in atmospheric pressure. The reader is referred to Freeze and Cherry (1979) for a basic understanding of the principles involved, and is further referred to papers by Stuart Rojstaczer (1988), Rojstaczer and Riley (1990), and A G Johnson (1973) which provide more advanced investigations into the subject. 
TABLE V

\section{MECHANISMS WHICH INDUCE FLUCTUATIONS IN} GROUNDWATER LEVELS

\begin{tabular}{|c|c|c|c|c|c|c|c|c|c|}
\hline Mechanism & $\begin{array}{l}\text { Uncon- } \\
\text { fined }\end{array}$ & $\begin{array}{l}\text { Con- } \\
\text { fined }\end{array}$ & Natural & Man & * Sd & D & Sea & $L$ & $\begin{array}{l}\text { Climatic } \\
\text { Influence }\end{array}$ \\
\hline Recharge & $x$ & & $x$ & & & & $x$ & & $x$ \\
\hline $\begin{array}{l}\text { Air entrapment } \\
\text { during recharge }\end{array}$ & $x$ & & $x$ & & $x$ & & & & $x$ \\
\hline $\begin{array}{l}\text { Evapotranspira- } \\
\text { tion }\end{array}$ & $x$ & & $x$ & & & $x$ & & & $x$ \\
\hline Bank-storage & $x$ & & $\underline{x}$ & & & $x$ & $x$ & & $x$ \\
\hline Tidal (Ocean) & $x$ & $x$ & $x$ & & & $x$ & & & \\
\hline Atmospheric & $x$ & $x$ & $x$ & & & $x$ & & & $x$ \\
\hline $\begin{array}{l}\text { External } \\
\text { loading } \\
\text { (confined) }\end{array}$ & & $x$ & & $x$ & $x$ & & & & \\
\hline Earthquakes & & $x$ & $x$ & & $x$ & & & & \\
\hline Pumping & $x$ & $x$ & & $x$ & & & & $x$ & \\
\hline Injection & & $x$ & & $x$ & & & & $x$ & \\
\hline $\begin{array}{l}\text { Artificial } \\
\text { recharge }\end{array}$ & $x$ & & & $x$ & & & & $x$ & \\
\hline Earth tides & $x$ & $x$ & $x$ & & & $x$ & & & $x$ \\
\hline
\end{tabular}

* Sd=Short duration; $D=D$ iurnal; Sea=Seasonal; $L=$ Long term

\section{ANALYSIS OF GROUNDWATER LEVEL FIELD OBSERVATIONS}

The observed groundwater levels for 12 of the 13 monitoring wells can be seen in Figures 54-57. Observed groundwater levels for monitoring well G7 are not included as problems with field equipment precluded any extensive accumulation of data. Comparing the groundwater level time series to the cumulative rainfall time series in Figure 58 , the groundwater levels are highest at the end of the wet season (early May), and lowest at the start of the wet season (late October). Hence, the seasonal fluctuations in the 
groundwater levels are due to the seasonal changes in precipitation.

Upon closer inspection of the groundwater level time series it can be seen that superimposed on the seasonal variations, are smaller but more frequent fluctuations in the groundwater levels. As shown earlier in Table $V$, these fluctuations could be caused by many different mechanisms. One potential mechanism that may be perturbing the groundwater levels is the tidal motions of the surrounding slough system. This tidal motion cloud be causing a swashing effect within the natural dike or landfill, influencing the temporal flux of leachate permeating from the dike.

To determine what mechanism(s) may be perturbing the groundwater levels, monitoring wells G1, G2, G3, G6, and D1a,C were arbitrarily selected as a sample population for use in a spectral analysis to investigate the frequency of the groundwater level oscillations. The spectral analysis is useful in determining which frequencies explain the variance of the time series Haans (1977). A first order estimate of the amplitude associated with each peak can be found in the relation, $a_{p}=\left(f_{w} P_{s}\right)^{1 / 2}$ where $a_{p}$ is the estimated amplitude, $f_{w}$ is fundamental frequency and $P_{s}$ is the power spectrum value. In this study the spectral analysis was used to determine at which frequencies the variances in observed groundwater levels occurred. Results of the spectral analysis are shown in Figures 59 and 60 (Note that each power spectrum value was 


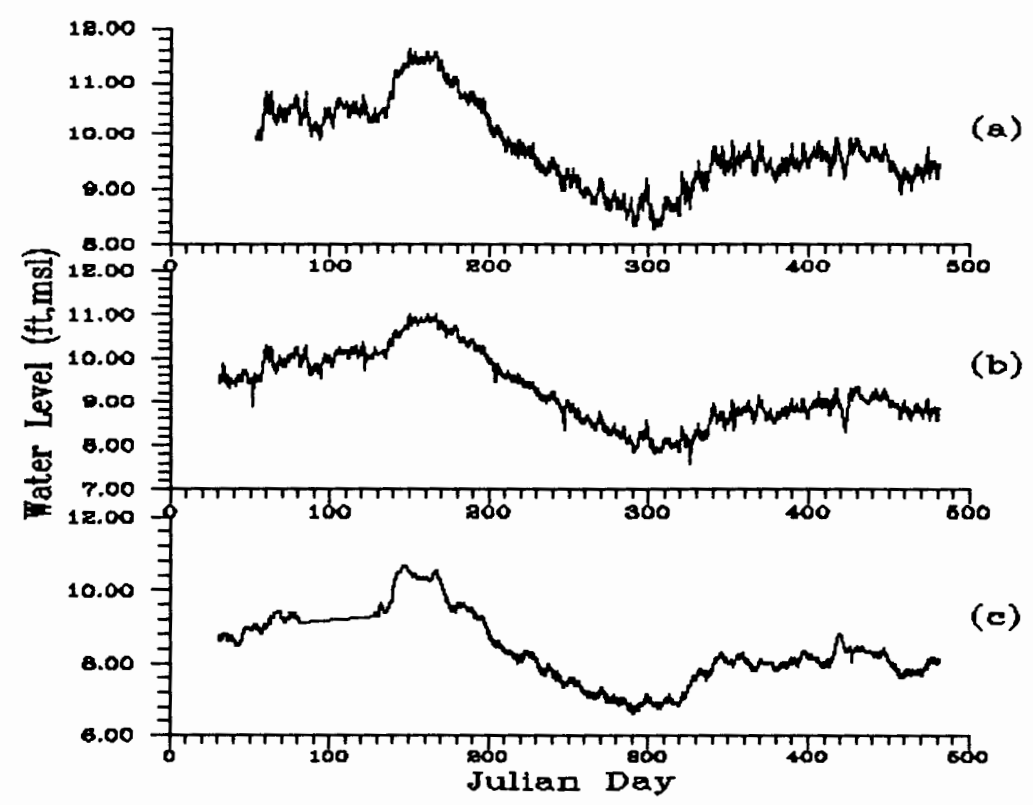

Figure 54. Observed groundwater levels at field monitor sites: (a) G1, (b) G2, (c) G3. Water levels are referenced to mean sea level (Julian day 1 is January 1, 1991).

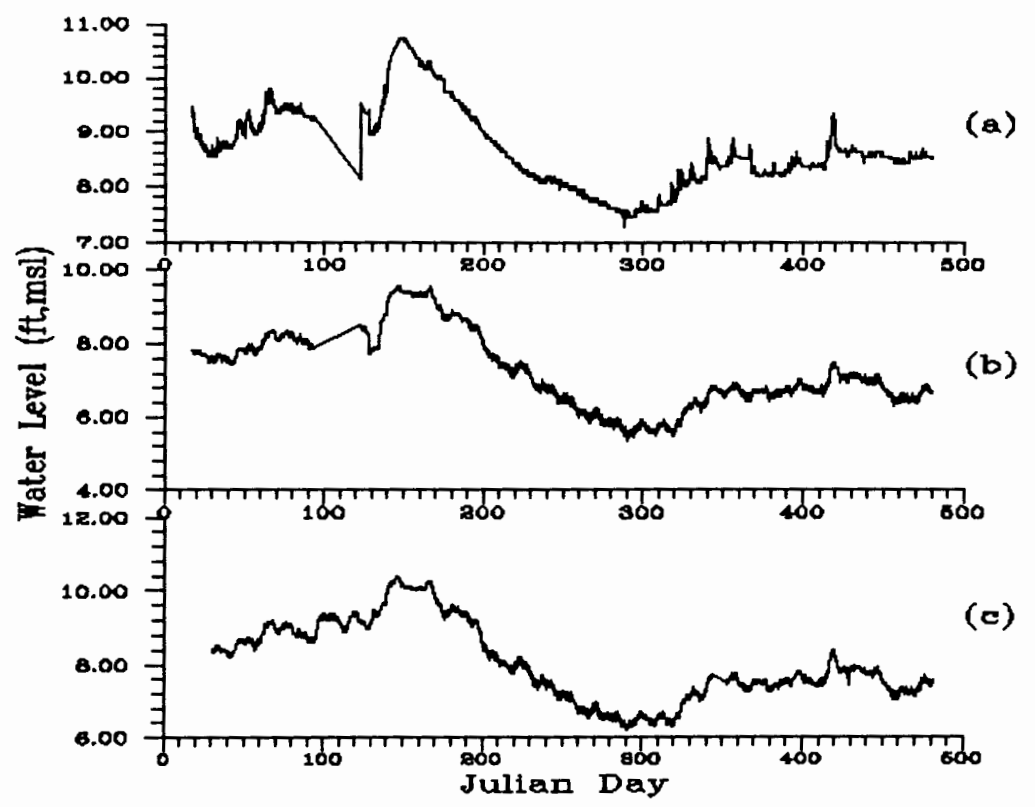

Figure 55. Observed groundwater levels from field monitor sites: (a) G5a, (b) G5b, (c) G6. Water levels are referenced to mean sea level (Julian day 1 is January 1, 1991). 


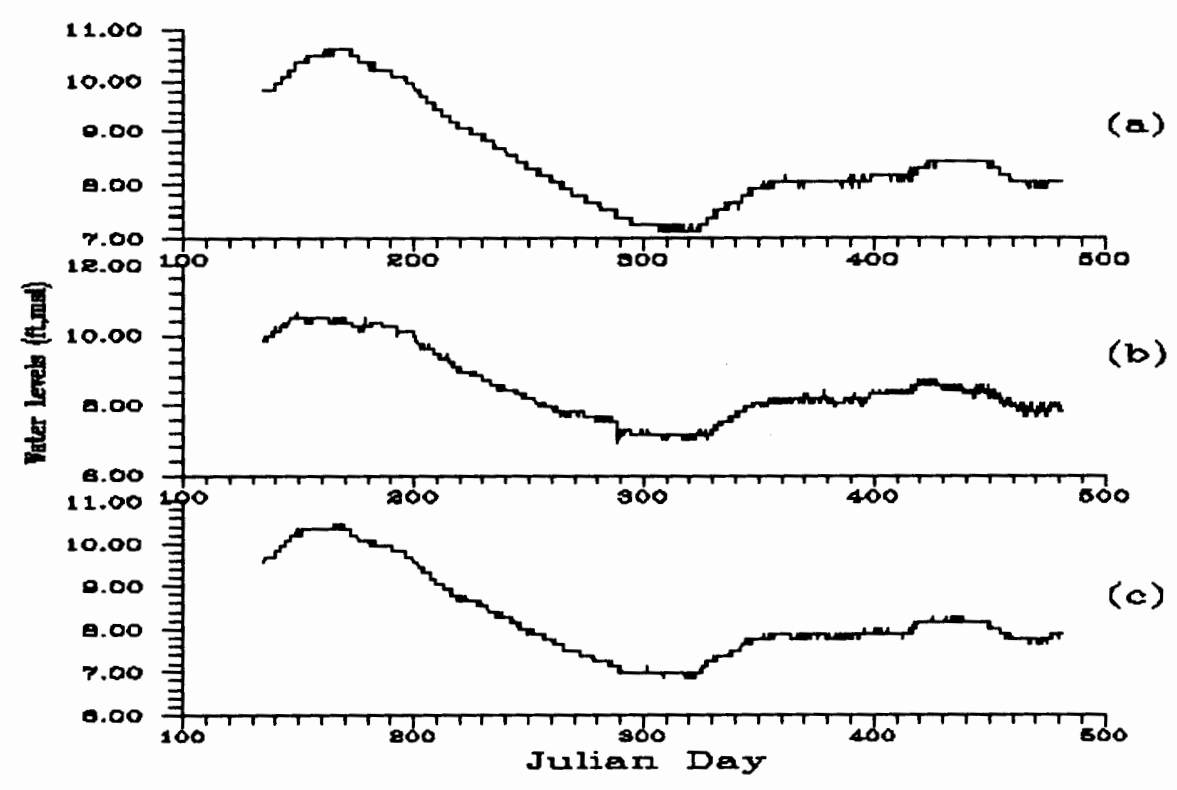

Figure 56. Observed groundwater levels at field monitor sites: (a) G8a, (b) G8b, (c) G8C. Water levels are referenced to mean sea level (Julian day 1 is January 1, 1991).

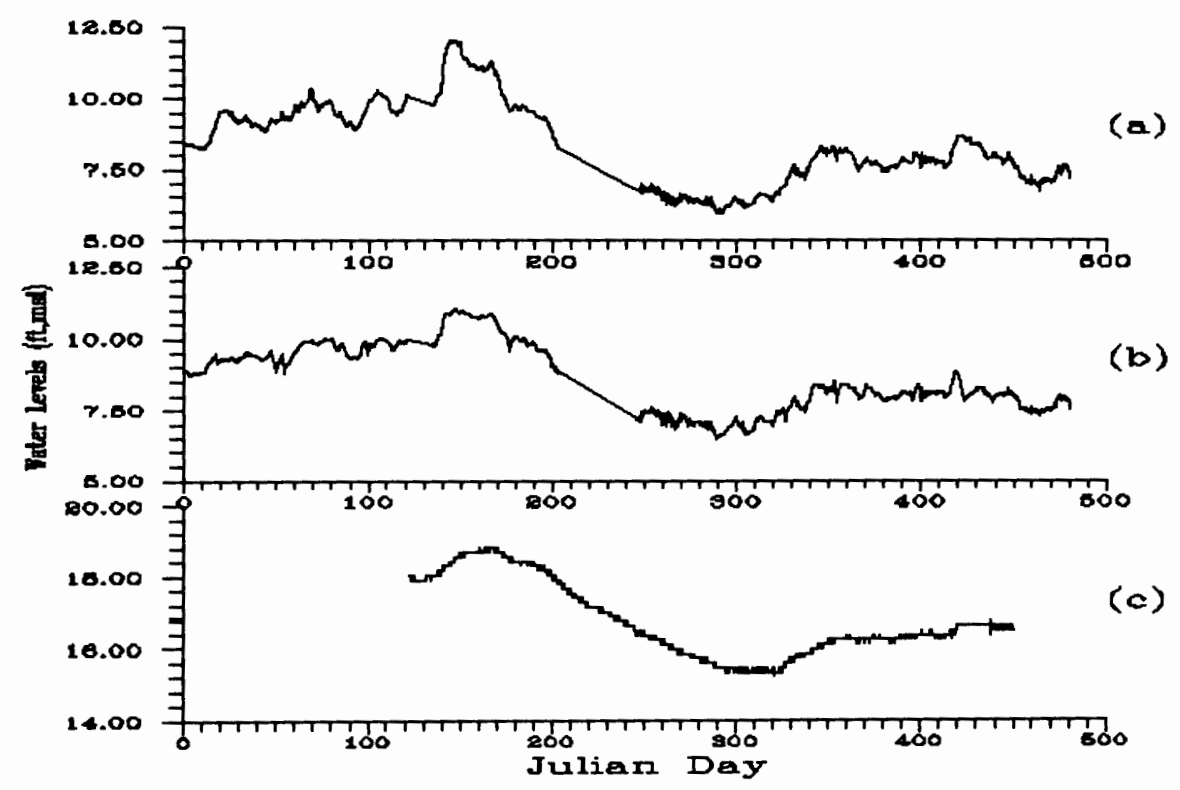

Figure 57. Observed groundwater levels at field monitor sites: (a) Dla, (b) Dlc, (c) Familian. Water levels are referenced to mean sea level (Julian day 1 is January 1, 1991). 


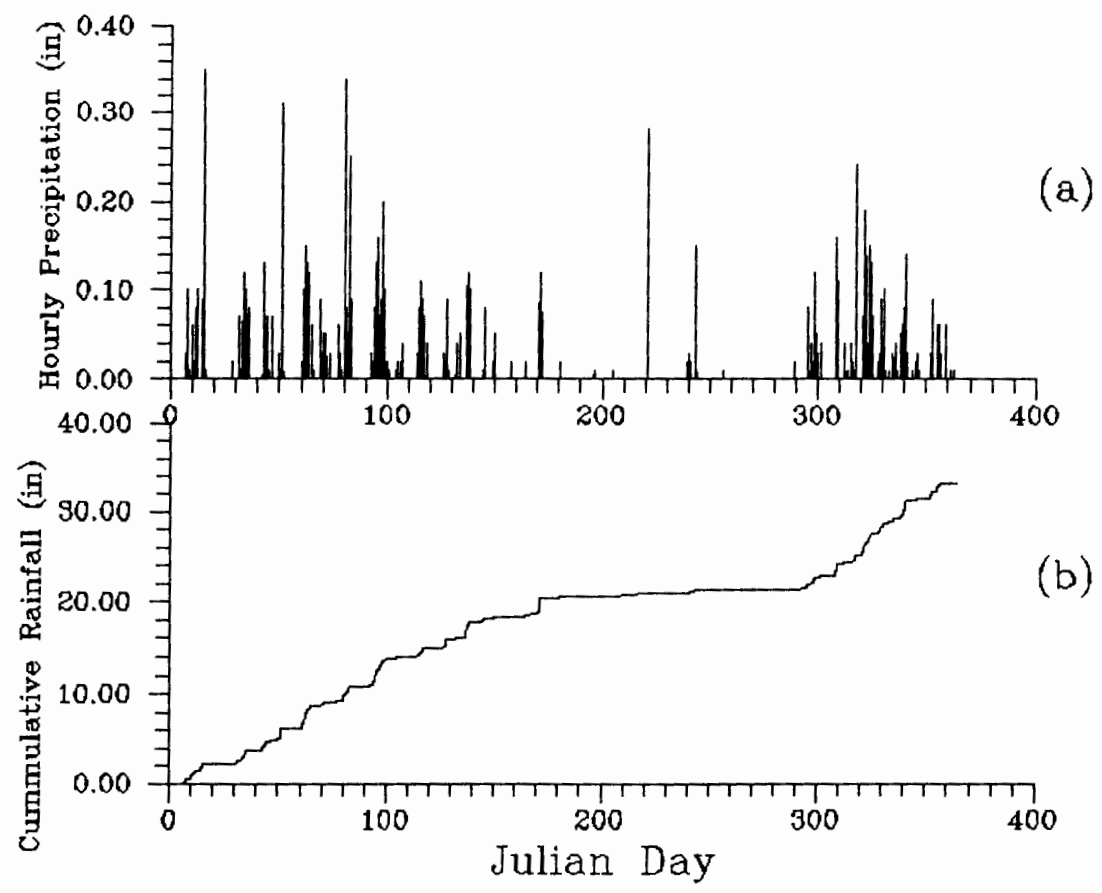

Figure 58. Observed precipitation events for Julian year 1991 displayed as: (a) hourly precipitation (water equivalent in inches), (b) cumulative rainfall depth (Julian day 1 is January 1, 1991).

multiplied by its associated frequency to better show the results). The spectral analysis showed that the largest amount of variance in all six time series is due to seasonal frequencies associated with the wet and dry periods. This is shown by the dominate peak at the far left for all wells. In addition, monitor wells G1, G2, G3, and G6 exhibit three smaller peaks to the right of the dominate peak, occurring at frequencies $0.07,0.9$, and 2 cycles/day, which have period lengths of 14,1 , and 0.5 days respectively. The smaller peaks are not readily apparent in monitor wells $\mathrm{D} 1 \mathrm{a}, \mathrm{C}$. These lessor peaks represent the smaller oscillations superimposed on the seasonal fluctuations. 
In addition to the groundwater level frequency analyses, spectral analyses were performed on the observed time series for the 1991 rainfall events and North Slough (station ENS) water elevations. The results of this analysis are shown in Figure 61. For both time series the greatest amount of variance is due to seasonal fluctuations. The slough water elevation time series, Figure 61a, has the same three smaller peaks to the right of the dominate peak at periods 14 day, 1 day, and 0.5 day. The rainfall event power spectrum, Figure 61b, shows that as the frequency increases, the amount of variance per frequency interval decreases with no apparent pattern to the distribution of the peaks. For the power

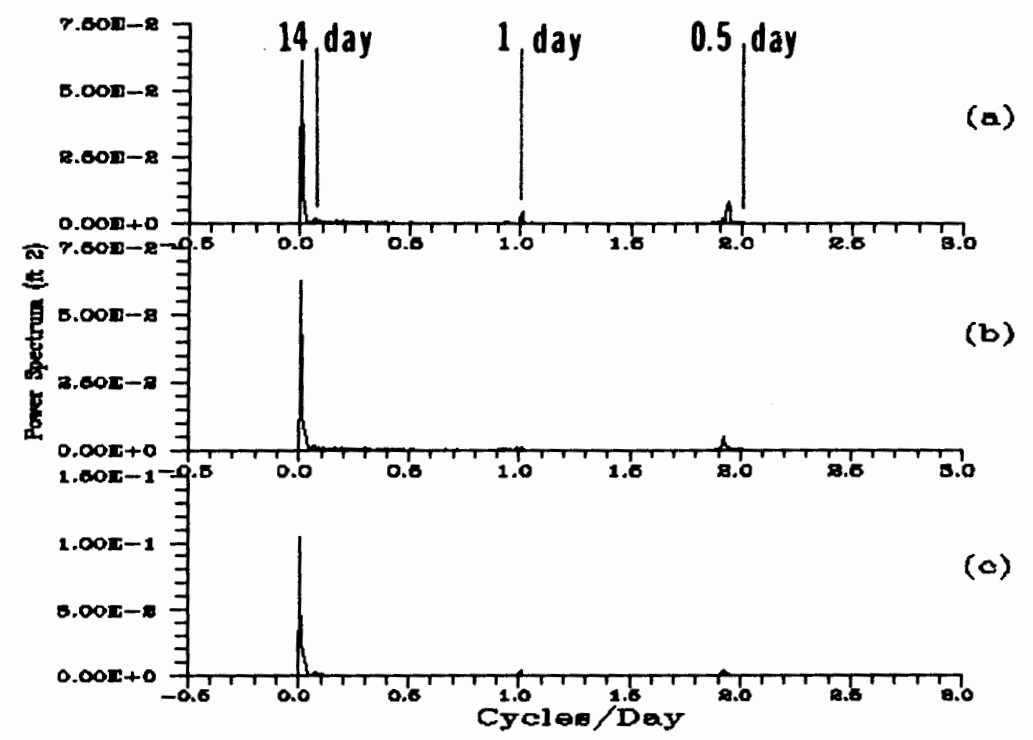

Figure 59. Power spectrum showing the amount of variance per interval of frequency for groundwater level time series: (a) G1, (b) G2, and (c) G3. The power spectrum has been multiplied by its corresponding frequency to better show the results 


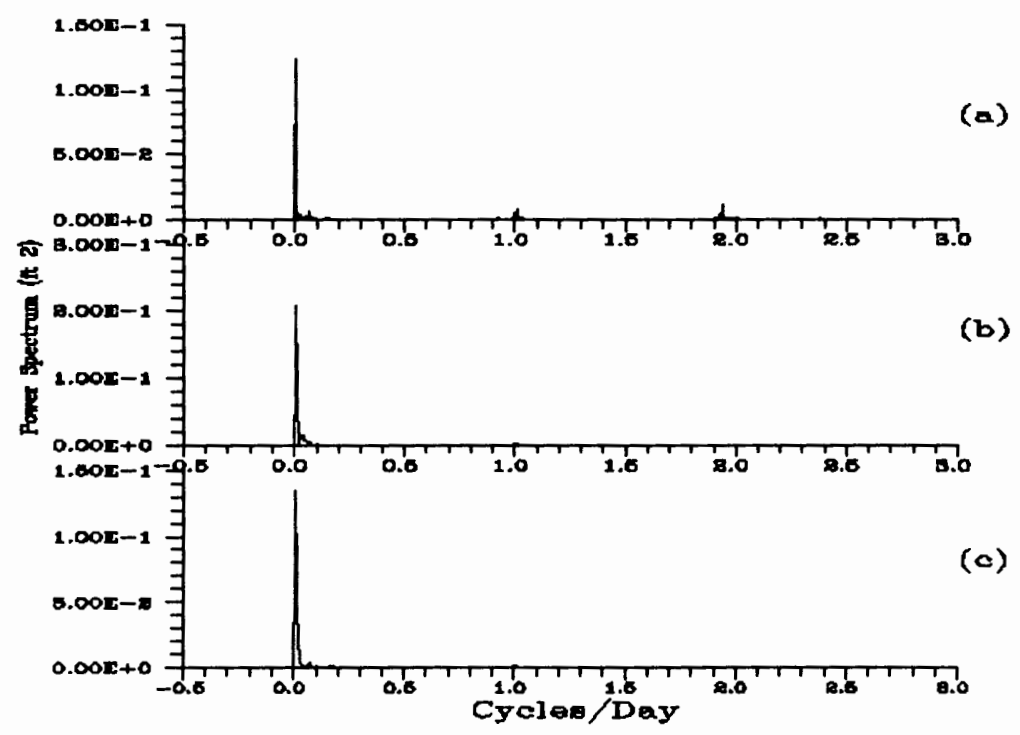

Figure 60. Power spectrum showing the amount of variance per interval of frequency for groundwater level time series: (a) G6, (b) Dla, and (c) Dlc. The power spectrum has been multiplied by its corresponding frequency to better show the results.

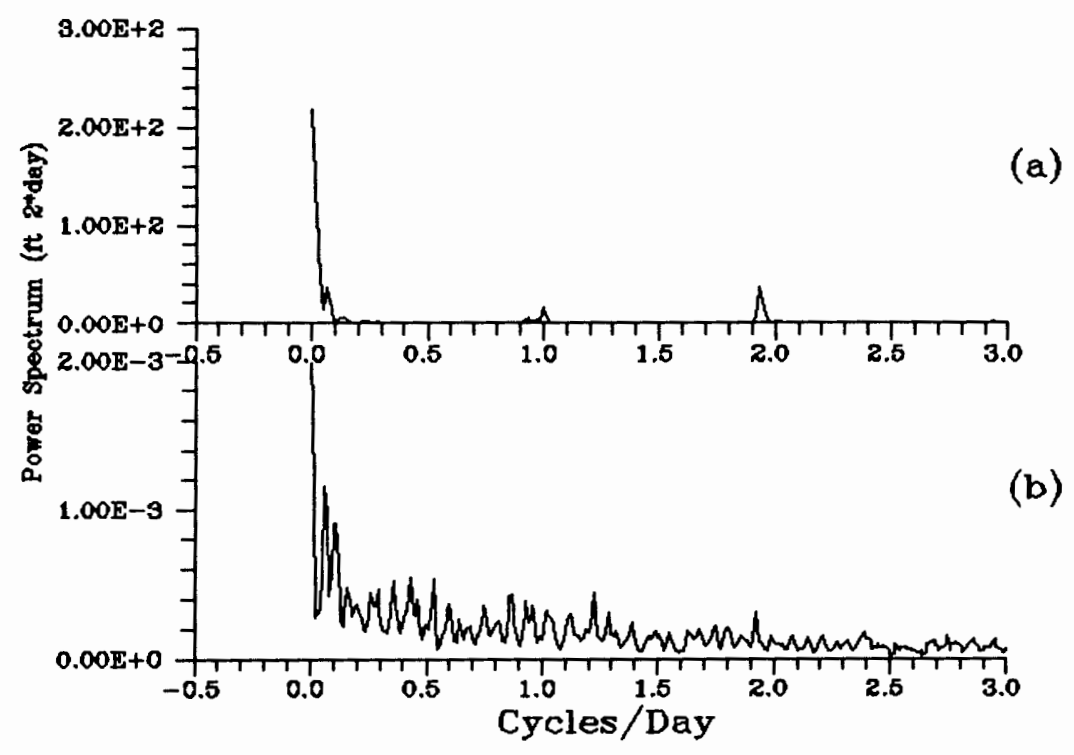

Figure 61. Power spectrum showing the amount of variance per interval of frequency for time series: (a) North slough, (b) Rainfall events. 
spectrum after the 14 day period the random distribution of, and lack of significant peaks are typical of random noise.

Hence, from the spectral analysis rainfall events do not drive the smaller cyclical perturbations, at periods less than 14 days, that appear in the groundwater system, and the North slough may be influencing groundwater levels, as the North slough system has the same frequency fingerprint as the groundwater system.

If it is assumed that a linear relation exists between the two time series, the cross-correlation matrix of the two systems will show to what degree slough water levels influence groundwater levels. But before the cross-correlation analysis can be performed, the seasonal influences must be removed. This was done by smoothing the observed time series using a 14 day moving average, and subsequently subtracting the smoothed time series from the observed time series. The resultant difference time series shows only perturbations with periods of 14 days and less and can be used for statistical analysis. All three time series observed, smoothed, and difference can be seen in Figures 62 - 72. The difference time series show that the range in water levels can be significant, e.g., in monitoring wells $G 1$ and G2, Figures 62 and 63 , groundwater levels can change as much as 0.9 ft over a 14 day period, Table VI summarizes the range in groundwater levels for Figures 62 - 72. In general all monitoring wells are subject to dynamic changes in water levels over short periods of time. 


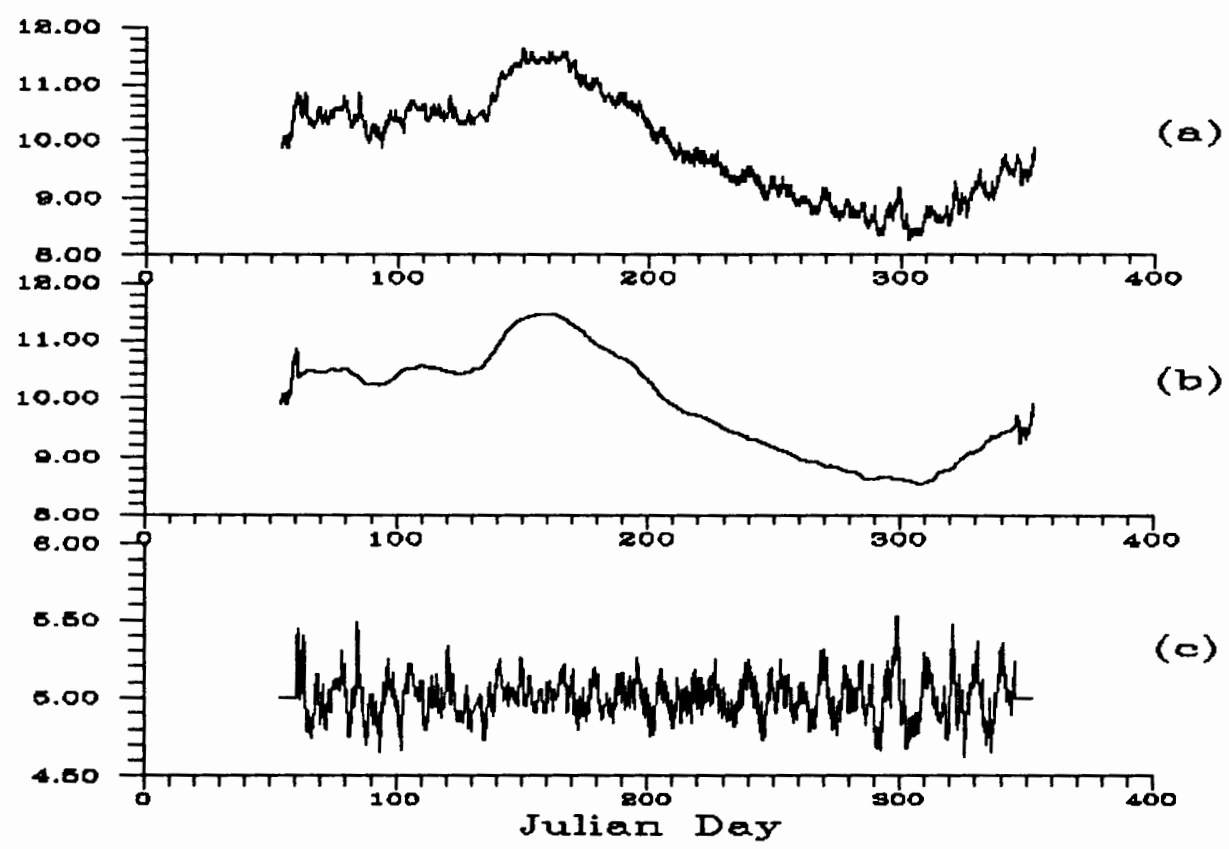

Fiqure 62. Groundwater level time series for monitor well Gl, each series being: (a) observed, (b) 14 day smoothed, (c) difference.

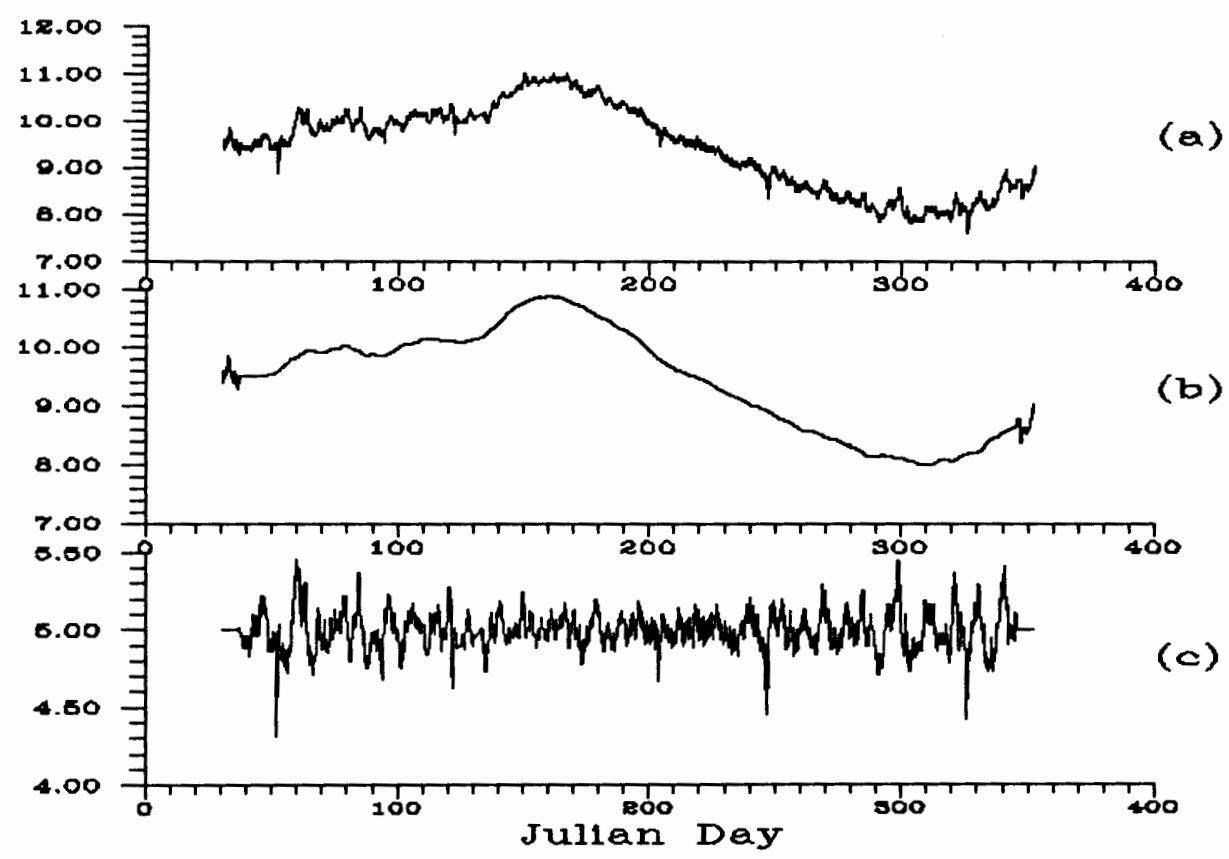

Figure 63. Groundwater level time series for monitor well G2, each series being: (a) observed, (b) 14 day smoothed, (c) difference. 
The variance in the groundwater levels appear to be a function of the season, larger variances occurring in the wet season, smaller variances in the dry season.

In addition to the groundwater time series differencing, slough water level time series were also difference to remove seasonal fluctuations. The difference slough water and groundwater time series were cross-correlated. Table VII shows what groupings were used for the cross-correlations. Figure 3 shows the relative location of each well monitoring site to the slough gaging stations. Results of the cross-correlation analysis are shown in Figures 73 - 76. The abscissa being the time lags at which the autocovariance function was computed,

\section{TABLE VI}

RANGE OF GROUNDWATER LEVELS WITH PERIODS 14 DAYS AND LESS

\begin{tabular}{|c|c|c|c|}
\hline Well & Range (ft) & Well & Range (ft) \\
\hline \hline Dla & 0.86 & DlC & 0.88 \\
\hline GI & 0.90 & G2 & 0.90 \\
\hline G3 & 0.59 & G6 & 0.63 \\
\hline G5a & 0.85 & G5b & 0.72 \\
\hline G8a & 0.30 & G8b & 0.73 \\
\hline G8C & 0.30 & . & G
\end{tabular}

one unit is 1.5 hours, and the dashed lines are the 95\% confidence limits. A negative lag indicates that groundwater level perturbations follow slough water level perturbations. 


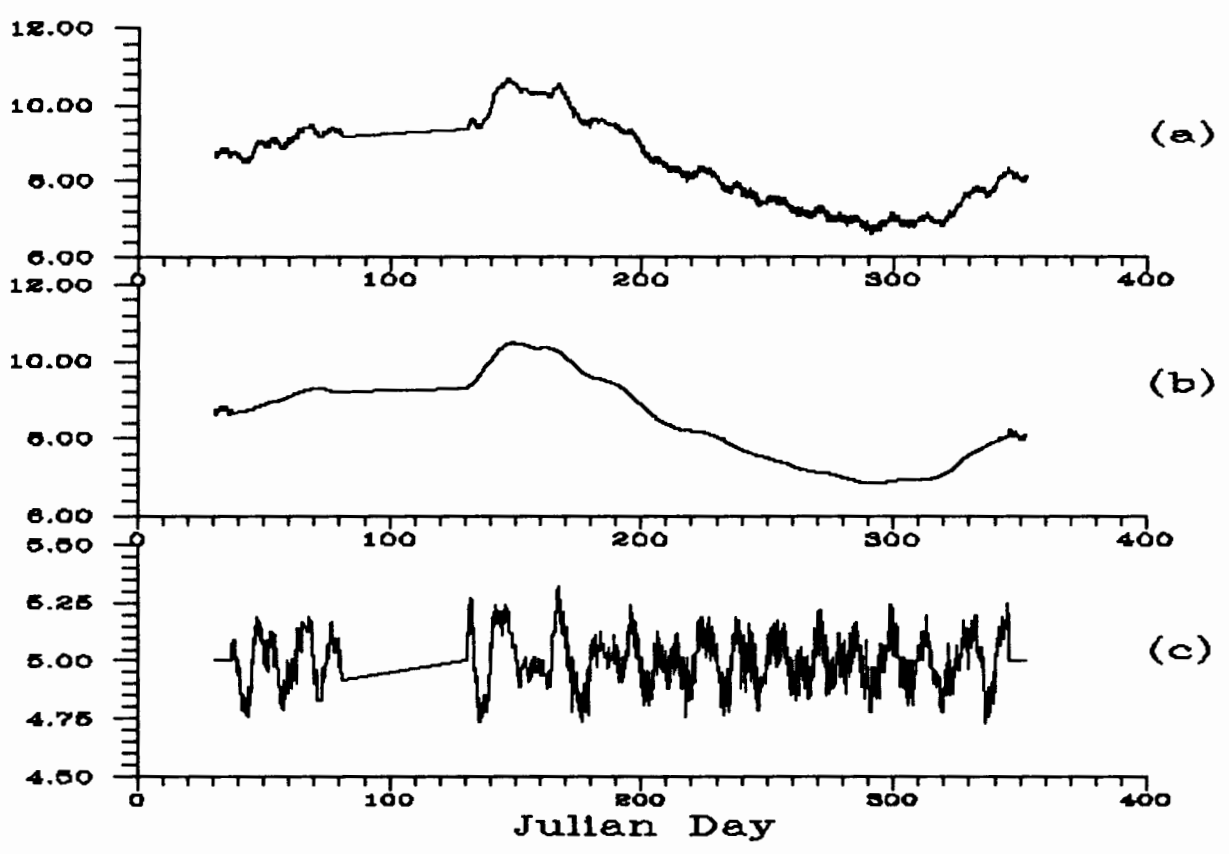

Figure 64. Groundwater level time series for monitor well G3, each series being: (a) obsereved, (b) 14 day smoothed, (c) differenced.

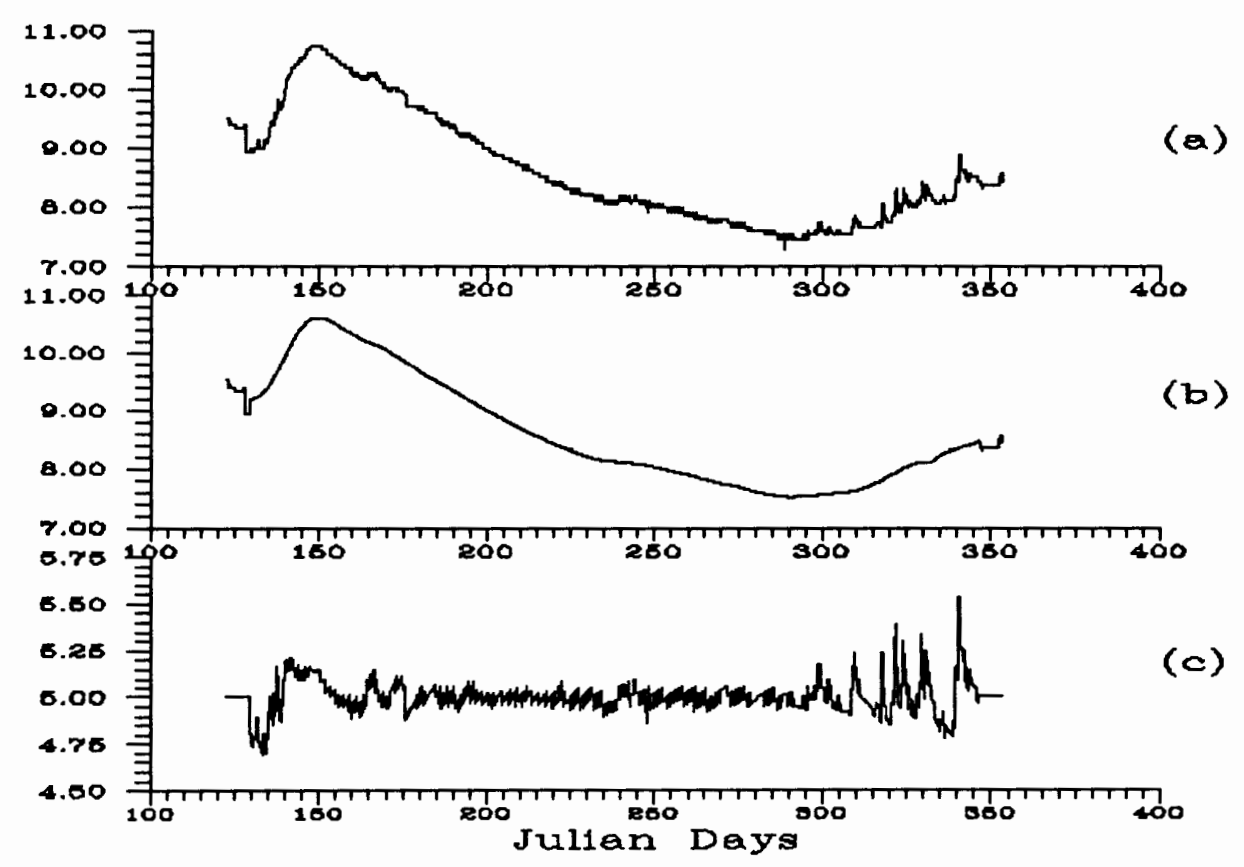

Figure 65. Groundwater level time series for monitor well G5a, each series being: (a) observed, (b) 14 day smoothed, (c) differenced. 


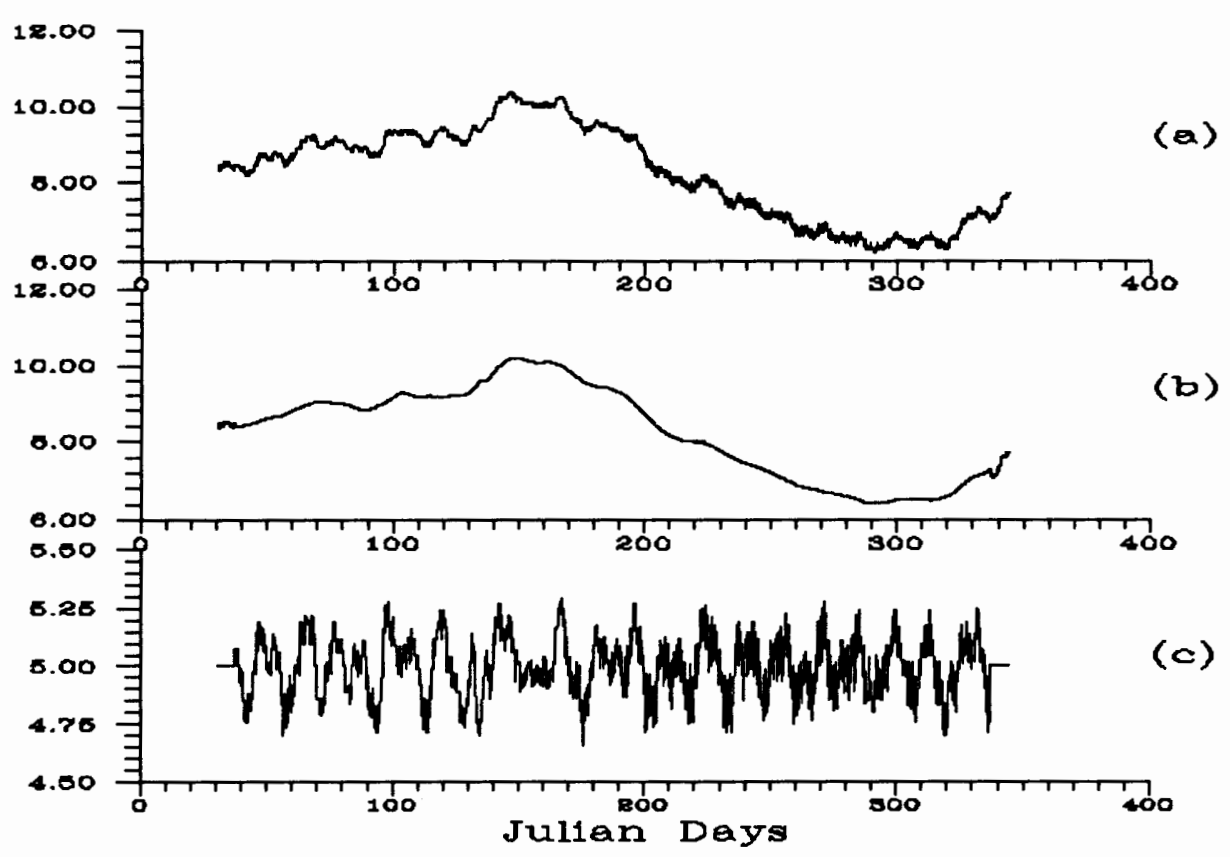

Figure 66. Groundwater level time series for monitor well G6, each series being: (a) observed, (b) 14 day smoothed, (c) differenced.

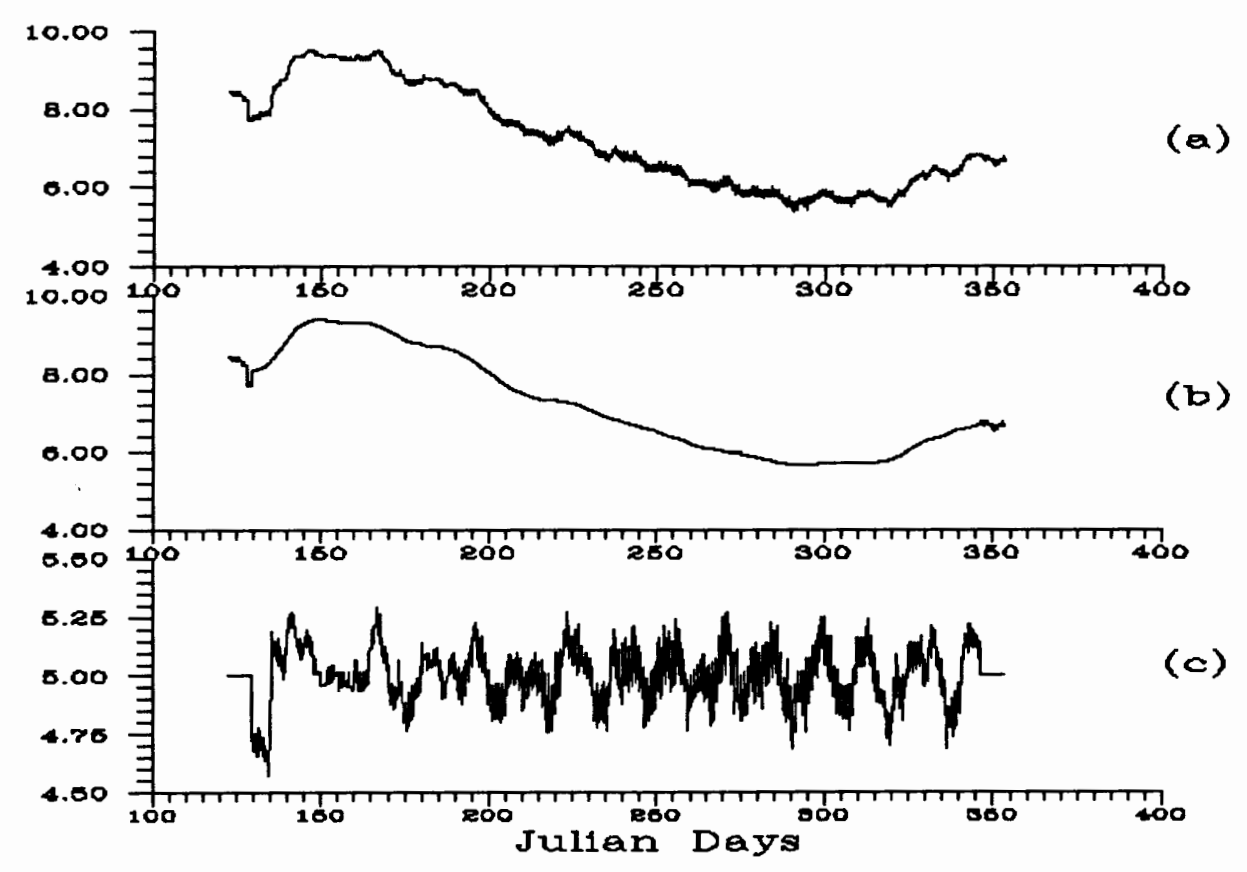

Fiqure 67. Groundwater level time series for monitor well G5b, each series being: (a) observed, (b) 14 day smoothed, (c) differenced. 


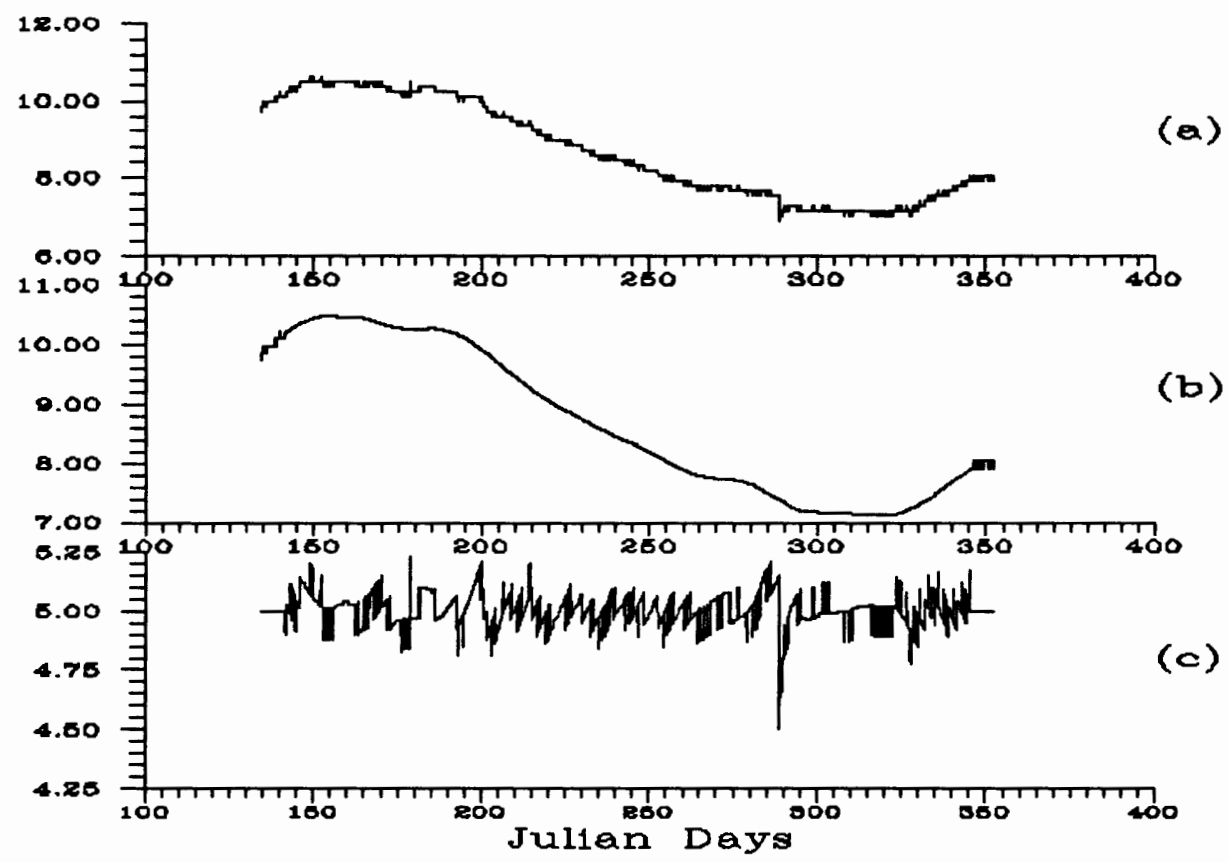

Figure 68. Groundwater level time series for monitor well G8b, each series being: (a) observed, (b) 14 day smoothed, (c) differenced.

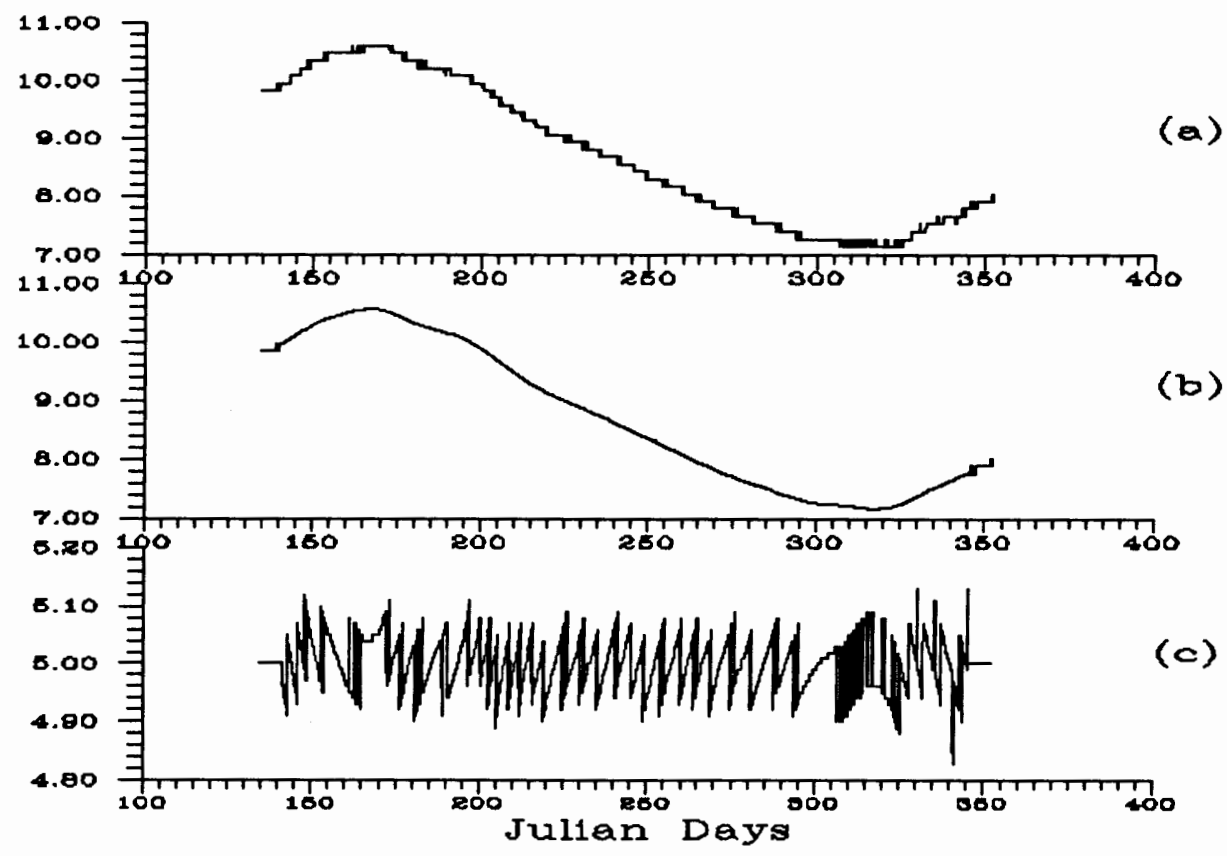

Figure 69. Groundwater level time series for monitor well G8a, each series being: (a) observed, (b) 14 day smoothed, (c) differenced. 


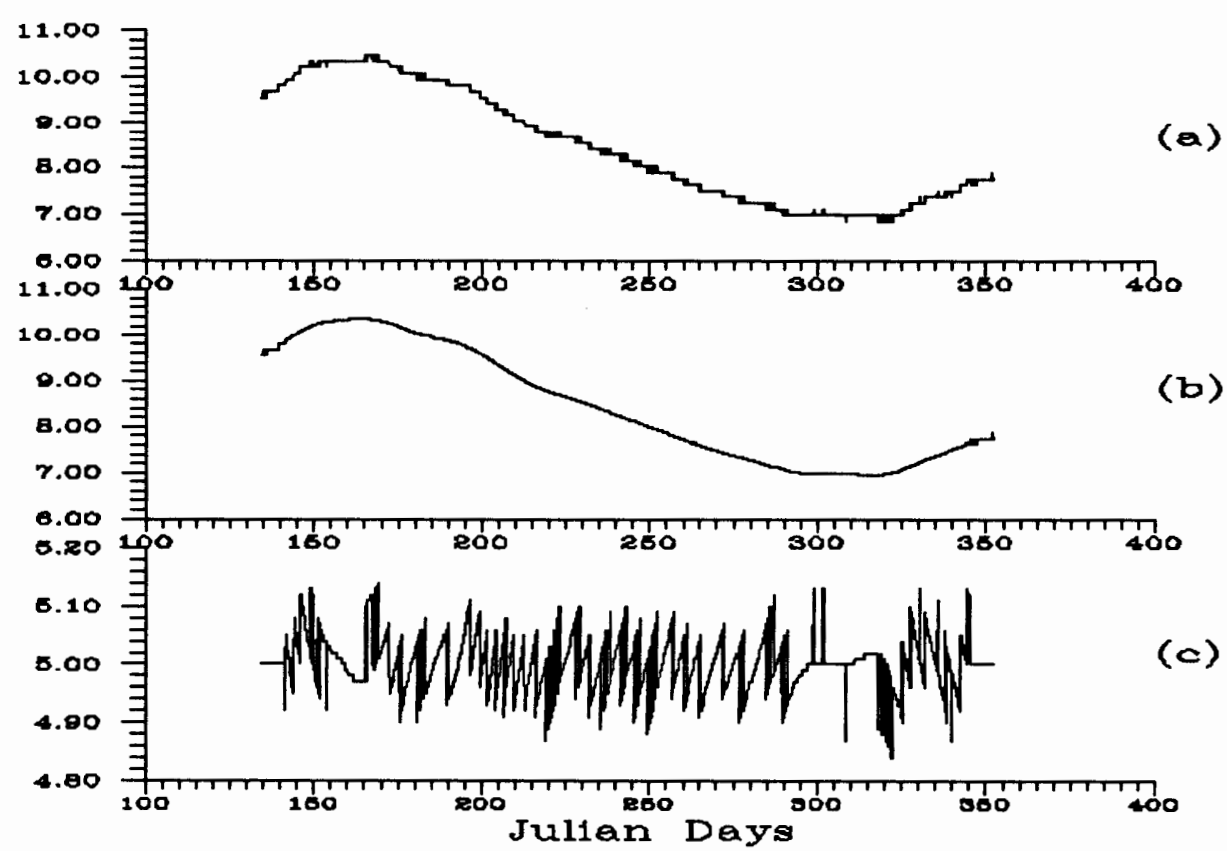

Figure 70. Groundwater level time series for monitor well G8C, each series being: (a) observed, (b) 14 day smoothed, (c) differenced.

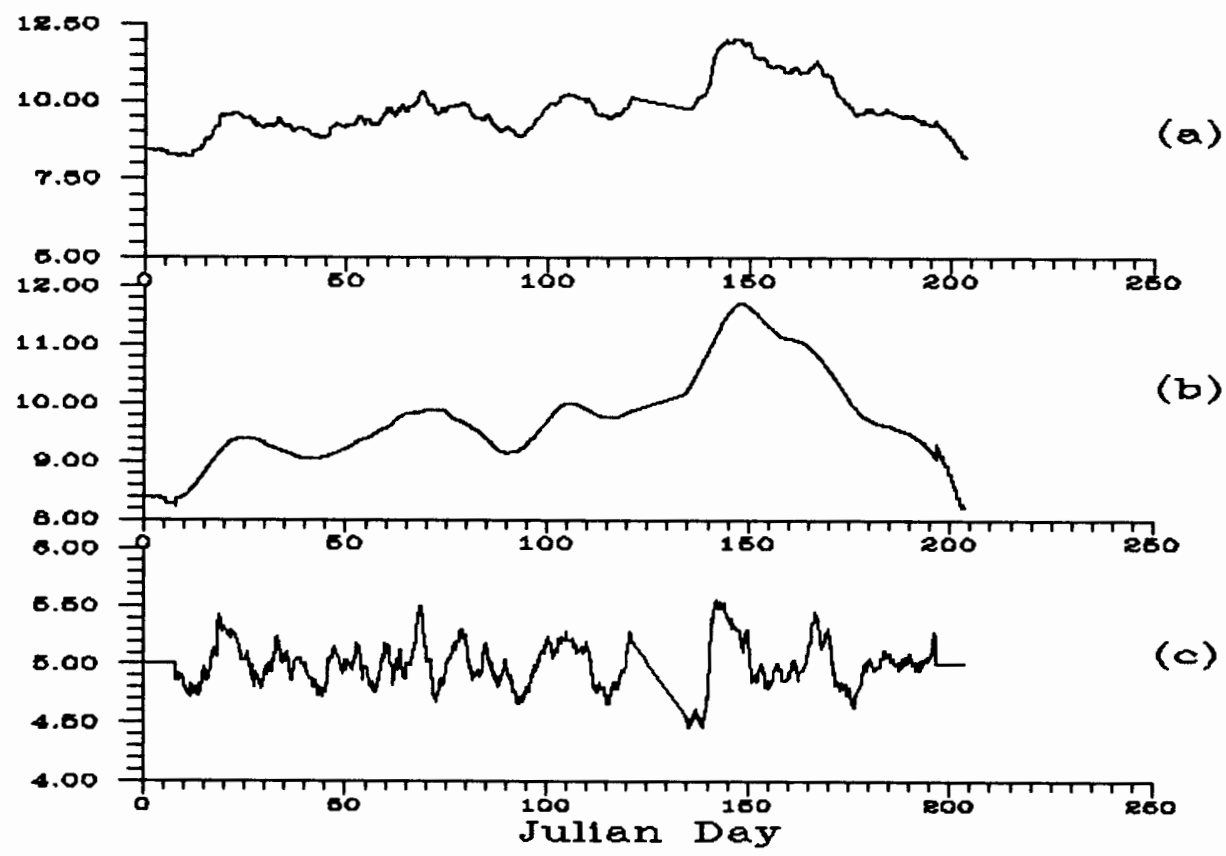

Figure 71. Groundwater level time series for monitor well Dla, each series being: (a) observed, (b) 14 day smoothed, (c) differenced. 


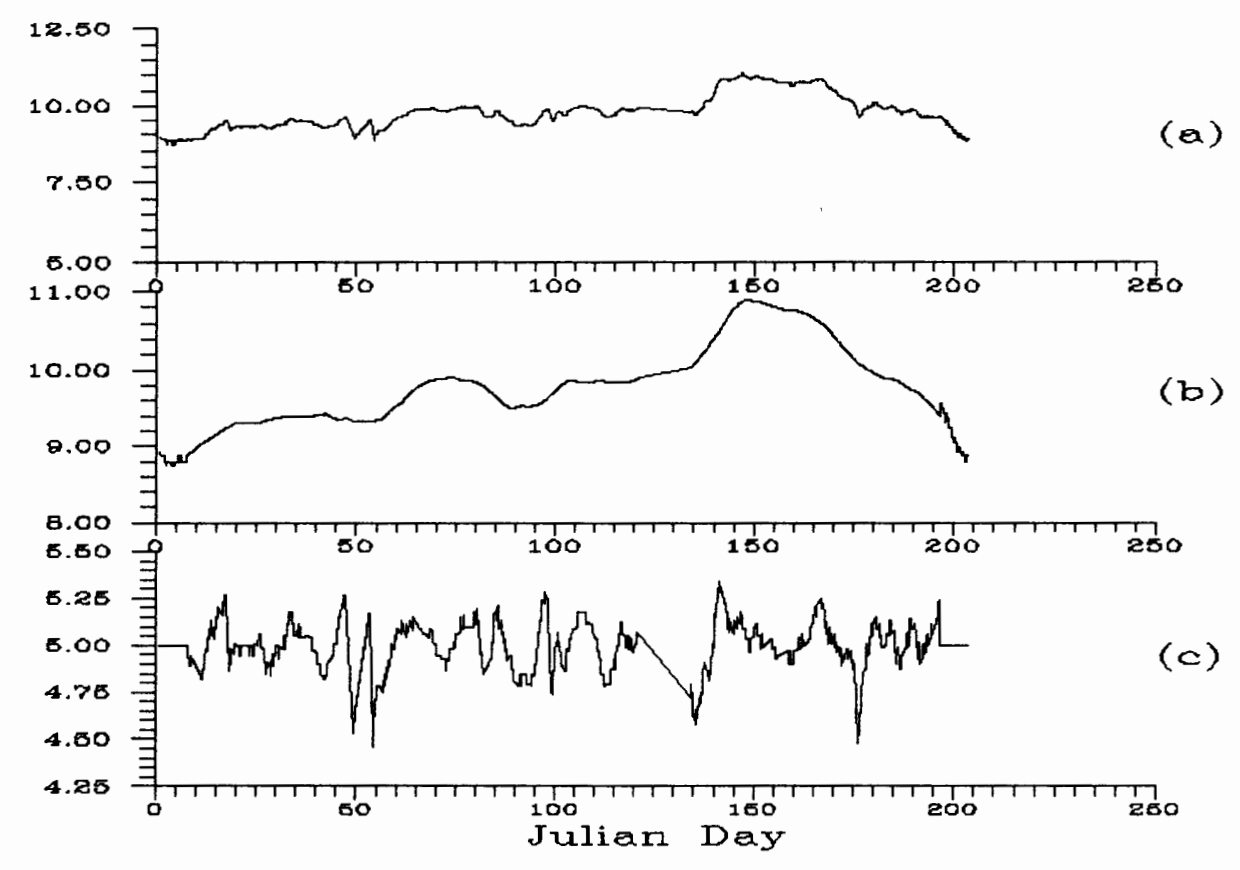

Figure 72. Groundwater level time series for monitor well D1c, each series being: (a) observed, (b) 14 day smoothed, (c) differenced.

TABLE VII

GROUPINGS USED IN THE CROSS-CORRELATIONS

\begin{tabular}{||l|l|}
\hline \multicolumn{1}{|c|}{ Slough Gaging Station } & Monitor Well \\
\hline \hline East North Slough & G3, G5ab \\
\hline Confluence at North Slough & D1ac, G6 \\
\hline St. Johns Bridge & G1, G2, G8abc \\
\hline
\end{tabular}

Assuming that the slough water system is perturbing the groundwater system, only the negative time lag area is of interest.

The cross-correlation study indicates that in all the monitoring wells the groundwater levels are significantly 


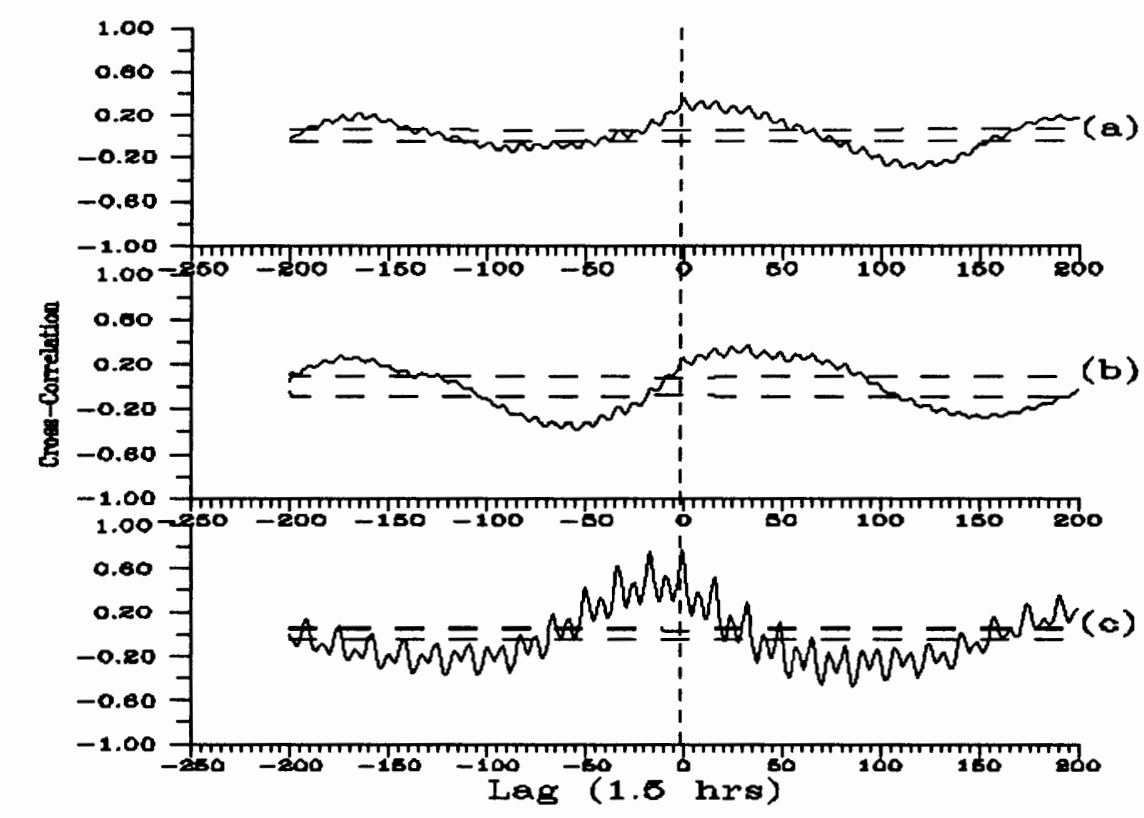

Figure 73. Cross-correlation matrix between the slough and groundwater monitoring sites: (a) G1, (b) G2, (c) G3. The dashed lines are the 95\% confidence intervals.

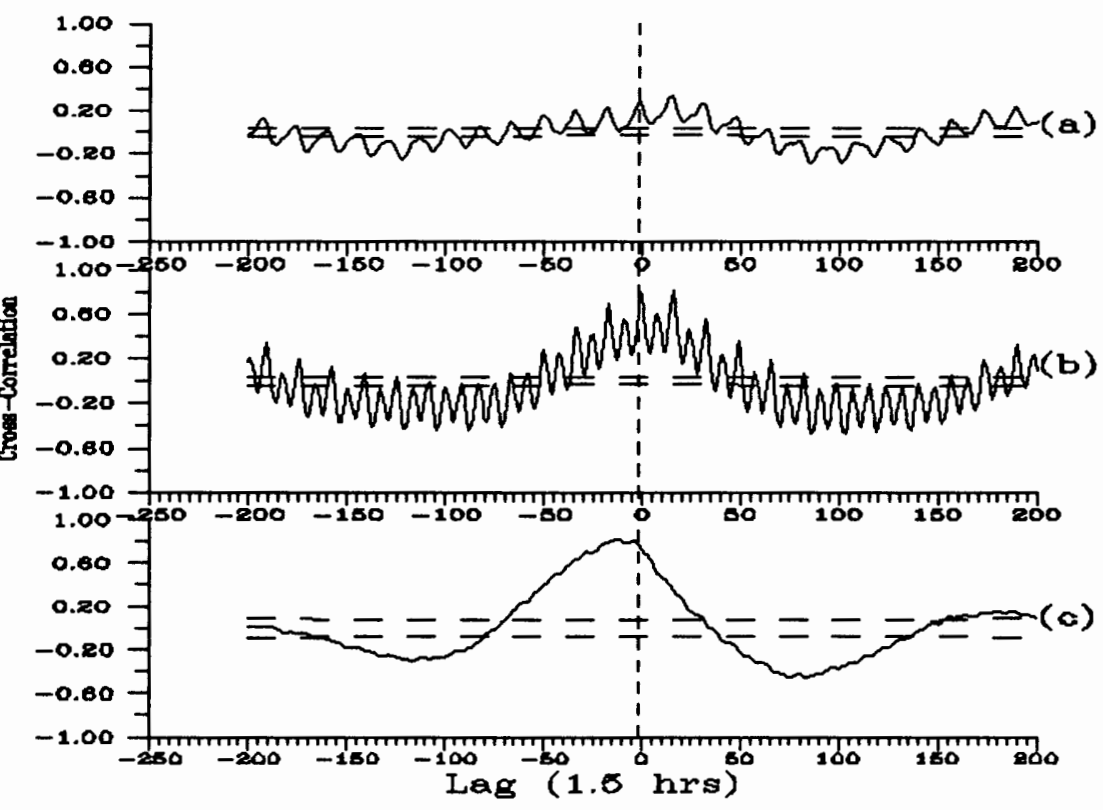

Figure 74. Cross-correlation matrix between the slough and groundwater monitor sites: (a) G5a, (b) G5b, (c) G6. The dashed lines are the $95 \%$ confidence intervals. 


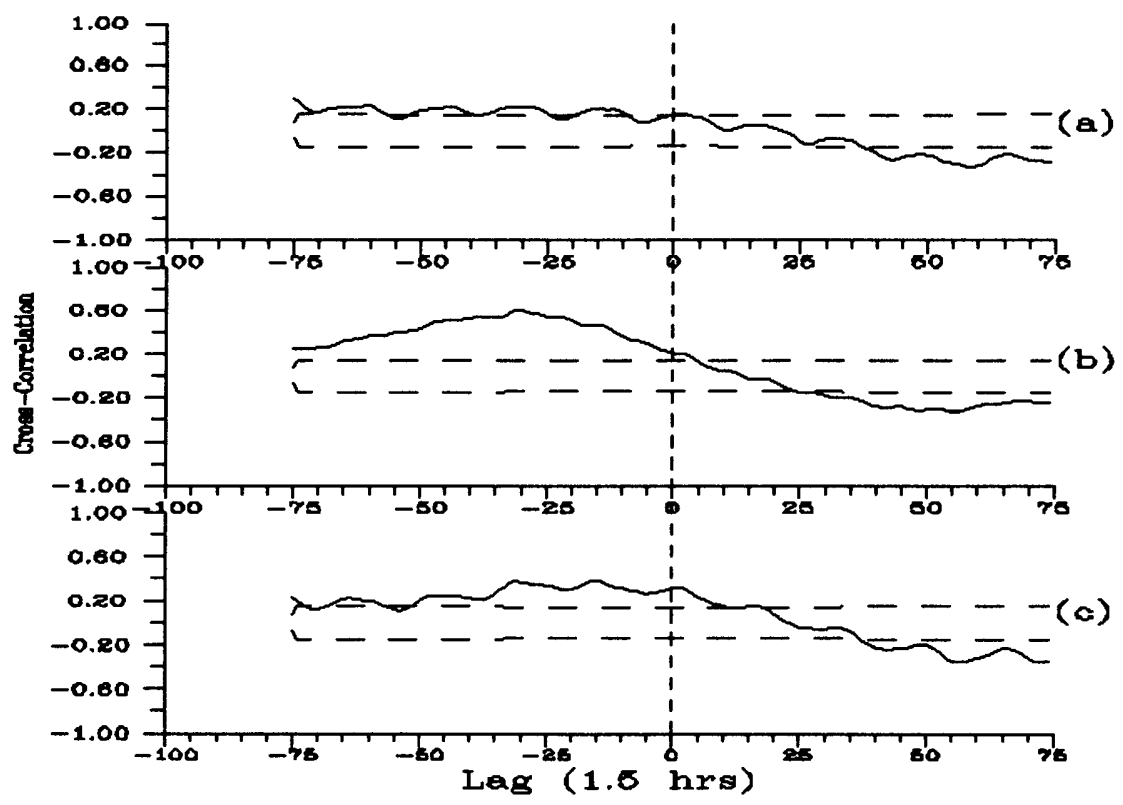

Figure 75. Cross-correlation between the slough and the groundwater monitoring sites: (a) G8a, (b) G8b, (c) G8C. The dashed lines are the $95 \%$ confidence intervals.

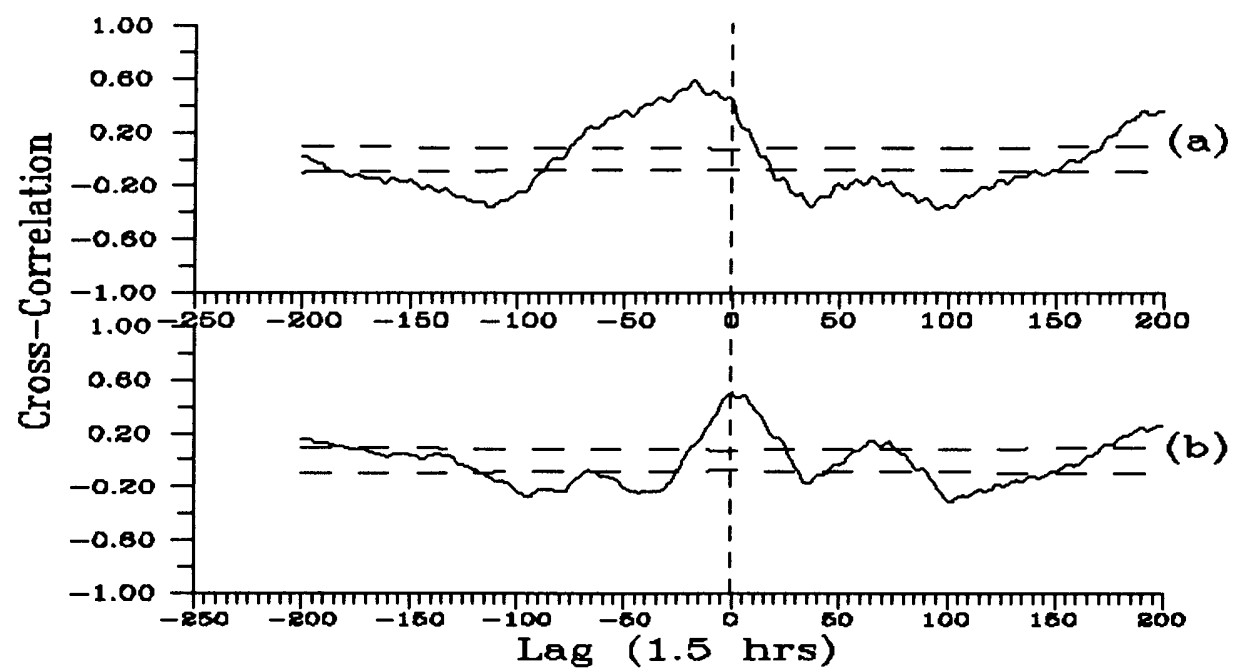

Figure 76. Cross-correlation matrix between the slough and groundwater monitoring sites: (a) Dla, (b) D1c. The dashed lines are the $95 \%$ confidence intervals. 
correlated with the water levels in the slough, or are correlated with some system which has the same frequency pattern as the slough system. The cross-correlation analysis does not prove that the slough water system is perturbing the groundwater levels; it only indicates that there is a significant linear relation between the two systems. It does however, make hydrological sense that the slough system could be perturbing the groundwater levels, and the crosscorrelation analysis certainly supports this.

In reviewing the cross-correlation figures, some interesting characteristics between the monitoring well and local slough waters are noted:

a) Figures $73 \mathrm{a}, \mathrm{b}$ : the common periods between wells G1, G2 and the slough are the 14 day (224 units) and semi-diurnal ( 8 units) periods. Well G2 groundwater perturbations precede slough water perturbations. This suggests that groundwater levels within well G2 are influenced by some other similar forcing system; Figure 73c, common periods between the slough and well G3 are the 14 day, diurnal (16 units), and the semi-diurnal periods. Well G3 is highly correlated with the slough.

b) Figure $74 \mathrm{a}$ : common periods between the slough and well G5a are the 14 day and diurnal periods, again groundwater perturbations precede those of the slough; Figure 74b: common periods between the slough and well G5b are the 14 day, diurnal and semi-diurnal; Figure 74c, monitoring well G6 may have the same 14 day period as the slough, however, the cross-correlation starts to oscillate within the bounds of the confidence interval indicating that the memory of the perturbation at zero lag is forgotten as the time lag increases. This may imply that perturbations from the slough are small and can be over ridden by other forcing mechanisms. Monitoring wells G5b and G6 are highly correlated with the slough.

C) Figure $75 \mathrm{a}$ and $\mathrm{c}$ : the common period between the slough and wells $G 8 a, c$ is the diurnal period; Figure $75 \mathrm{~b}$ the common period is the 14 day. An 
interesting note is that well $\mathrm{G} 8 \mathrm{~b}$ is much more correlated to the slough than either of its companion wells. Earlier studies also showed greater differences in the chloride concentrations and electrical conductivities in well G8b when compared to its companion wells G8a,c.

d) Figure $76 \mathrm{a}$ and $\mathrm{b}$ : both monitoring wells are highly correlated to the slough, but the oscillations appear sporadic and are difficult to interpret. Well Dla does show a slight commonality in the semi-diurnal range. The groundwater level time series for both wells is discontinuous at parts and this may be contributing to the sporadic cross-correlation results.

Monitoring wells $\mathrm{G1}, \mathrm{G2}, \mathrm{G3}$ and $\mathrm{G} 5 \mathrm{ab}$ indicate a high degree of persistence in the diurnal and semi-diurnal range. This indicates that other random forcing mechanisms have little influence on day to day or week to week groundwater fluctuations.

Two other mechanisms which influence groundwater levels are earth tides and barometric pressure variations. These forcing mechanisms occur approximately, if not exactly, at the same frequencies as the surrounding sloughs (Ritzi, Sorooshian, Hsieh 1991). It is possible that some of the correlation exhibited in the above analysis may be due to these two mechanisms. The degree to which barometric pressure changes can influence groundwater levels can be represented as $\Delta \mathrm{p}_{\mathrm{a}} \mathrm{B}=\gamma \Delta \mathrm{h}$ where $\mathrm{B}$ is the barometric efficiency $(0 \leq \mathrm{B} \leq 1), \gamma$ is the specific weight of water and $\Delta \mathrm{p}_{\mathrm{a}}$ and $\Delta \mathrm{h}$ are the barometric pressure and well water level change respectively (Todd, 1980). For $\mathrm{B}=1.0$ and $\Delta \mathrm{p}_{\mathrm{a}}=1 \mathrm{in}-\mathrm{Hg}, \Delta \mathrm{h}=1.1 \mathrm{ft}$. cross-spectral techniques can be employed to determine the 
contribution of each forcing mechanism to groundwater perturbations (Rojstaczer and Riley, 1990); however, the application of this method is beyond the study scope. A brief spectral analysis and time series plot of the barometric pressure for a partial period of the study is given in appendix D.

\section{HYDRAULIC GRADIENT ANALYSIS}

The mechanisms which can influence groundwater levels shown in Table $\mathrm{V}$ need to be considered when determining the horizontal or vertical gradients in the groundwater system. Atmospheric effects, even though potentially significant in explaining water level changes within a well, are beyond the scope of this study.

The subsequent vertical gradient analyses accounted for changes in hydraulic conductivity due to different soil layers, Freeze and Cherry (1979). Values for hydraulic conductivities were obtained from Sweet Edwards/EMCON, (1989), and are listed in Table VIII. The hydraulic conductivity values used in monitoring wells $G 8 \mathrm{~b}, \mathrm{C}$ are from monitoring wells G5b and G6. Hydraulic conductivity tests were not performed in monitoring wells G8abc. Horizontal gradients are computed only within a single aquifer system, i.e., observations of groundwater heads from wells tapping different aquifers are not compared. This is consistent with methods used in evaluating the horizontal distribution of electrical 
TABLE VIII

GENERAL CHARACTERISTICS OF MONITORING WELLS

\begin{tabular}{|c|c|c|c|c|c|}
\hline Hell & $\begin{array}{l}\text { Bottom Elevation } \\
(\mathrm{ft}, \mathrm{ms}()\end{array}$ & $\begin{array}{l}\text { Soil Type at } \\
\text { Screened Interval }\end{array}$ & $\begin{array}{l}\text { Hell CoO } \\
x \\
\text { (East) }\end{array}$ & $\begin{array}{c}\text { dinates } \\
Y \\
\text { (North) }\end{array}$ & $\begin{array}{c}\text { Hydraul ic } \\
\text { Conduct ivity } \\
\text { (ft/day) }\end{array}$ \\
\hline G1 & -34.5 & silt-silty sand & 12366.78 & 1199.84 & 0.059 \\
\hline G2 & -36 & silt-Fine sand & 11017.76 & 1243.87 & 0.043 \\
\hline G3 & -28.5 & silt & 13550.39 & 3829.03 & 0.024 \\
\hline G5a & -7 & silty sand & 13386.98 & 4050.07 & 0.0845 \\
\hline G5b & -44.5 & Sandy gravel & 13387.16 & 4053.37 & 390 \\
\hline G6 & -168.5 & Sandy gravel & 9232.21 & 2663.33 & 280 \\
\hline G7 & -25 & Sand & 10713.34 & 3491.24 & 0.14 \\
\hline G8a & -6 & Sand-silty sand & 14562.19 & 1145.89 & $0.0845^{*}$ \\
\hline G8b & -40.5 & Sandy gravel & 14563.92 & 1140.19 & $390^{* *}$ \\
\hline G8C & -79 & Sandy gravel & 14563.86 & 1140.34 & $390^{* *}$ \\
\hline DIa & -12 & Clay & 9300.86 & 3238.83 & ??? \\
\hline D1C & -83 & Clay & 9295.29 & 3224.78 & ??? \\
\hline HI & 0.625 & Refuse & 10232.05 & 3036.57 & $0.0026^{*}$ \\
\hline H2 & 6.125 & Refuse & 11409.06 & 3045.77 & $0.00062^{*}$ \\
\hline H3 & 8.625 & Refuse & 11710.04 & 1619.10 & $0.00076^{*}$ \\
\hline 14 & 7.625 & Refuse & 12739.83 & 2950.86 & $0.00128^{*}$ \\
\hline H5 & 21.625 & Refuse & 13865.41 & 3030.78 & $0.00992^{*}$ \\
\hline
\end{tabular}

* Copied values from monitoring well G5a

* Copied values from monitoring wells G5b and G6

- Obtained from Parametrix Inc. and Cornforth Inc (1990) Source: Sweet Edwards/EMCON 1989

conductivity and chloride.

\section{Vertical Gradients}

The screened intervals for monitoring wells Dla,c straddle two different soil types, see Figure 77. From the 
well logs most of the screened interval for both wells is in the clay stratum. It is assumed that the straddling of the different soil types will have a negligible effect in computing the vertical gradient. All vertical distances are computed from the center of the screened length, see Figure 77.

Monitor Wells G5a,b. Vertical hydraulic gradient time series for the upper sand and lower sandy gravel stratums are shown in Figures $78 \mathrm{a}, \mathrm{b}$ respectively. The time averaged hydraulic gradient for each stratum was $7.967 \times 10^{-2} \mathrm{ft} / \mathrm{ft}$ for the upper sand and $1.726 \times 10^{-5} \mathrm{ft} / \mathrm{ft}$ for the lower sandy gravel. Gradients were generally greatest during the dry season and smallest during the wet.

Comparison plots between monitoring wells $\mathrm{G} 5 \mathrm{a}, \mathrm{b}$ and Bybee Iake in Figure 79 show that surface water levels in Bybee Lake are higher than groundwater levels, but groundwater levels in well G5a appear to approach Bybee Lake water levels near the start of the wet season. The control weir between Bybee Lake and the North Slough keeps Bybee Lake at an artificially high level (10.4 ft, msl). During field sampling trips, water was almost always flowing from Bybee Lake into the North Slough. The control weir has been tampered with such that a continuous outflow from Bybee Lake to the North Slough occurs when lake levels exceed the slough levels.

From Figure 80 , one might reason that if the weir were removed, water levels in Bybee Lake could fall below 


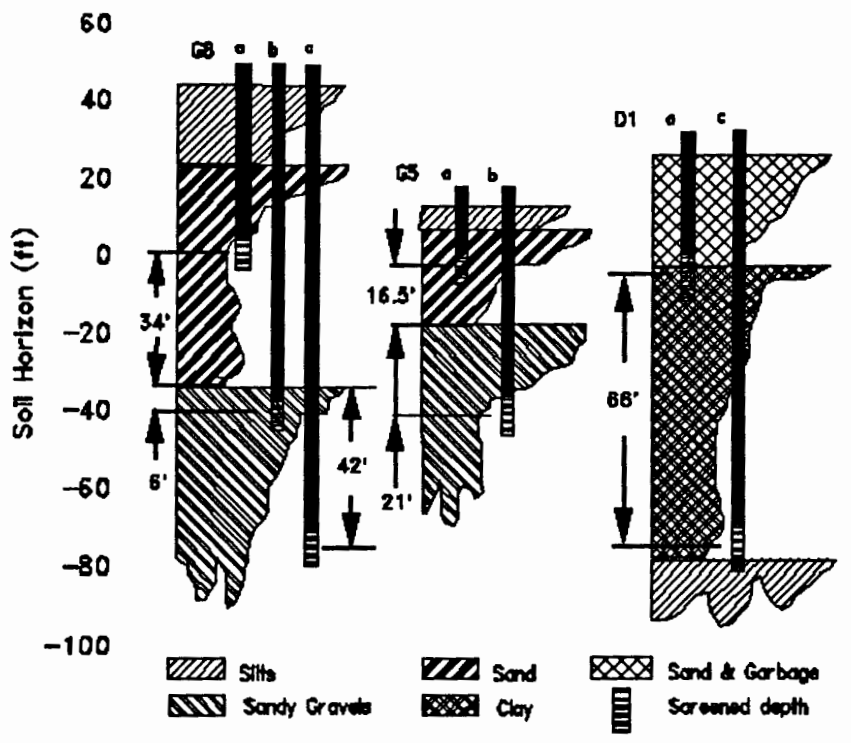

Fiqure 77. Vertical cross-sections showing soil types at each screened interval and distances between intervals for multiple completion wells used in the vertical gradient analysis.

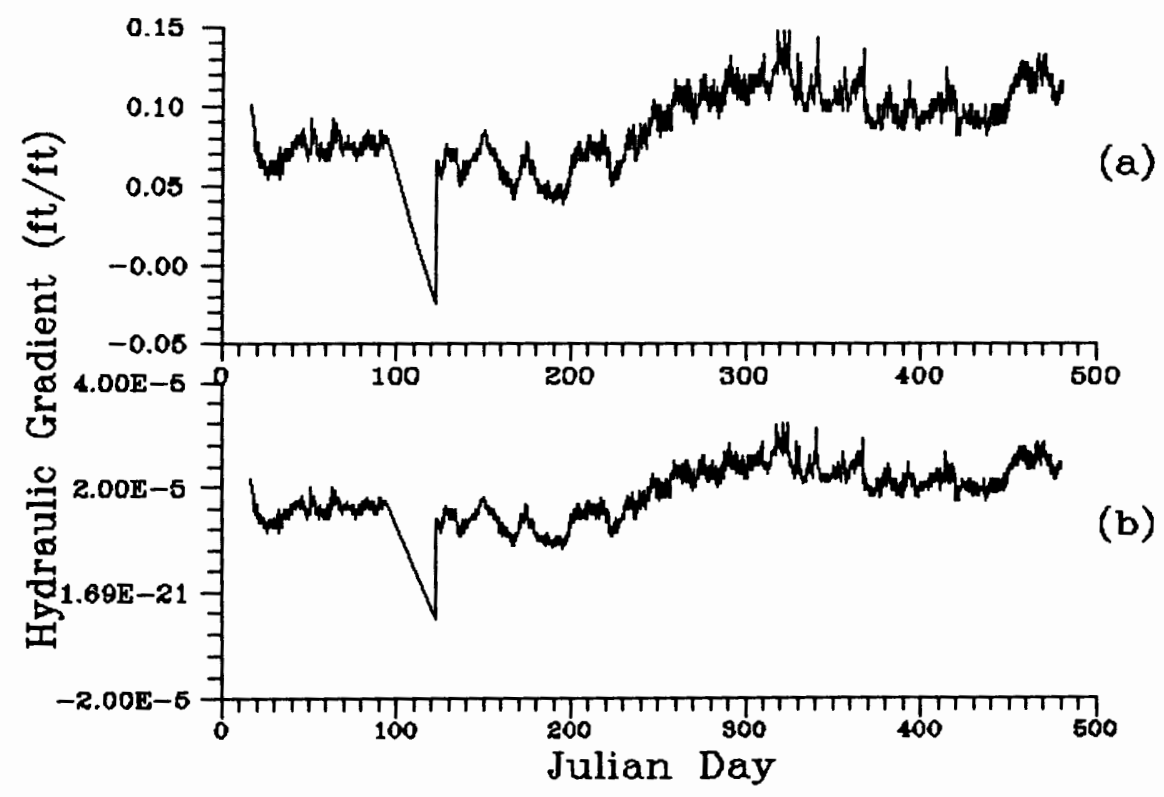

Figure 78. Vertical hydraulic gradient at monitor well G5ab. Each figure is the gradient in: (a) upper sand stratum, and (b) the lower sandy gravel stratum. Positive values indicate downward flow. 


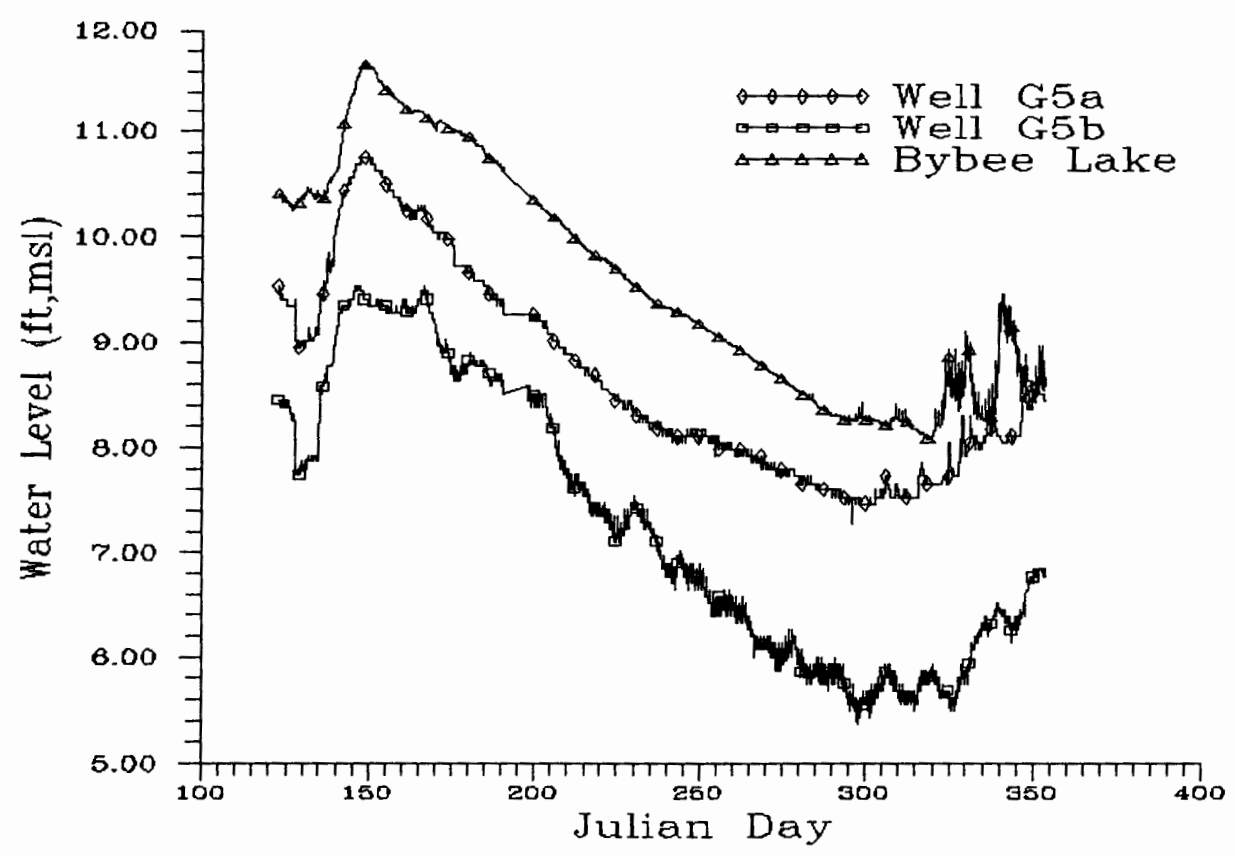

Figure 79. Comparisons between the water level time series at monitor well $\mathrm{G} 5 \mathrm{ab}$ and near by Bybee Lake

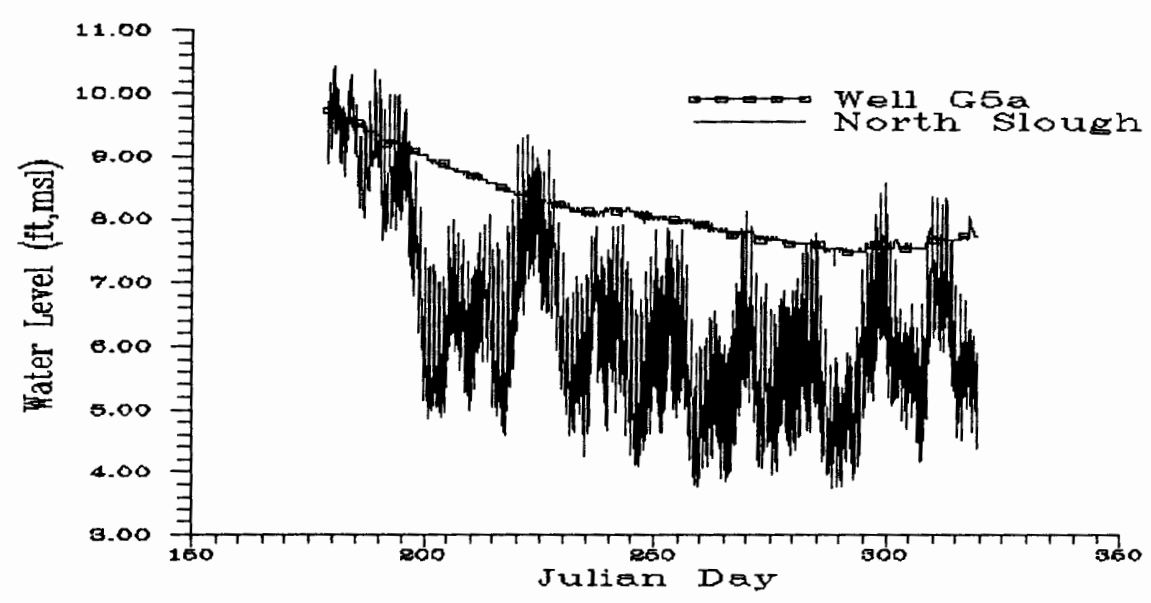

Figure 80. Comparison between groundwater levels at monitoring well G5ab and water levels in the North slough.

groundwater levels in the sandy aquifer during some period of the year. This would most likely occur during the dry period, 
as Bybee Lake water levels are dictated primarily by precipitation and evapotranspiration (Fishman 1986). If it is assumed that slough water levels would be indicative of Bybee Lake levels during the dry periods, then groundwater would flow from the sandy aquifer into Bybee Lake. Figure 80 shows that groundwater levels in well G5a are higher than water levels in the North Slough. Generally, upper aquifer groundwater levels are higher than the slough levels in the other monitoring wells. However, the water level time series shows that Bybee Lake currently recharges the local groundwater system for the period of study.

Monitoring wells D1a,c. The vertical hydraulic gradient at monitoring well Dlac is shown in Figure 81. The gradient direction oscillates over the period of study; however, the

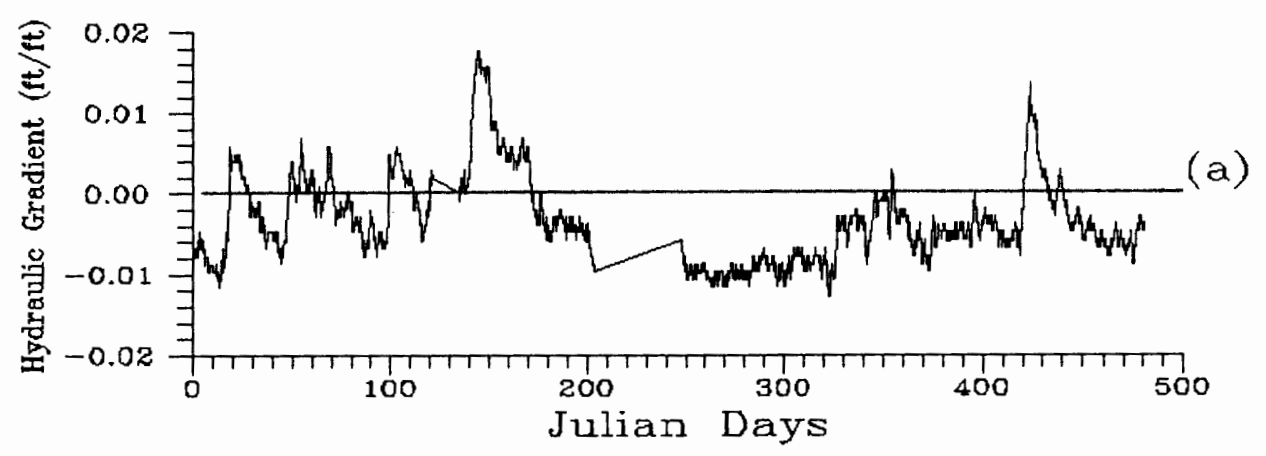

Figure 81. Vertical hydraulic gradient at monitor well Dlac.

time averaged gradient direction is negative $\left(-3.597 \times 10^{-3}\right.$ ft/ft) implying upward flow. Referring to the observed groundwater level time series in Figures $53 a, b$, the 
groundwater levels between julian days 1 and 150 are generally higher (more positive gradient) than the levels between julian days 350 and 490 (more negative gradient). Hence, when the groundwater levels are low, the vertical gradient at well Dlac may be predominantly upward.

Monitoring wells G8abc. The vertical gradients shown in Figure 82 display inconsistent groundwater movements. In the upper sandy stratum, the flow direction oscillates between positive and negative, and the time averaged gradient is slightly positive, $3.363 \times 10^{-4} \mathrm{ft} / \mathrm{ft}$ downward. The lower sandy gravel stratum also oscillates, and the time averaged gradient is $6.804 \times 10^{-4} \mathrm{ft} / \mathrm{ft}$ downward. Superimposing the two gradient time series, Figure $82 \mathrm{c}$, the two series are a mirror image. When the gradient in the upper stratum becomes more positive, the gradient in the lower stratum becomes more negative. Thus, when the hydraulic head in well G8b increases, the downward flow in the upper stratum decreases or even reverses direction. Concomitantly downward flow in the lower stratum increases. Recall from the cross-correlation analysis that the correlation of monitoring well G8b to the slough was much greater than its two companion wells. What may be occurring is that a preferential flow path between well G8b and the slough, or some similar system, exists. Changes in the surface water level would be transmitted through the preferred path, increasing the hydraulic head in well $68 \mathrm{~b}$, and then transmitted to companion wells G8a,c. Sweet Edwards/EMCON 
(1986) reported an alternating gradient direction in wells G8a,b,c and that groundwater levels in monitoring well G8abc were influenced by surface water changes.

\section{Isocontours of Horizontal Hydraulic Head}

The isocontour plots of the hydraulic head over horizontal space show the horizontal hydraulic gradient at a point in time. The isocontours presented in this section

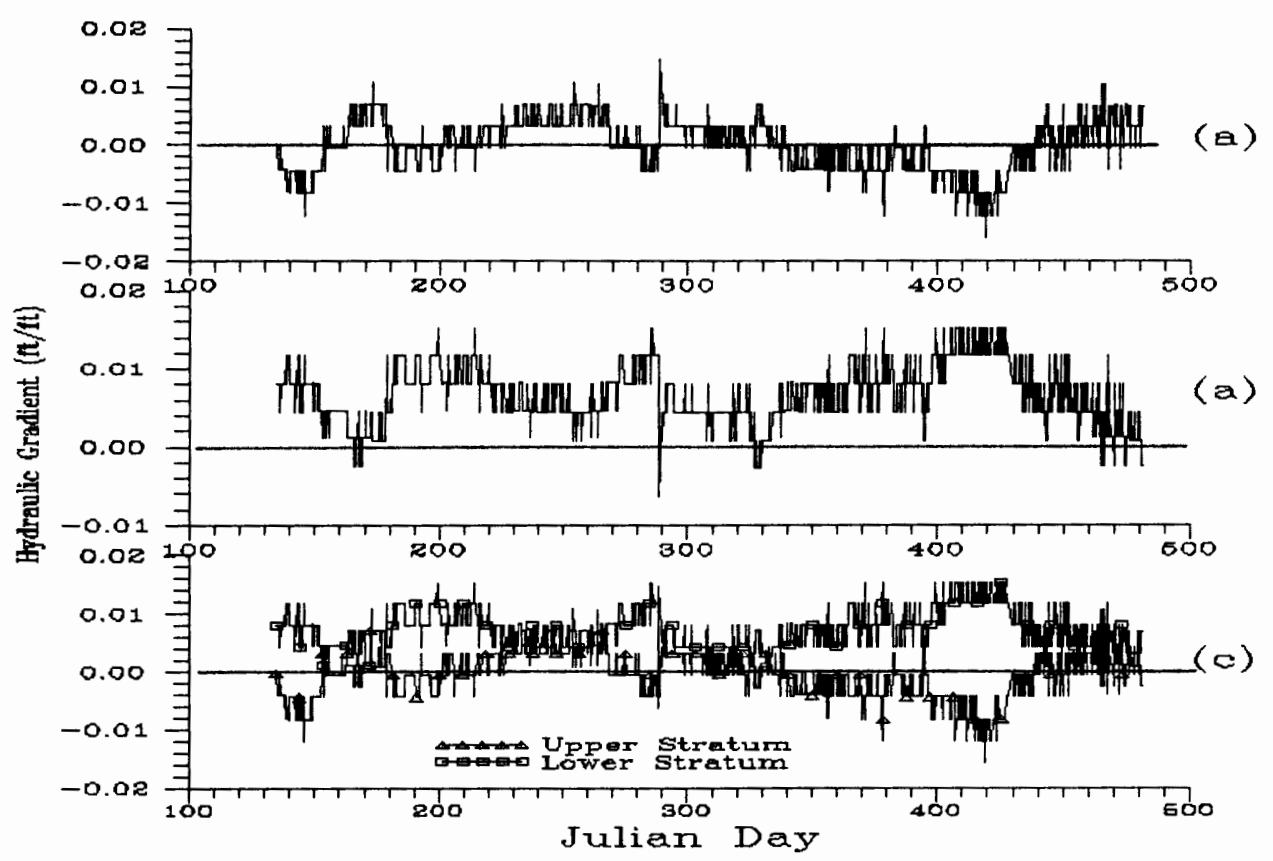

Figure 82. Vertical hydraulic gradient at monitor well G8abc. Gradients in each stratum are: (a) upper sandy, (b) lower sandy gravel. Figure 82c shows the two superimposed gradient time series.

represent the maximum and minimum groundwater levels of the observed time series, i.e., julian days 170 and 310 respectively. In addition it needs to be noted that all the monitoring wells are located on or outside the perimeter dike, 
and only three to four wells are used to develop the isocontours. The isocontours do not account for the groundwater mound within the landfill.

Isocontours for the hydraulic head in the upper silt aquitard, julian days 170 and 310, are shown in Figures 83 and 84 respectively. The plots show that the horizontal gradient generally points in the northeasterly direction, and typically remains so throughout the period of study, see Figure 85 . This is in disagreement with Sweet Edwards/EMCON (1989) which showed the shallow aquifer horizontal gradient to be in northwesterly direction. However, Figures 83 and 84 do show a northwesterly horizontal gradient between monitoring wells G2 and Dlc.

Groundwater levels in monitoring well Dlc exceeded levels in wells G2 and G3 around julian day 150 for approximately 5 days. The difference in head was within the assumed measurement errors and can be ignored. The hydraulic gradient is dynamic and should not always be viewed as the idealized steady state condition presented in the isocontour plots.

The smaller groundwater level fluctuations (14 days and less in duration) in monitoring wells $G 1$ and $G 2$ appeared to be in synchronous oscillation.

Isocontours of the hydraulic head in the lower sandy/gravel aquifer, at julian days 170 and 310 , are shown in Figures 86 and 87 . The plots indicate that the horizontal gradient is towards the Columbia River, which is in general 


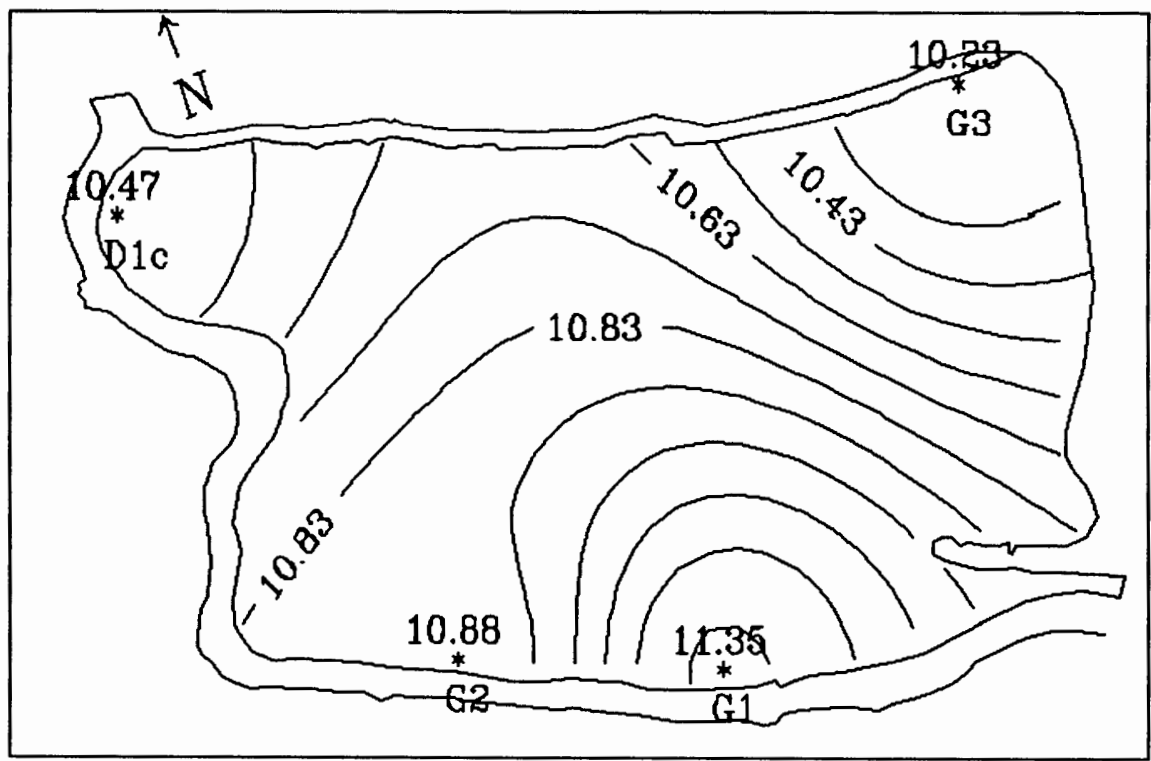

Figure 83. Isocontours of the hydraulic head in the upper silt aquitard, julian day 170 (5/19/91) . Only four interpolation points were used.

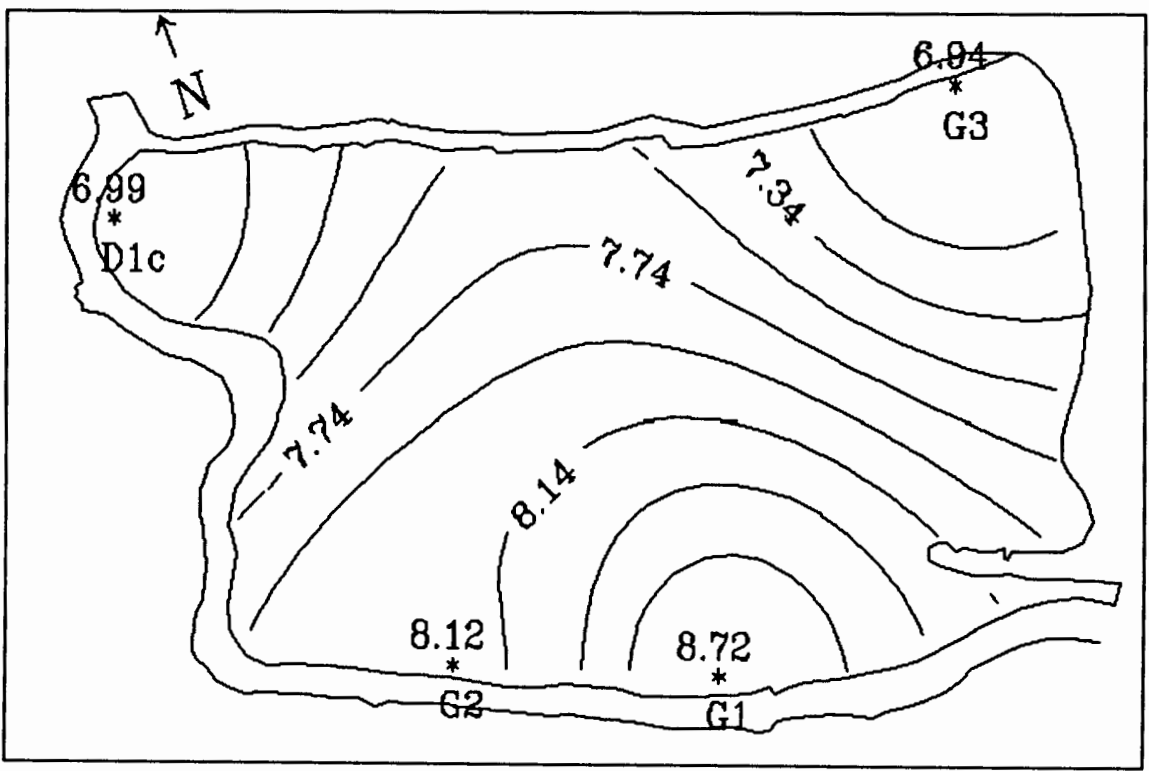

Figure 84. Isocontours of the hydraulic head in the upper silt aquitard, julian day 310 (11/6/91). Only four interpolation points were used. 


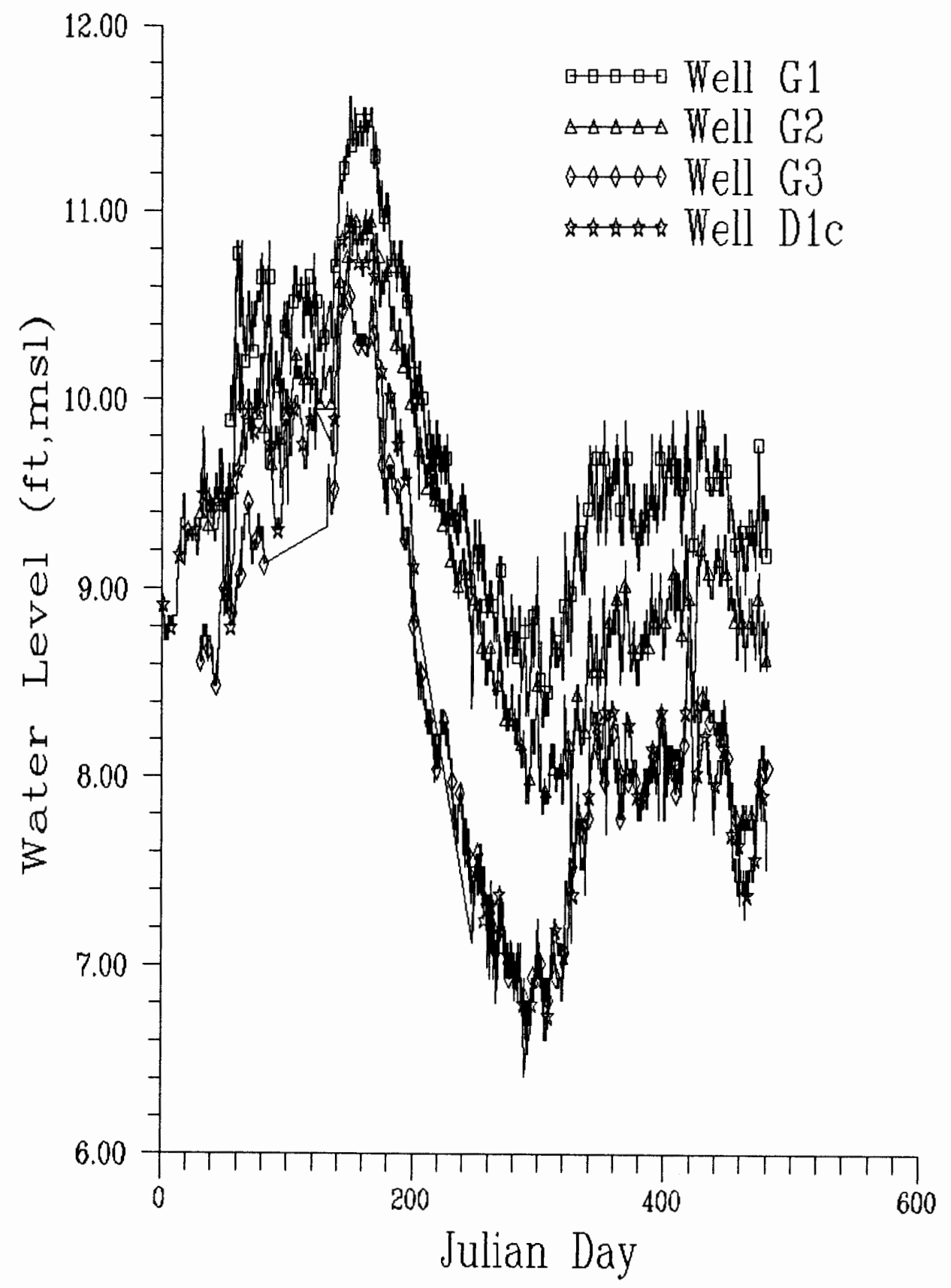

Figure 85. Comparison plot of the groundwater level time series for monitor wells completed in the upper silt aquitard.

agreement with Fishman (1986). Sweet Edwards/EMCON, however, reported horizontal gradients in a northwesterly direction. 


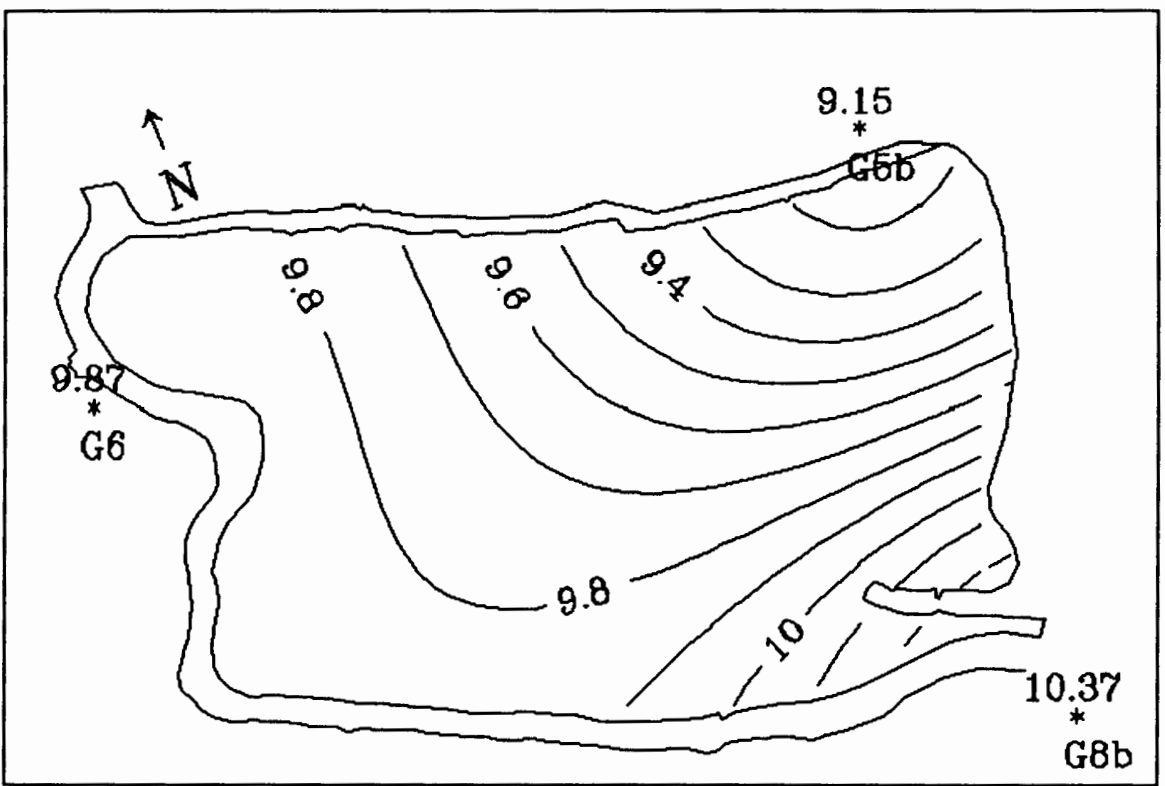

Figure 86. Isocontours of the hydraulic head in the lower sandy/gravel aquifer, julian day 170 $(5 / 19 / 91)$. Only three iterpolation points were used.

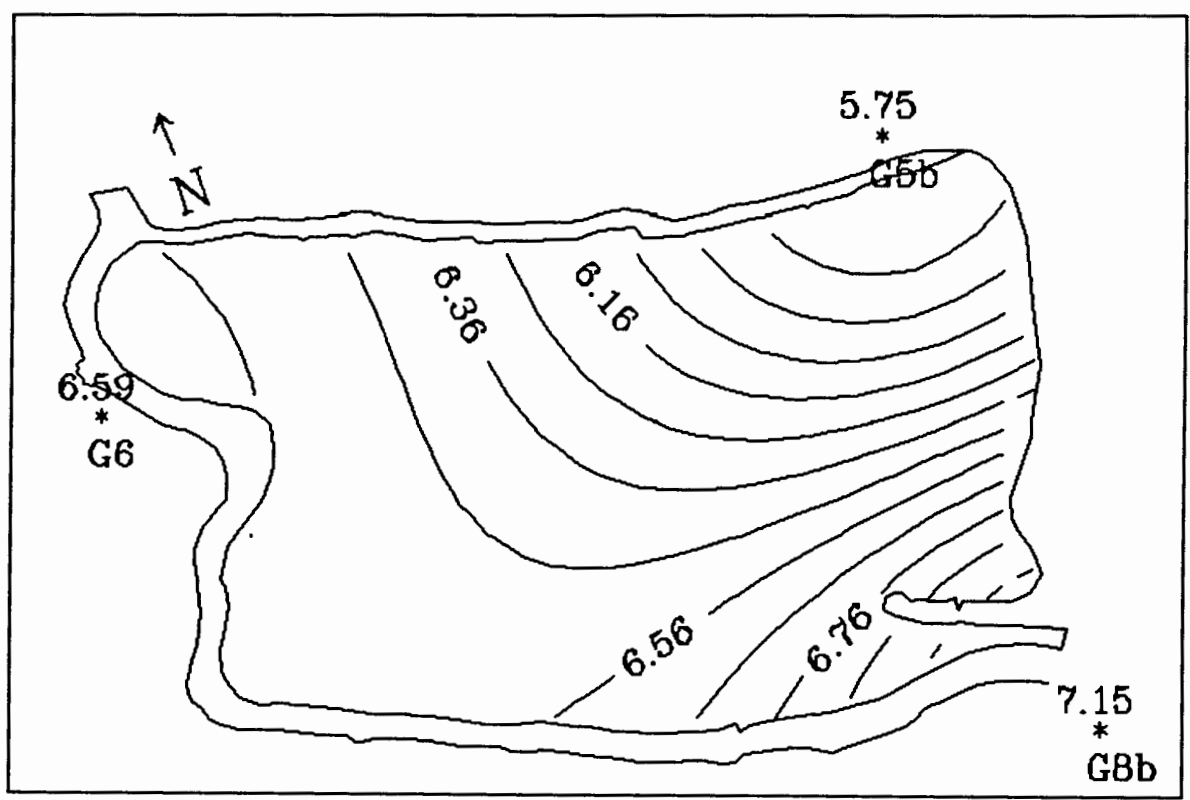

Figure 87. Isocontours of the hydraulic head in the lower sandy/gravel aquifer, julian day 310 $(11 / 6 / 91)$. Only three iterpolation points were used. 


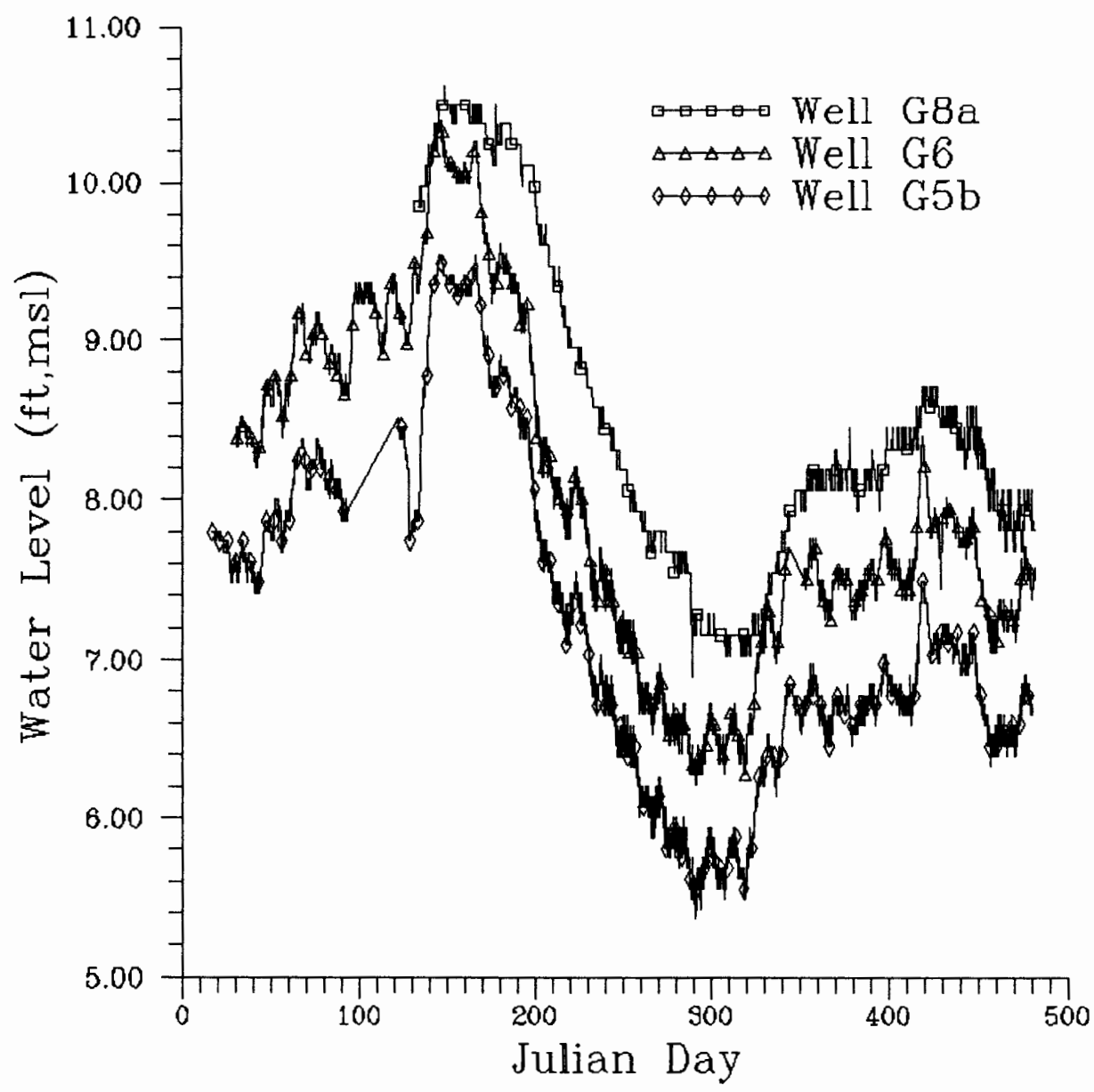

Figure 88. Comparison plot of the groundwater level time series for monitoring wells completed in the lower sandy/gravel aquifer.

The difference could be that only three monitoring wells were used in this study to develop the isocontours, and that sweet Edwards/EMCON used monitoring well G8C rather than G8b as was used in this study.

Groundwater fluctuations in monitoring wells $\mathrm{G} 5 \mathrm{~b}$ and $\mathrm{G} 6$ appear to be correlated at time series scales of 14 days and less.

While the instantaneous groundwater level time series 
comparison plots show the hydraulic gradient to be highly dynamic, the time averaged gradient direction is northeasterly. What is most interesting in the time series comparison plots is the high degree of correlation between groundwater fluctuations in some of the wells. The synchronous oscillations observed in the comparison plots combined with the earlier cross-correlation analysis, gives very strong evidence that the groundwater system underneath the landfill is being perturbed by some mechanism with dominate periods of 14 days, 1 day, and 0.5 days. 


\section{CHAPTER IV}

\section{COMPUTER MODEL DEVELOPMENT AND ANALYSIS}

\section{DYNAMICS OF THE GROUNDWATER SYSTEM PERTURBED BY TIDAL MOTIONS AT THE BEACH INTERFACE}

Although there is a plethora of literature concerning groundwater phenomena in general, there is a dearth of literature investigating the dynamics of groundwater motion at a beach interface subject to oscillating boundary conditions. It is important to understand groundwater motions at the beach interface and inland. The ability to predict the phreatic groundwater motion is crucial to the analysis of groundwater transport from the st. Johns Landfill to the Columbia and North sloughs.

In a study by Dominick, wilkins and Roberts (1971) they developed a finite difference computer model to predict the phreatic surface within an ocean beach, using observed groundwater levels at the top of the intertidal zone as the boundary conditions. Their study noted that ocean water levels were consistently below groundwater levels within the beach swash zone, the difference was attributed to wave energy superimposed on the tides. Because the principles which governed the raising of the groundwater level were not completely understood, they did not use ocean water levels as 
the boundary conditions. Their model did however, accurately predict inland groundwater levels using intertidal zone boundary conditions.

The sloping face of the beach in conjunction with the tidal motions caused the time averaged groundwater level to rise within the beach (Nielson 1990). Nielson developed a one dimensional analytical model using a linear form of the Boussinesq's equation employing perturbation techniques, and assumed that a seepage face at the beach did not develop (the boundary could move along the abscissa in accord with tidal motions). The boundary conditions were functions of time and space. Groundwater and ocean tidal observations used for model verification were obtained from a beach not subject to wave motions. The model was in very good agreement with recorded groundwater levels when the observed ocean and groundwater levels were still coupled, but became less so at low tides due to the development of a seepage face. Nielsen's study was helpful in that it showed that the asymmetry of the boundary at the sloping beach face can cause superelevation of the groundwater level within the beach since it is easier for surface waters to filter down into the beach than out horizontally.

once the ability to predict the transient groundwater level was achieved, the next step was to determine the effective flow rate of water through the porous media. Dominick, wilkins, and Roberts (1971) computed the net 
groundwater flow rate by integrating (trapezoidal approximation) the predicted instantaneous groundwater flux through a vertical plane over one tidal period. Serfes, (1991), employed a weighted average smoothing technique on the observed groundwater level time series to determine the mean groundwater level. The resultant mean groundwater levels were used to determine the time averaged hydraulic gradient, from which the net groundwater flow rate could be computed. To determine the time lag between tidal motions at the beach face and fluctuations at some inland observation well, Erskine (1991) employed some basic statistical methods.

DEVELOPMENT OF THE COMPUTER MODEL

\section{Governing Differential Equation}

The governing differential equation for transient groundwater flow in a unconfined aquifer, Bear (1979) is:

$$
\nabla \cdot K h \nabla h=S \frac{\partial h}{\partial t}
$$

where:

$$
\begin{aligned}
& \mathrm{K}=\text { hydraulic conductivity }\left[\mathrm{LT}^{-1}\right] \\
& \mathrm{h}=\text { hydraulic head }[\mathrm{L}] \\
& \mathrm{S}=\text { specific yield }[-]
\end{aligned}
$$

Implicit in the derivation of equation (1) is:

(a) The velocity of the matrix solids is small compared to the fluid velocity.

(b) The hydraulic conductivity is independent of 
the fluid density.

(c) The hydraulic conductivity and the specific yield are independent of changes in porosity due to matrix deformation.

(d) Spatial changes in fluid densities are much smaller than temporal changes.

(e) Dupuit assumptions apply.

For one-dimension flow, equation (1) becomes,

$$
\frac{\partial}{\partial x}\left(K h \frac{\partial h}{\partial x}\right)=S \frac{\partial h}{\partial t}
$$

subject to initial and boundary conditions. Assuming that Forchheimer boundary conditions apply,

$$
\begin{aligned}
& h(x, t)=b(L, t) \\
& h(x, t)=b\left(x^{\prime}, t\right) \\
& h(x, 0)=\phi(x)
\end{aligned}
$$

where $b(L, t)$ is the boundary condition at $x=L, b(x, t)$ is a moving boundary near the origin, and $\phi(x)$ is the initial phreatic surface. However, because of the non-linear nature of equation (2) no explicit analytical solution is possible. Equation (2) can be rewritten in the form,

$$
\frac{\partial}{\partial x}\left(K \frac{\partial h^{2}}{\partial x}\right)=\frac{S}{h} \frac{\partial h^{2}}{\partial t}
$$

letting $\mathbf{v}=h^{2}$ and substituting back into equation (3),

$$
\frac{\partial}{\partial x}\left(K \frac{\partial v}{\partial x}\right)=\frac{S}{\sqrt{v}} \frac{\partial v}{\partial t}
$$


The form of equation (4) is still nonlinear in terms of $v$, however, a quasi-nonlinear solution to equation (4) can be obtained by implementing numerical finite differencing techniques. In finite difference form $\sqrt{v}$ is set equal to head values at the previous time step. The equation is then quasi-nonlinear because the value of $\sqrt{v}$ is allowed to change with time.

For a more general form it is desired that the hydraulic conductivity and storativity be a function of $x, K=K(x)$, $S=S(x)$. A conservative finite difference form of equation (4) must be used to assure numerical stability (Anderson, Tannehill, Pletcher, (1984)). Using the central difference to approximate the first partial derivative on the lefthand side, equation (4) becomes,

$$
\left.K \frac{\partial v}{\partial x}\right|_{i+1 / 2}-\left.K \frac{\partial v}{\partial x}\right|_{i-1 / 2}=\frac{S \Delta x}{\sqrt{v}} \frac{\partial v}{\partial t}
$$

Subscripts identify spatial location. All the terms on the lefthand side of equation (5) are defined at nodal points $i+1 / 2$ and $i-1 / 2$, the desired form would be in terms of nodal point $i$. The hydraulic conductivity at nodal points $i+1 / 2$ and i-1/2 can be estimated as the harmonic mean of hydraulic conductivities at whole nodal points, $i . e ., i-1, i, i+1$, etc. (Bear (1979)). For equally spaced cells the general form of the harmonic mean between cells is, 


$$
K_{i+1 / 2}=\frac{2 K_{i} K_{i+1}}{K_{i}+K_{i+1}}
$$

Substituting equation ( 6 ) into equation (5), letting $k_{i+1 / 2}=K_{p}$ and $\mathrm{K}_{\mathrm{i}-1 / 2}=\mathrm{K}_{\mathrm{q}}$, writing the two spatial derivatives in central difference form, and employing a general explicit-implicit technique to solve the temporal derivative, equation becomes,

$$
\begin{aligned}
v_{i}^{n+1}-v_{i}^{n} & =\beta \theta\left[K_{p}\left(v_{i+1}^{n+1}-v_{i}^{n+1}\right)+K_{q}\left(v_{i-1}^{n+1}-v_{i}^{n+1}\right)\right] \\
& +(1-\theta) \beta\left[K_{p}\left(v_{1+1}^{n}-v_{i}^{n}\right)+K_{q}\left(v_{1-1}^{n}-v_{1}^{n}\right)\right]
\end{aligned}
$$

where:

$$
\beta=\frac{\sqrt{v_{i}^{n}} \Delta t}{S_{i} \Delta x^{2}}
$$

Superscripts identify the time sequence. Theta is the temporal interpolation factor. When $\theta=1$, the solution is fully implicit; and when $\theta=0$, the solution is explicit. Approximating $\sqrt{v^{n+1}}$ by $\sqrt{v^{n}}$ is acceptable as long as the difference in head between time steps is small (Wang and Anderson, (1982)). However, a more accurate and stable method is the predictor-corrector technique as suggested by Remson, Hornberger and Molz (1971). The finite difference algorithms for each are, 
Predictor (solving for $v_{i}^{n+1 / 2}$ )

$$
\begin{aligned}
\frac{\Delta x^{2} S_{i}}{\sqrt{v_{i}^{n}}}\left[\frac{v_{i}^{n+1 / 2}-v_{i}^{n}}{\frac{\Delta t}{2}}\right] & =\theta\left[K_{p}\left(v_{i+1}^{n+1 / 2}-v_{i}^{n+1 / 2}\right)+K_{q}\left(v_{i-1}^{n+1 / 2}-v_{i}^{n+1 / 2}\right)\right] \\
& +(1-\theta)\left[K_{p}\left(v_{i+1}^{n}-v_{i}^{n}\right)+K_{q}\left(v_{i-1}^{n}-v_{i}^{n}\right)\right]
\end{aligned}
$$

Corrector

$$
\begin{aligned}
\frac{\Delta x^{2} S_{i}}{\sqrt{v_{i}^{n+1 / 2}}}\left[\frac{v_{i}^{n+1}-v_{i}^{n}}{\Delta t}\right] & =\theta\left[K_{p}\left(v_{i+1}^{n+1}-v_{i}^{n+1}\right)+K_{q}\left(v_{i-1}^{n+1}-v_{i}^{n+1}\right)\right] \\
& +(1-\theta)\left[K_{p}\left(v_{i+1}^{n}-v_{i}^{n}\right)+K_{q}\left(v_{i-1}^{n}-v_{i}^{n}\right)\right]
\end{aligned}
$$

Both equations (8) and (9) are solved using the general technique shown in equation (7), and the subsequent set of linear algebraic equations are solved using the Thomas algorithm.

\section{Modeling Assumptions}

A physical interpretation of the mathematical model is shown in Figure 89. The following conditions are assumed in the development of the model:

(a) The beach interface is vertical.

(b) The bottom of the phreatic aquifer is at the same elevation as the slough channel bottom $(-1$ $\mathrm{ft}, \mathrm{msl})$. This implies that upward leakage of groundwater into the slough is negligible.

(c) The bottom of the phreatic aquifer is impervious.

Although Nielson (1990) has shown that the effect of a sloping beach raised groundwater levels and introduced non- 
symmetrical wave forms in the porous matrix, the purpose of this model was to determine the degree to which the tidal motions in the Columbia and North Sloughs influence the

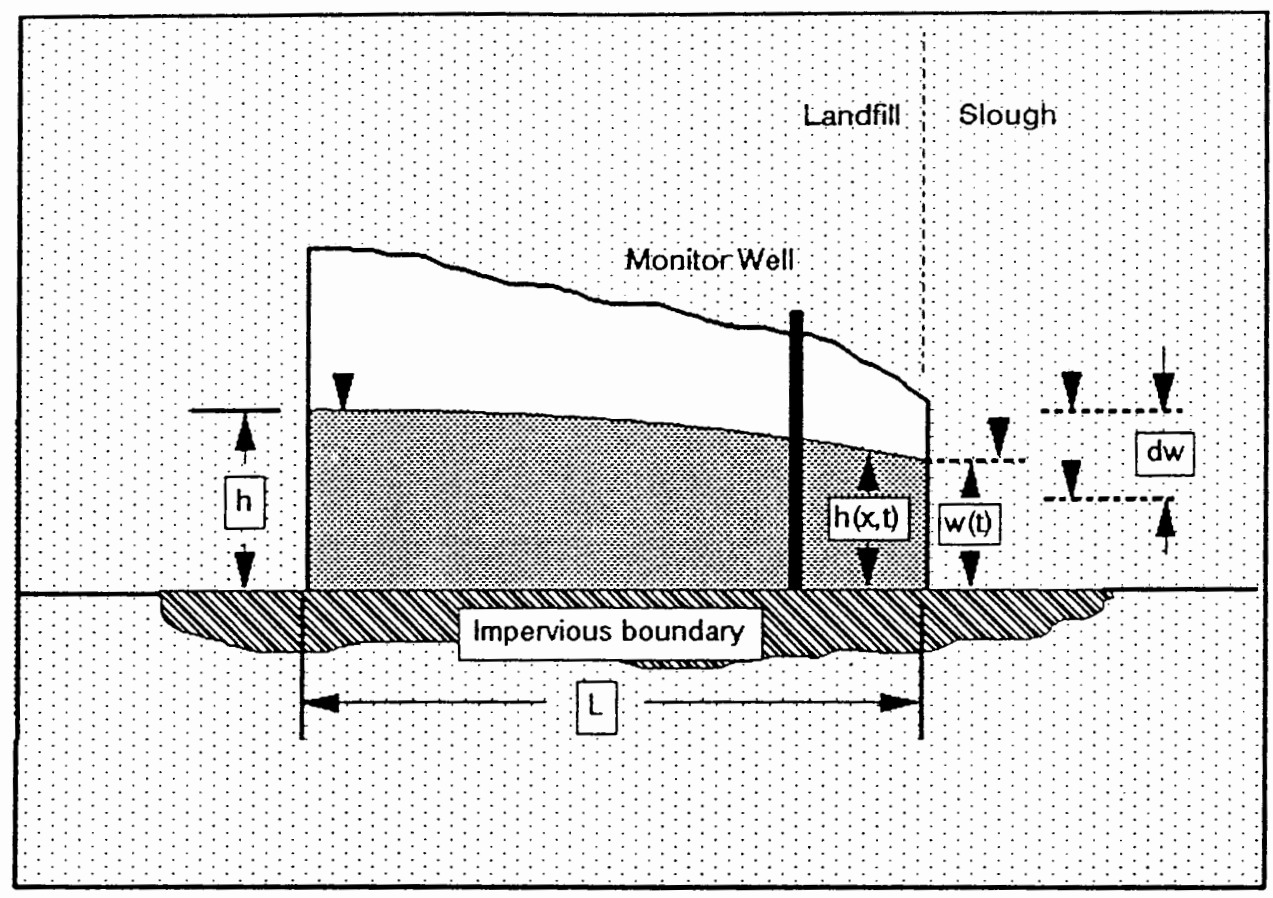

Figure 89 . Physical representation of the computer model.

phreatic surface. It was assumed that the computer model can adequately predict the groundwater tidal envelop. If the results warrant a more elaborate model, additional studies can be performed at a later date.

Definitions of the variables used in Figure 89 are as follows:

(a) $\mathbf{h}$ is the fixed inland groundwater level and $\mathbf{h}(\mathbf{x}, \mathbf{t})$ is the dynamic groundwater level near the beach interface. The distance inland to which the groundwater, $h(x, t)$, will oscillate is dependent upon the hydraulic conductivity, $k$, and the specific yield, $S$. At some distance L inland tidal 
motions will cease to influence the groundwater and it will remain constant over short periods of time, assuming no sources or sinks exist.

(b) $w(t)$ is the time dependent slough water level and $d w$ is the difference between maximum and minimum tides. Slough gaging stations maintained by PSU having proximateness to the monitoring wells did not provide long enough water level time series for the modeling study. Thus, values used for w(t) in the simulation are the observed slough water levels at the USGS Lombard street bridge gaging station. The amplitude attenuation of the tidal wave from the USGS gaging station to any monitoring well site was assumed to be small.

It was also assumed that the observed groundwater fluctuations in the monitoring wells adequately reflected fluctuations at the phreatic surface, and that the wells are completed at $-1 \mathrm{ft}$, msl. Actual completion depths range from -28.5 to $-80 \mathrm{ft}$, msl which means that groundwater levels will probably behave like semi-confined to confined aquifer types. The phreatic surface model will determine how close the monitoring well groundwater levels reflect the phreatic surface.

\section{Model Verification}

For steady-state Darcy flow through a porous medium (Bear, 1979),

$$
\ell=g h(x)=-K h(x) \frac{d h}{d x}=\text { const }
$$

where $Q$ is the flow per unit width $\left(\mathrm{L}^{2} \mathrm{~T}^{-1}\right)$ restricted to unconfined flow in a aquifer with $\mathrm{N}$ vertical strata (Bear (1979)), 


$$
Q=\frac{\left(h_{o}^{2}-h_{L}^{2}\right)}{2} \sum_{i=1}^{N}\left(K_{i} / L_{i}\right)
$$

where:

$\mathrm{h}_{\mathrm{o}}=$ hydraulic head at $\mathrm{x}=0[\mathrm{~L}]$

$h_{L}=$ hydraulic head at $x=L$ (the seepage face) [L]

$L_{i}=$ segment length with hydraulic conductivity $K_{i}[L]$

Equation (11) can be rearranged to solve for the hydraulic head as a function of $x$ and can also be used to verify the correct operation of the numerical computer model used to solve equations ( 8 ) and (9).

The computer model was set-up as a vertically stratified, unconfined aquifer having two different hydraulic conductivities. It was then run from an initial arbitrary surface with constant boundary conditions for an extended period of time. Equation (11) was rearranged to solve for the steady state hydraulic head along the abscissa for the same vertically stratified unconfined aquifer. Figure 90 depicts the convergence of the computer simulated phreatic surface from the initial surface to the final steady state surface determined by equation (11).

ESTIMATION OF MODELING PARAMETERS AND BOUNDARY SET

\section{Modeling Parameters}

Estimates for the hydraulic conductivity within the 
perimeter dike and landfill interior were obtained from the field exploration study conducted by Paramatrix Inc. and

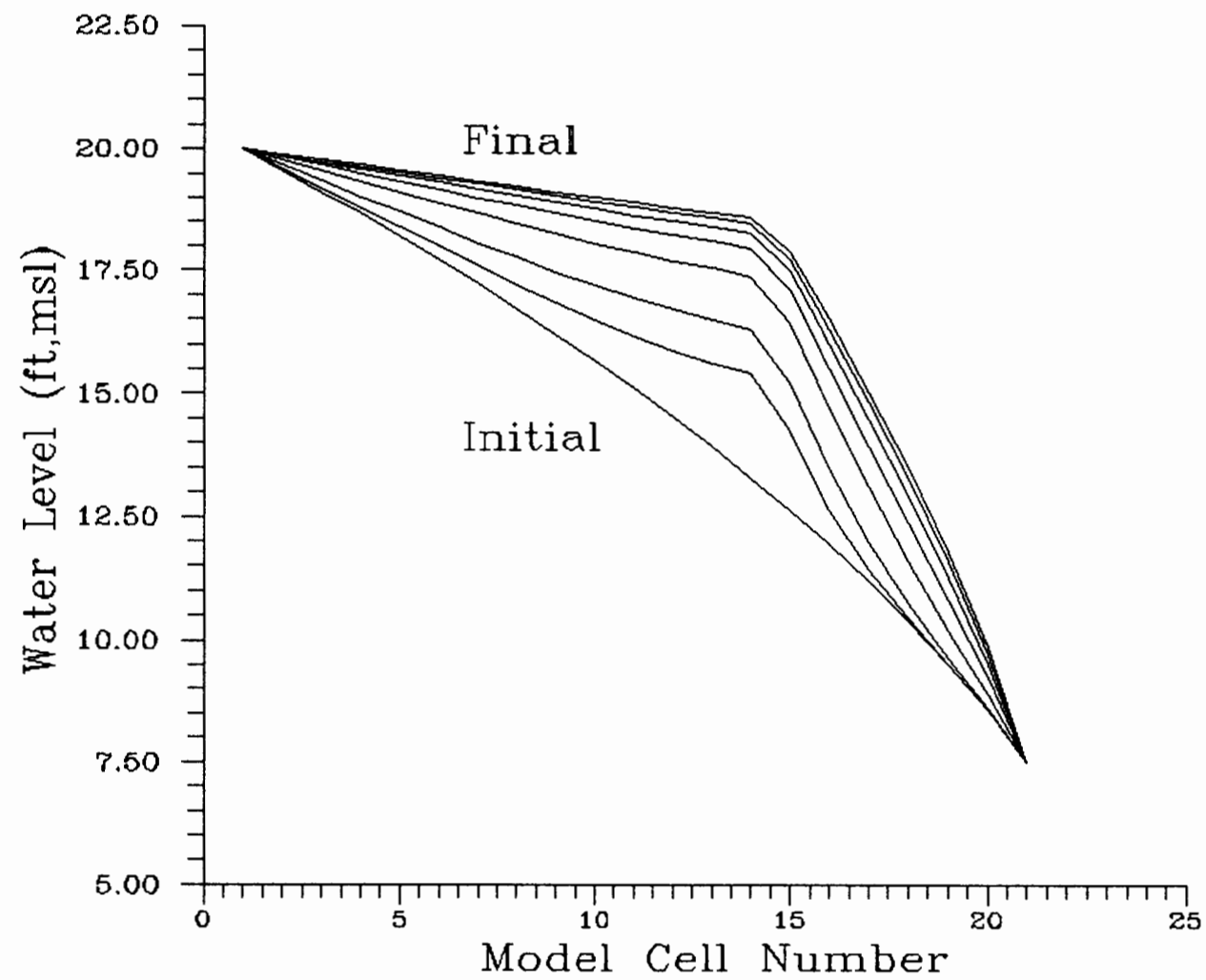

Figure 90. The hydraulic head predicted by the computer model for a vertically stratified, unconfined aquifer. The computer model converges to the steady state analytical (final) surface predicted by equation (11).

Cornforth Consultants Inc. (1990). A total of 16 sample estimates were taken for hydraulic conductivities in the perimeter dike, and 5 sample estimates were taken in the landfill interior. The two sample populations for the hydraulic conductivities were tested to determine if the perimeter dike values were statistically different from the 
landfill interior values. All sample estimates were log transformed prior to statistical analysis Haans (1977). The resultant transformed populations were then tested for conformance to a log normal distribution using the Shapirowilks test. Normalcy tests indicated that the transformed data could be assumed to fit a log normal distribution (see appendix D) .

Statistical tests (at the 95\% confidence) on the estimated mean and variance of the two populations indicated they came from the same population (see appendix E). The results of the statistical analysis implied that a single value for the hydraulic conductivity could be used in the computer model. Table IX summarizes the test statistics.

Estimates for soil porosity in monitoring wells G1, G2, G5a, and G7 were obtained from the Sweet Edwards/EMCON (1989) report. Since monitoring wells $\mathrm{Gl}$ and $\mathrm{G2}$ were completed in the same soil type as the perimeter dike, porosity estimates for monitoring wells G1 and G2 were assumed to represent porosity values in the perimeter dike. The average of the two values is, $\overline{\mathrm{n}}=0.58$.

Porosity estimates for the landfill interior were computed from the dry/wet unit soil weights given in the Paramatrix Inc. and Cornforth Consultants Inc. (1990) laboratory report. The relation between the dry/wet unit soil weights and the porosity, 


$$
n=1-\frac{\gamma_{d r y}}{G_{s} \gamma_{w e t}}
$$

where:

$$
\begin{aligned}
& \mathrm{n}=\text { soil porosity }[-] \\
& \gamma_{\mathrm{dry}}=\text { dry unit weight }\left[\mathrm{ML}^{-3}\right] \\
& \gamma_{\text {wet }}=\text { wet unit weight }\left[\mathrm{ML}^{-2}\right] \\
& \mathrm{G}_{\mathrm{s}}=\text { specific gravity }\left(\text { assume } \mathrm{G}_{\mathrm{s}}=2.56\right) \quad[-]
\end{aligned}
$$

A total of five sample estimates for porosity were computed and the average of the five was, $\bar{n}=0.723$.

TABLE IX

STATISTICS OF LOG TRANSFORMED DATA

\begin{tabular}{||c|c|c|c|}
\hline & Perimeter Dike & Landfill Interior & Combined \\
\hline $\begin{array}{c}\text { Number of } \\
\text { cases }\end{array}$ & 16 & 5 & 21 \\
\hline ln(mean) & -17.0452 & -17.7332 & -17.218 \\
\hline $\begin{array}{c}\text { variance in } \\
\text { ln space }\end{array}$ & 3.0474 & 1.2874 & 2.6331 \\
\hline $\begin{array}{c}\text { Transformed } \\
\text { Mean (ft } / \mathrm{s})\end{array}$ & $3.957 \times 10^{-8}$ & $1.989 \times 10^{-8}$ & $3.33 \times 10^{-8}$ \\
\hline
\end{tabular}

For an unconfined aquifer the relation between porosity (n) and specific yield $\left(S_{y}\right)$ [-] was

$$
S_{y}+S_{r}=n
$$

where $S_{r}[-]$ is the specific retention. In general, as the soil grain size decreased, the specific retention increased and the specific yield decreased. For silts and clays, typically $s_{r}>s_{y} \cdot s_{y}$ was assumed to be $0.51 n$. For the computer 
analysis the specific yields of the perimeter dike and landfill interior were assumed to be significantly different. Thus for the landfill, $S_{y}=0.369$; and for the perimeter dike, $S_{y}=0.296$

\section{Boundary Data set}

As mentioned earlier, the intent of the computer modeling study was to determine what influence tidal motions in the slough have on the phreatic surface within the landfill. The boundary data set used to simulate the slough comes from the USGS Lombard street data file which was approximately 108 days in length. It was desired to model the tidal motions in the slough as a circular series. A circular series more realistically represents a continuous time series, i.e., the water level on the first and last day of the simulation will be equal. To do this, the USGS data set was mirrored around the last day of the sequence, increasing the simulation time to 216 days. To restrict the study to tidal motions with periods of 14 days and less, seasonal influences in the slough time series were removed using the same 14 day smoothing technique used on the groundwater time series. Figure 91 shows the observed, smoothed, and differenced USGS Lombard street time series, as well as the groundwater time series for monitoring well Gl. The differenced USGS time series shown in Figure 91c was used in the computer model to simulate tidal motions in the slough.

Boundary conditions for the landfill interior came from 


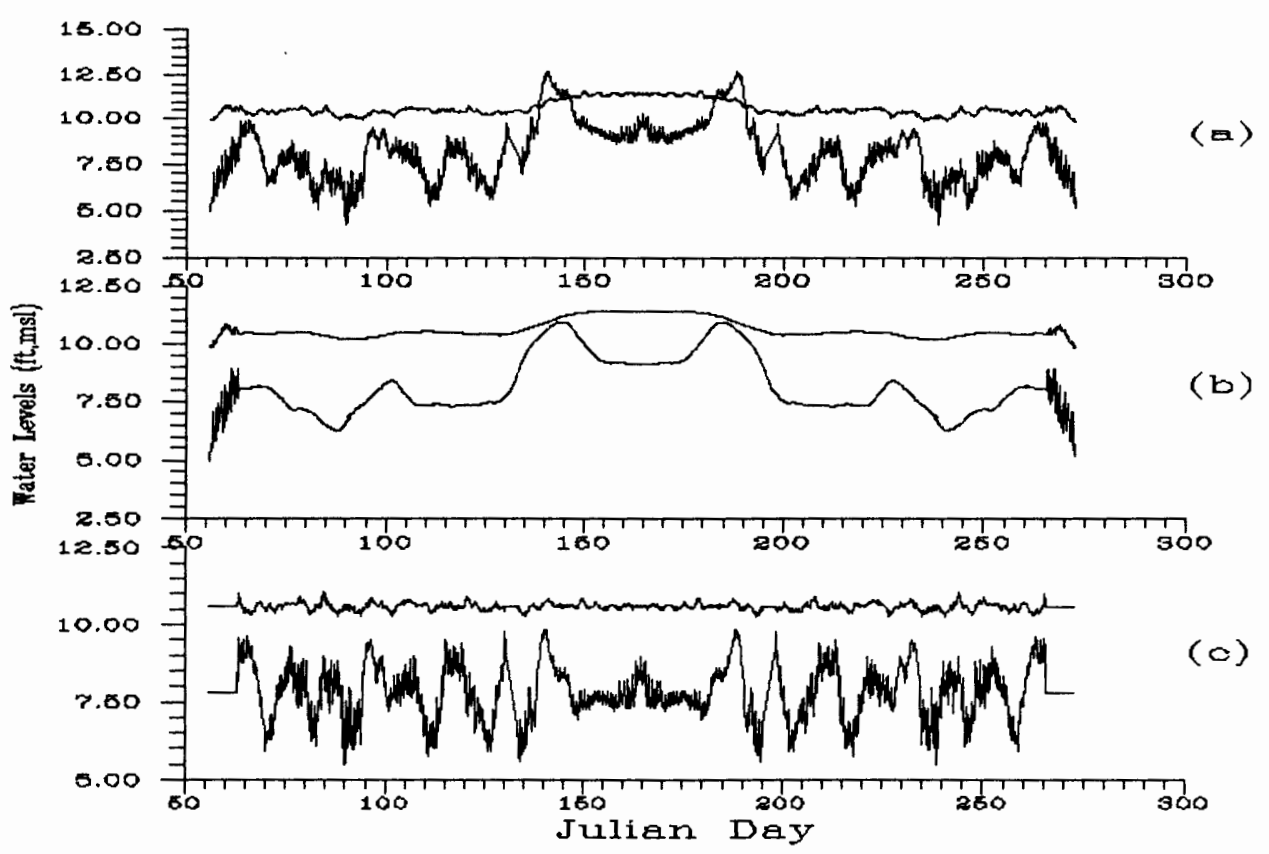

Figure 91. Mirrored USGS Lombard and monitor well G1 water level time series, (a) observed, (b) smoothed, (c) differenced. The upper time series in each figure is monitor well GI.

an unpublished field study by Paramatrix Inc. The groundwater levels were from monitoring wells $\mathrm{H}-1$ through $\mathrm{H}-5$. The average groundwater level in each monitoring well was used for the interior boundary condition. The interior boundaries conditions remained constant with time.

\section{COMPUTER SIMULATION ANALYSIS}

\section{Pre-Modeling Time Requirements}

Once the computer model was verified by comparing the numerical solution to an analytical solution, the next step was to determine how sensitive the predicted hydraulic heads were to initial head conditions. In other words, how long 
would the model have to run before the initial conditions no longer influenced the predicted heads. To determine the initial run time requirements, the initial groundwater levels were set to an arbitrary surface elevation, and the model was then run tracking the predicted phreatic surface over time. During the simulation, at an arbitrary point in time, the maximum and minimum hydraulic heads were recorded giving an envelope in which the predicted hydraulic heads were expected to lie. For example, if the total simulation run time was 10 years, the model was allowed to warm-up for the first 5 years, then for the remaining 5 years the maximum and minimum hydraulic heads at each node were recorded. The subsequent hydraulic head envelope shows how much the predicted hydraulic heads have changed from the initial conditions. Figure 92 shows the progression of the head envelope for $K=8.88 \times 10^{-8} \mathrm{ft} / \mathrm{s}$ and $S=0.3$. Node 1 is the interior well, node 55 the slough boundary, and the $\Delta x$ spacing is $1 \mathrm{ft}$. Once the initial conditions were forgotten, the shape of the head envelope will remain constant with time. The shape of the head envelope can be used as a visual guide to indicate that current hydraulic heads were acting independent of the initial conditions.

\section{Computer simulations}

Three computer models for monitoring wells G1, G2, and G3 were developed to investigate the influence tidal motions in the slough have on groundwater levels within the landfill, and hence, the flow of leachate from the landfill into the slough. 


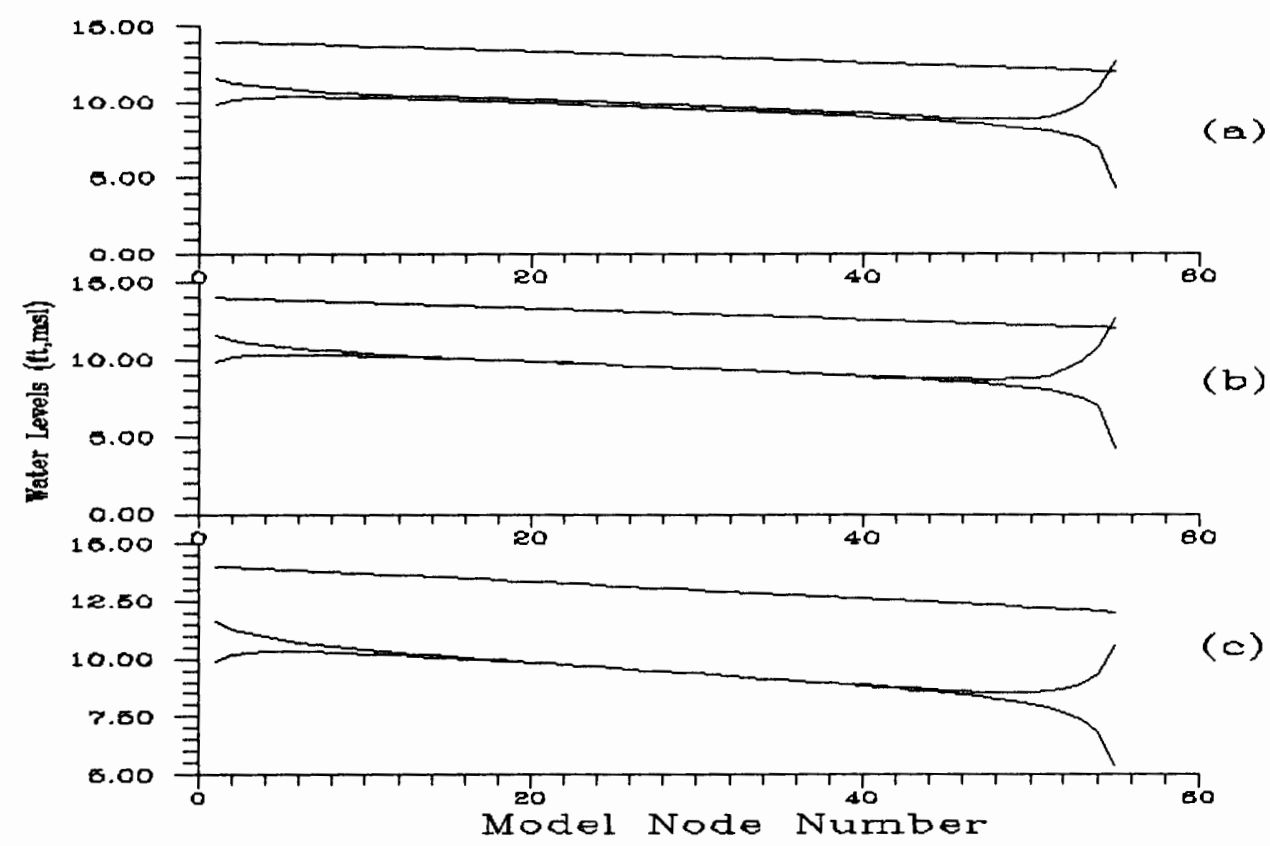

Figure 92. Computed head envelops after premodeling runtimes (a) 5 yrs, (b) 25 yrs, (c) 75 yrs. The upper line in each figure is the initial phreatic surface. All soil parameter estimates are the same.

In each model the interior boundary condition was represented by the average groundwater level in monitoring wells $\mathrm{H}-3$ and $\mathrm{H}-5$. Table $\mathrm{X}$ shows the averaged interior groundwater level for each $\mathrm{H}$-well, perimeter G-well groundwater range, and the field estimated soil parameter values. H-well and G-well assignments were made based on the proximity of each set of wells. The groundwater level ranges for the G-wells were obtained from Table VI. As mentioned earlier, the differenced USGS Lombard slough data set shown in Figure 91 was used to simulate the expected tidal motions of the slough waters near each 'G' monitoring well.

The groundwater ranges were used in the first computer 
simulations to calibrate the storativity values ' $S$ ' for each

TABLE $X$

SUMMARY OF SOIL PARAMETER ESTIMATES AND

GROUNDWATER LEVEL RANGES USED FOR THE

COMPUTER SIMULATIONS

\begin{tabular}{||c|c|c|c|c|c|}
\hline $\begin{array}{c}\text { Perimeter } \\
\text { Dike We11 }\end{array}$ & $\begin{array}{c}\text { Interior } \\
\text { H-Wel1 } \\
\text { (average) }\end{array}$ & $\begin{array}{c}\text { Groundwater } \\
\text { Level Range } \\
\text { G-we11 }\end{array}$ & $\begin{array}{c}\text { Hydraulic } \\
\text { Conductivity } \\
\text { (field) }\end{array}$ & \multicolumn{2}{|c|}{$\begin{array}{c}\text { Storativity } \\
\text { Land Dike } \\
\text { (field) }\end{array}$} \\
\hline G-1 & $\begin{array}{c}\text { H-3 } \\
38.51 \mathrm{ft}\end{array}$ & $0.9 \mathrm{ft}$ & $\begin{array}{c}3.33 \times 10^{-8} \\
(\mathrm{ft} / \mathrm{s})\end{array}$ & 0.37 & 0.29 \\
\hline $\mathrm{G}-2$ & $\begin{array}{c}\mathrm{H}-3 \\
38.51 \mathrm{ft}\end{array}$ & $0.9 \mathrm{ft}$ & $\begin{array}{c}3.33 \times 10^{-8} \\
(\mathrm{ft} / \mathrm{s})\end{array}$ & 0.37 & 0.29 \\
\hline $\mathrm{G}-3$ & $\begin{array}{c}\mathrm{H}-5 \\
57.85 \mathrm{ft}\end{array}$ & $0.59 \mathrm{ft}$ & $\begin{array}{c}3.33 \times 10^{-8} \\
(\mathrm{ft} / \mathrm{s})\end{array}$ & 0.37 & 0.29 \\
\hline
\end{tabular}

well. The calibration was as follows: (1) Time averaged water levels at the interior and slough boundaries were used to set the initial phreatic surface elevation. (2) The computer model was allowed to run for 5849 days before modeling results were analyzed. (3) Given the initial storativity, the model was run for approximately 2383 days continuously recording the groundwater tidal range at the perimeter well location. (4) The predicted groundwater level range was compared to the observed. If they were equal, no adjustment was made to the storativity value. If the two ranges did not match, the storativity was iteratively adjusted until the predicted range converged to within $\pm 0.01 \mathrm{ft}$ of the observed groundwater range. Once the tolerance was reached the iteration process was terminated and the model output the current storativity value and the corresponding head envelope. Results of the 
calibration simulations are summarized in Figures $93-95$.

The second computer simulation predicted the head envelope for each well using the field estimated soil parameter values, where: hydraulic conductivity, $\mathrm{K}=3.33 \times 10^{-8}$ (ft/s), storativity values, $s=0.369$ and $s=0.269$ for the landfill interior and perimeter dike respectively. Results from the observed field estimate simulations are summarized in Figures 96 - 98. Table XI also summarizes the results of the computer simulation and the observed soil parameter estimates. Essentially what was being compared in the two computer simulations was the storativity-hydraulic conductivity ratio, $s / K$. To better illustrate how the value of the ratio effects groundwater levels, equation (2) can be rewritten assuming the tidal amplitude is small compared to the aquifer depth $D$, and the hydraulic conductivity is constant along $x$, equation (2) becomes,

$$
\frac{\partial^{2} h}{\partial x^{2}}=\frac{S}{K D} \frac{\partial h}{\partial t}
$$

requiring the boundary conditions to be,

$$
\begin{aligned}
\frac{\partial h}{\partial t} & =0, \quad x \rightarrow \infty \\
h(0, t) & =D+\sum A_{j} \cos \left(j \omega t-\phi_{j}\right)
\end{aligned}
$$




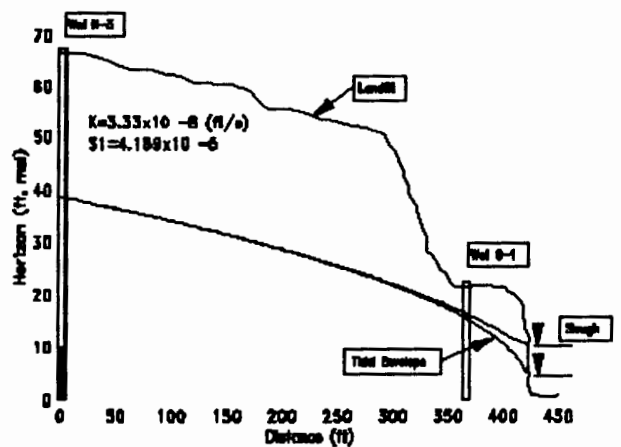

Figure 93. Head envelope from storativity calibration, $\mathrm{SI}$ is assumed constant along ' $\mathrm{x}$ '.

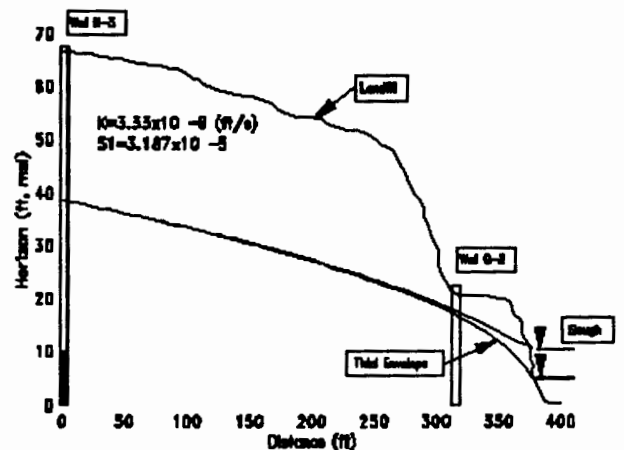

Figure 94. Head envelope from storativity calibration, $S 1$ is assumed constant along ' $\mathrm{x}$ '.

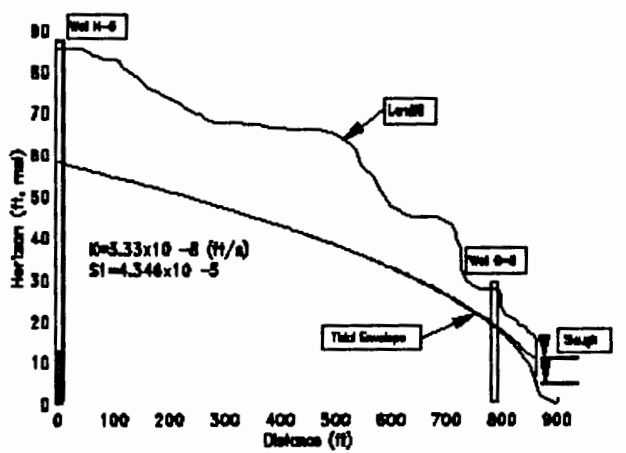

Figure 95. Head envelope from storativity calibration, $\mathrm{SI}$ is assumed constant along ' $x$ '.

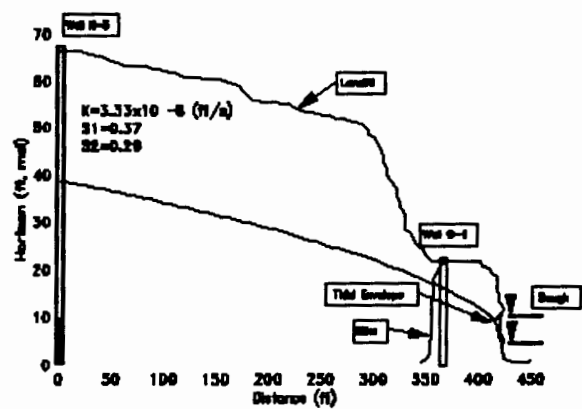

Figure 96. Head envelope using the field estimated soil parameters. S1 and S2 are the landfill and dike storativities respectively.

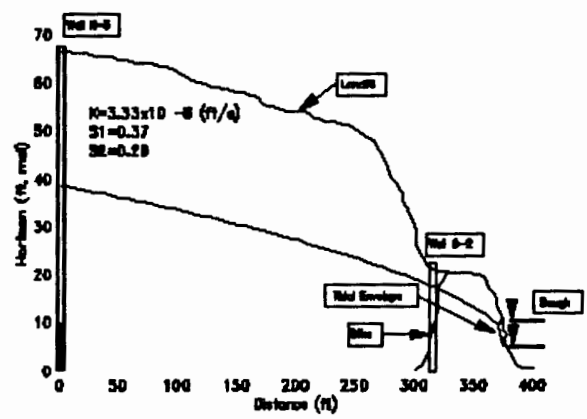

Figure 97. Head envelope using field estimated soil parameters. S1 and S2 are the landfill and dike storativities respectively.

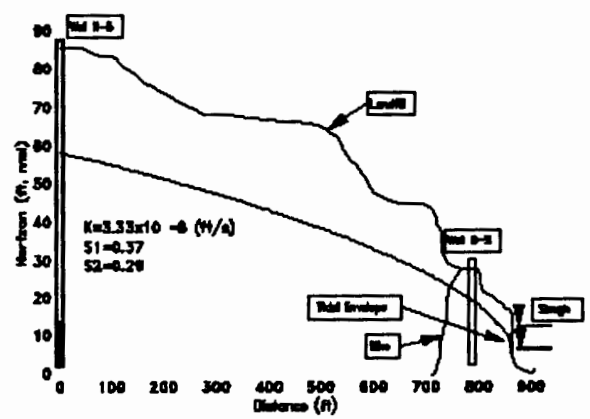

Figure 98. Head envelope using field estimated soil parameters. S1 and S2 are the landfill and dike storativities respectively. 
where: $D=$ mean sea level [L]

$$
\begin{aligned}
& A_{j}=\text { tidal amplitude of harmonic } j[L] \\
& \phi_{j}=\text { phase lag of harmonic } j[-]
\end{aligned}
$$

The boundary condition at the beach, $h(0, t)$, is a Fourier series representing a complicated tidal variation with frequency $\omega$. The analytical solution to equation (14) is,

$$
h(x, t)=D+\sum A_{j} \cos \left(j \omega t-\phi_{j}-\sqrt{j k x}\right) e^{-\sqrt{j k x}}
$$

where:

$$
k=\sqrt{\frac{S \omega}{2 K D}}
$$

With regard to equation (14), as the ratio $S / K$ approaches zero, the equation acts like the steady state equation, implying that tidal perturbations in the slough are transferred almost instantaneously through the groundwater system. The larger the $\mathrm{S} / \mathrm{K}$ ratio becomes the more the perturbations will be dampened along the abscissa. Figures 93 - 98 show the degree to which the slough perturbations are dampened for larger $S / K$ values. For the observed soil parameter estimates, the tidal envelope does not extend much more than five feet into the perimeter dike. Whereas, for the calibrated storativity, the tidal envelope extends up to 150 feet (through the perimeter dike and into the landfill). The differences between what is expected, Figures $96-98$, and 
what is observed, Figures 93 - 95, are quite significant.

If it is assumed that the hydraulic conductivity values are correct, then the calibrated storativity values are four

TABLE XI

OBSERVED AND CALIBRATED SOIL PARAMETER ESTIMATES

\begin{tabular}{|c|c|c|c|c|}
\hline $\begin{array}{c}\text { Monitoring } \\
\text { Well }\end{array}$ & $\begin{array}{c}\text { Observed } \\
\text { Storativity }\end{array}$ & $\begin{array}{c}\text { Cal ibrated } \\
\text { Storativity }\end{array}$ & $\begin{array}{c}\text { Observed } \\
\text { Hydraulic } \\
\text { Conductivity } \\
\text { (ft/s) }\end{array}$ & $\begin{array}{c}\text { Cal ibrated } \\
\text { Hydraulic } \\
\text { Conductivity } \\
\text { (ft/s) }\end{array}$ \\
\hline G-1 & 0.33 & $4.189 \times 10^{-5}$ & $3.33 \times 10^{-8}$ & $2.62 \times 10^{-4}$ \\
\hline G-2 & 0.33 & $3.187 \times 10^{-5}$ & $3.33 \times 10^{-8}$ & $3.45 \times 10^{-4}$ \\
\hline$G-3$ & 0.33 & $4.346 \times 10^{-5}$ & $3.33 \times 10^{-8}$ & $2.53 \times 10^{-4}$ \\
\hline
\end{tabular}

orders of magnitude smaller than the observed values. The calibrated values are more representative of confined aquifers than unconfined.

The value of the ratio $S / K$ can be varied by either increasing/decreasing the numerator or the denominator. In the computer model, calibration adjustments were made to the numerator as a matter of convenience. If it is assumed that the observed storativity values are correct, then a calibrated hydraulic conductivity can be computed from the modeling results. The calibrated hydraulic conductivities given in Table XI are within typically observed hydraulic conductivities for silt to silty sand soils.

For any type of aquifer composed of a homogeneous porous matrix, the observed hydraulic conductivity can exceed the hydraulic conductivity associated with the porous matrix type. 
This is possible if fractures exist within the porous matrix structure. Water transport in the fractures will exceed that in the porous matrix. Two different types of transport continua are in existence, fractured and diffusive (Darcy) flow. However, a single continuum model can adequately model the two continua (Berkowitz, Bear, Braester, 1988) by using a single 'equivalent' hydraulic conductivity to model the fractured aquifer. The calibrated hydraulic conductivities given in Table XI may represent the equivalent hydraulic conductivity for a fractured unconfined aquifer. If the monitoring wells were completed in fractured aquifers, the field estimated hydraulic conductivities should have values close to those given in Table XI. For the specific monitoring wells G-1, G-2, and G-3 the hydraulic conductivity field estimates, as determined by Sweet Edwards/EMCON (1989), were four orders of magnitude smaller than the calibrated values (see Table XII). From the large differences in the calibrated and observed hydraulic conductivity values it does not seem likely that the monitoring wells tap a fractured aquifer. The observed hydraulic conductivity values are fairly representative of sandy silt soils.

comparing the observed and calibrated soil parameter values for both the storativity and hydraulic conductivity and the head envelopes, the modeling assumptions used to simulate groundwater levels do not seem to be appropriate. The 
TABLE XII

COMPARISONS OF THE FIELD ESTIMATED AND

CALIBRATED HYDRAULIC CONDUCTIVITY

\begin{tabular}{|c|c|c|}
\hline $\begin{array}{c}\text { Monitoring } \\
\text { We11 }\end{array}$ & $\begin{array}{c}\text { Observed Hydraulic } \\
\text { Conduct ivity }\end{array}$ & $\begin{array}{c}\text { Calibrated Hydraulic } \\
\text { Conductivity }\end{array}$ \\
\hline G-1 & $6.89 \times 10^{-7}$ & $2.26 \times 10^{-4}$ \\
\hline G-2 & $4.92 \times 10^{-7}$ & $3.45 \times 10^{-4}$ \\
\hline G-3 & $2.85 \times 10^{-7}$ & $2.53 \times 10^{-4}$ \\
\hline
\end{tabular}

Swe e t Edwa rds/EMOON, 1989

assumption that the monitoring wells adequately reflect the phreatic surface is not appropriate. Nevertheless, time averaged flow rates computed from the simulation are informative as an order of magnitude estimate. Table XIII presents the estimated computer simulated and steady state analytical (using time averaged heads at the boundaries) groundwater flow rates from the landfill to the surrounding slough waters.

The average flow of leachate from the landfill into the slough was estimated by averaging the simulated flow rates and multiplying the average flow rate by the landfill perimeter exposed to the slough.

$$
\begin{aligned}
& \boldsymbol{Q}=\left[5.90 \times 10^{-8}\left(\mathrm{ft}^{3} / \mathrm{s} / \mathrm{ft}\right)\right][10184 \mathrm{ft}] \\
& \boldsymbol{Q}=6.01 \times 10^{-4} \mathrm{ft}^{3} / \mathrm{s} \text { or } 51.91 \mathrm{ft}^{3} / \mathrm{day}
\end{aligned}
$$

The estimated flow rate results from the simulation should only be used as an order of magnitude estimate as the groundwater perturbations that occurred in the monitoring wells may be better predicted by using a different model type. 
TABLE XIII

TIME AVERAGED GROUNDWATER LEVELS AND HORIZONTAL FLOW RATES FROM THE COMPUTER SIMULATION

\begin{tabular}{|c|c|c|c|c|c|c|c|}
\hline \multirow{2}{*}{$\begin{array}{l}\text { Interior } \\
\text { Well }\end{array}$} & \multirow{2}{*}{$\begin{array}{l}\text { Perimeter } \\
\text { Well }\end{array}$} & \multirow{2}{*}{$\begin{array}{l}\text { Hydraul ic } \\
\text { Conductivity } \\
\text { (ft/s) }\end{array}$} & \multicolumn{2}{|c|}{$\begin{array}{c}\text { Groundwater Level } \\
\text { at Boundary }\end{array}$} & \multicolumn{2}{|c|}{$\begin{array}{c}\text { Computed Flow } \\
\left(\mathrm{ft}^{3} / \mathrm{s} / \mathrm{ft}\right)\end{array}$} & \multirow{2}{*}{$\begin{array}{l}\text { Analytical } \\
\left(f t^{3} / s / f t\right)\end{array}$} \\
\hline & & & Interior & Slough & $\begin{array}{c}\text { location } \\
1\end{array}$ & $\begin{array}{c}\text { location } \\
2\end{array}$ & \\
\hline H3 & G1 & $3.33 \times 10^{-8}$ & 38.51 & 8.31 & $5.44 \times 10^{-8}$ & $5.45 \times 10^{-8}$ & $5.59 \times 10^{-8}$ \\
\hline $\mathrm{H3}$ & G2 & $3.33 \times 10^{-8}$ & 38.51 & 8.31 & $6.08 \times 10^{-8}$ & $6.10 \times 10^{-8}$ & $6.29 \times 10^{-8}$ \\
\hline H5 & G3 & $3.33 \times 10^{-8}$ & 57.85 & 8.31 & $6.13 \times 10^{-8}$ & $6.19 \times 10^{-8}$ & $6.36 \times 10^{-8}$ \\
\hline
\end{tabular}

For example, a two-dimensional unconfined aquifer that allows slough level perturbations to diffuse through the aquifer depths, a semi-confined/confined aquifer loaded on top by the changing slough levels, or by a larger confined aquifer subject to tidal perturbations at its boundaries. The later scenario may be easily investigated, very crudely, by employing equation (16) using a single harmonic series to represent the tidal variations.

\section{COLUMBIA RIVER TIDAL INFLUENCES}

The sandy/gravel aquifer is overlain by a layer of Columbia river sands and floodplain sediments (Fishman 1986). These two upper layers cover the aquifer from the St. Johns Landfill to the Columbia River. The sandy/gravel aquifer was speculated to rise to within five feet of the Bybee Lake bottom.

Groundwater level studies have suggested that the 
Columbia River indirectly influences the regional groundwater hydraulic head in the sandy/gravel aquifer (Fishman 1986). Since the sandy/gravel aquifer is basically confined, equation (16) can be employed to determine whether the groundwater perturbations observed in the monitoring wells around st. Johns Landfill, were due to tidal motions in the columbia River.

The sandy/gravel aquifer ranges in thickness from 300 to 600 feet between the Columbia River Gorge and the Trojan Nuclear Power Plant (Fishman (1986)) . Hydraulic conductivities (at monitoring wells G5b and G6) and storativity estimates for the aquifer from Sweet Edwards/EMCON (1986), and City of Portland Water Bureau Pilot Well study (1978), respectively are given in Table XIV. Tidal characteristics at the USGS Lombard street bridge slough gaging station were used to approximate the tidal characteristics in the Columbia River. Table XIV shows the values used to compute expected groundwater amplitudes and time lags at monitoring wells G5b and G6. Values for the observed groundwater tidal amplitudes were estimated from the differenced groundwater level time series shown in Figures 65 and 66. The calculated and observed amplitudes are given in Table XIV, in columns identified by a and A respectively, see shaded area. For both monitoring wells, the calculated amplitudes are approximately five times the observed. It is expected that actual groundwater tidal perturbations from the Columbia River would be much smaller 
TABLE XIV

COLUMBIA RIVER TIDAL INFLUENCES ON THE GROUNDWATER UNDER ST. JOHNS LANDFILL

\begin{tabular}{|c|c|c|c|c|c|c|c|c|c|}
\hline $\begin{array}{l}\text { Monitoring } \\
\text { Mell }\end{array}$ & s & $\underset{(f t)}{d}$ & $\begin{array}{c}K \\
(\mathrm{ft} / \text { day })\end{array}$ & $\begin{array}{c}T_{0} \\
\text { (day) }\end{array}$ & $\begin{array}{c}x \\
(f t)\end{array}$ & $\begin{array}{r}a_{0} \\
(f t)\end{array}$ & $(6+1$ & $(t+1)$ & $\begin{array}{c}t_{L} \\
\text { (day) }\end{array}$ \\
\hline G5b & 0.00055 & 450 & 259 & 14 & 5573 & 2.18 & 1.82 & 0.36 & 0.404 \\
\hline G6 & 0.00055 & 450 & 135 & 14 & 7868 & 2.18 & $1 / 53$ & 0.32 & 0.79 \\
\hline
\end{tabular}

S = Storativity: $\quad d=$ Aquifer depth

$K=$ Hydraul ic conductivity; $\quad T_{0}=$ Period;

$x=D i s t a n c e$ inland from bank; $a_{0}=$ Amplitude of forcing wave

$a=$ Predicted amplitude at $x ; A=0 b s e r v e d$ ampl $i$ tude at $x$

$t_{L}=T$ ime lag at $x$

than those predicted by equation (16) because of soil heterogeneities and other subsurface anomalies which tend to dampen wave activity. Even though the analysis is simplistic, it indicates that the observed groundwater perturbations in all the monitoring wells may be caused by tidal motions in the Columbia River.

Recall that the horizontal gradient analysis indicated that tidal motions did not cause the gradient to reverse directions. Hence, a swash zone beneath St. Johns Landfill (which would have the potential to carry contaminated groundwater up gradient of the southwest landfill boundaries, spreading the contaminant plume over a greater area) did not exist. 
CHAPTER V

SUMMARY AND CONCLUSIONS

The installation of the continuous groundwater level monitoring system provided a very detailed description of groundwater levels over the year of study. Even periodic variations as small as one half day were recorded. In addition, the monthly groundwater sampling gave insight into the seasonal or temporal variations in groundwater geochemical constituents. While the resultant data were informative, it should be kept in mind that the study was a single year. The data set represents a single sample drawn from a very large population, and all analyses or conclusions are an estimate of the expected.

Monthly groundwater samples - monitoring chloride concentrations, electrical conductivity, and temperature allowed a formative estimate of the leachate penetration depth and the statistical significance of chemical indicator trends. observed average electrical conductivities for monitoring wells: Dlc, $614 \mu \mathrm{mhos} / \mathrm{cm}(-80 \mathrm{ft}) ; \mathrm{Gl}, 1097 \mu \mathrm{mhos} / \mathrm{cm}(-34 \mathrm{ft})$; G2, $800 \mu \mathrm{mhos} / \mathrm{cm}(-36 \mathrm{ft}) ; \mathrm{G} 3,550 \mu \mathrm{mhos} / \mathrm{cm}(-28 \mathrm{ft}) ; \mathrm{G} 5 \mathrm{a}, 635$ $\mu$ mhos/cm (-7 ft); G6, $504 \mu \mathrm{mhos} / \mathrm{cm}(-168 \mathrm{ft}) ; \mathrm{G7}, 2450$ $\mu$ mhos/cm (-25 ft) exceed the observed natural electrical conductivity level of $300 \mu \mathrm{mhos} / \mathrm{cm}$. The elevated conductivity 
levels for the above monitoring wells indicate that the leachate plume has penetrated the upper silt aquitard (wells G1, G2, and G3) and could be moving along the silt-sand aquifer interface (wells G5a and G7) towards the columbia River. If additional statistical information for the natural background conductivity levels were available, the significance of the monitoring well results could be determined. The Fishman study (1986) also reported that migration of the leachate through the upper silt layer had occurred.

The simple linear regression analysis indicated that a statistically significant (positive) trend in chloride concentrations existed. However, the analysis did not indicate whether electrical conductivity levels were increasing or decreasing over the period of study. Nor did a visual inspection of comparison plots between geochemical indicators electrical conductivity/chloride concentrations and electrical conductivity/temperature reveal significant correlations among the constituents.

Time series plots of the groundwater levels and the frequency analysis showed that groundwater levels were predominantly influenced by seasonal changes in rainfall. Additional cross-correlation analyses showed that several of the wells were perturbed by a forcing mechanism having superimposed periods of $14,1,0.5$ days. Possible forcing mechanisms could be local slough waters or the columbia River. 
However, the forcing mechanism did not cause a noticeable swashing beneath the landfill.

Vertical hydraulic gradient analyses at monitoring well $H 5$ indicated an average downward flow rate of $Q_{v}=2.59 \times 10^{4}$ ( $\mathrm{ft}^{3} /$ day), see appendix F. Horizontal leachate flow rates from the landfill to the surrounding slough waters were estimated from computer simulations, an averaged order of magnitude estimate was $\Omega_{h}=52$ ( $\left.\mathrm{ft}^{3} / \mathrm{day}\right)$. Vertical leachate seepage contributes a significantly greater portion of contamination to local water systems than horizontal seepage. Computer simulations showed that the time averaged horizontal flow rate can be computed from the steady state flow equation, using time averaged water levels at the boundaries to predict interior groundwater levels. An estimate of the horizontal flow rate after the landfill capping could be computed using the expected time averaged landfill and slough water levels. Computer simulation results also indicated that the observed groundwater levels in the monitoring wells (G1,G2, and G3) do not accurately represent the phreatic groundwater surface. An estimate of the phreatic surface elevation could be computed by using the average vertical gradient from monitoring well G5ab $(0.07967 \mathrm{ft} / \mathrm{ft})$, as the expected vertical gradient at monitoring wells G1, G2, and G3. Using an average well depth of $30 \mathrm{ft}$, the estimated head loss $\Delta \mathrm{h} \approx(0.07967)(30) \approx 2 \mathrm{ft}$. Thus, the phreatic surface could be two feet higher in elevation than monitoring wells G1, G2, and G3 indicate. 
Comparisons of groundwater levels for monitoring well G5ab with Bybee Lake and the North Slough, indicated that if the control weir between Bybee Lake and the North Slough were removed, groundwater could seep into Bybee Lake. At present though, Bybee Lake recharges the local groundwater.

The continuous groundwater monitoring study and subsequent analyses have shown that the magnitude of horizontal seepage volumes are insignificant compared to vertical leachate seepage volumes. The potential for contamination of local water systems comes primarily from vertical seepage. Given the large volume of leachate that seeps from the landfill into the groundwater, further studies should be conducted to determine what effect lowering Bybee Lake water levels may have on groundwater flow direction. If groundwater were to recharge Bybee Lake, there could be a serious potential for contamination of Bybee Lake from the Landfill.

Additionally, continuation of the monthly groundwater sampling program would provide the needed information to determine the significance and the rate of the observed geochemical groundwater constituent trends. 


\section{REFERENCES}

Anderson, Dale, John Tannehil, and Richard Pletcher. 1984. Computational Fluid Mechanics and Heat Transfer, Hemisphere Publishing Corporation, New York

Bear, Jacob. 1979. Hydraulics of Groundwater, McGraw-Hill Publishing Company, New York

Berkowitz, Brian, Jacob Bear, and Carol Braester. 1988. "Continuum Models for Contaminated Transport in Fractured Porous Formations" Water Resources Research, Vol. 24, No. $8,1225-1236$

Bredehoeft, John. 1967. "Response of Well-Aquifer Systems to Earth Tides," Journal of Geophysical Research, 72, 30753087

Custodio, Emilio. G. A. Bruggeman. 1987. "Groundwater Problems in Coastal Areas," in International Hydrology Programme, Publication of the IHP Working Group on Changes in the Salt-Fresh water Balance in Deltas.

Dominick, Thomas F., Bert Wilkins, and Harry Roberts. 1971. "Mathematical Model for Beach Groundwater Fluctuations," Water Resources Research, Vol 7, No. 8, 1626-1635

Erskine, A. D.. 1991. "The Effect of Tidal Fluctuation on a Coastal Aquifer in the UK," Ground Water, Vol. 29, No. 4, 556-562

Fishman Environmental Services. 1986. "Smith and Bybee Lakes Environmental Studies," Prepared for Port of Portland and city of Portland Bureau of Environmental Services, Portland, Oregon

Freeze Allen, and John Cherry. 1979. Groundwater, PrenticeHall, N.J.

Haans, Charles T.. 1977. Statistical Methods in Hydrology, Iowa State University Press, Iowa

Hirsh, Robert M., James Slack, and Richard Smith. 1982 . "Techniques of Trend Analysis for Monthly Water quality Data," Water Resources Research, Vol 18, No. 1, 107-121 
Johnson, A. G.. 1973. "Pore Pressure Changes Associated with Creep Events on the San Andreas Fault," Ph.D. thesis, Dept. of Geophysics, Standford University, Standford Calif., 177 pp.

Nielson, Peter. 1990. "Tidal Dynamics of the Water Table in Beaches," Water Resources Research, Vol. 26, No. 9, 21272134

Paramatrix Inc., and Cornforth Consultants Inc.. 1990. "St. Johns Landfill Closure," Prepared for Metro, Solid Waste Division, Portland, Oregon

Remson, I., G. Hornberger, and F. Molz. 1971. Numerical Methods for Subsurface Hydrologic systems, Wiley Intersciences

Ritzi, Robert Willaim. Soroosh Sorooshian, Paul Hsieh. 1991. "Estimation of Fluid Flow Properties From the Response of Water Levels in Wells to the Combined Atmospheric and Earth Tide Forces," Water Resources Research, Vol. 27, No. $5,883-893$

Rojstaczer, Stuart, and Francis Riley. 1990. "Response of the Water Level in a Well to Earth Tides and Atmospheric Loading Under Unconfined Conditions," Water Resources Research, Vol. 26, No. 8, 1803-1817

Rojstaczer, stuart. 1988. "Determination of Fluid Flow Properties From the Response of Water Levels in Wells to Atmospheric Loading," Water Resources Research, Vol. 24, No. 11, 1927-1938

Serfes, Michaels E.. 1991. "Determining the Mean Hydraulic Gradient of Groundwater Affected by Tidal Fluctuations," Ground Water, Vol. 29, No. 4, 549-555

Sweet Edwards/EMCON, Inc.. 1989. "Water Quality Impact Investigation and Environmental Management options," Prepared for Metro, Solid Waste Division, Portland, oregon

Todd, David K. 1980. Groundwater Hydrology. Wiley, New York

Wang, Herbert, and Mary Anderson. 1982. Introduction to Groundwater Modeling, W.H. Freeman and Company, New York 
APPENDIX A

SPECIFICATIONS FOR LAB AND FIELD INSTRUMENTS 
This appendix presents additional technical specifications for the instrumentation used in the groundwater study.

\section{Chloride Concentrations}

Chloride Ion Selective Electrode (ISE)

ISE-8760, ISE-8770

OMEGA Engineering Inc.

Reproducibility Direct electrode measurements can be reproduced within $\pm 2 \%$ if the electrode is calibrated every hour. Factors such as temperature fluctuations, drift, and noise limit reproducibility, it is independent of solution concentration as long as concentrations are within the electrode operating range.

Temperature Samples and standards should be within $\pm 1^{\circ} \mathrm{C}$ of each other, since electrode potentials are influenced by changes in temperature. Changes affect the slope of the calibration curve, Table A-I shows the effect temperature changes have on the curve slope.

Electrode Response The time required to reach $99 \%$ of the sTable electrode potential reading, the electrode response time, varies from several seconds in highly concentrated solutions to several minutes near the detection limit. 
TABLE A-I

TEMPERATURE INFLUENCES ON CURVE SLOPE

\begin{tabular}{|c|c|}
\hline Temperature $\left({ }^{\circ} \mathrm{C}\right)$ & Curve slope \\
\hline 0 & 54.2 \\
\hline 10 & 56.2 \\
\hline 20 & 58.2 \\
\hline 25 & 59.2 \\
\hline 30 & 60.1 \\
\hline 40 & 62.1 \\
\hline 50 & 64.1 \\
\hline
\end{tabular}

\section{Specifications}

$\begin{array}{ll}\text { Concentration Range: } & 1.8 \text { to } 35000 \mathrm{ppm} \\ \text { pH Range: } & 2 \text { to } 12 \\ \text { Temperature Range: } & 0^{\circ} \text { to } 80^{\circ} \mathrm{C}\end{array}$

Electrical Conductance and Temperature

Conductivity, Salinity, and Temperature Field Probe

Model 140

ORION Research Inc., Laboratory Products Group

The Model 140 provides automatic temperature compensations when deviating from the $25^{\circ} \mathrm{C}$ reference temperature.

Specifications

Modes/Ranges:

Conductivity.... $0 \mu \mathrm{S} / \mathrm{cm}$ to $1999 \mathrm{mS} / \mathrm{cm}$ 
Temperature....-5 to $90^{\circ} \mathrm{C}$

Accuracy :

Conductivity.... $\leq 0.5 \%$ of measuring value,

\pm 1 digit in range of 0 to $35^{\circ} \mathrm{C}$

for natural water measurements with temperature compensation in $\mathrm{nLF}$ mode.

Temperature.... $\leq 0.2^{\circ} \mathrm{C}$ w/in -5 to $+40^{\circ} \mathrm{C}$

$\leq 0.3^{\circ} \mathrm{C} \mathrm{w} /$ in 40 to $70^{\circ} \mathrm{C}$

$\leq 0.5^{\circ} \mathrm{C} \mathrm{w} /$ in 70 to $90^{\circ} \mathrm{C}$

\section{Hydrostatic Water Depth}

Hydrostatic Water Depth Probe

Model $6508 \mathrm{a} / \mathrm{b} / \mathrm{c} / \mathrm{d}$

UNIDATA

The water depth probe is internally calibrated for clean water (specific gravity $=1.0$ ) at room temperature. The electronic sensor is temperature compensated however, the probe does not compensate for water density variations due to temperature changes. Probes are vented to the atmosphere thus giving gauge pressure readings.

\section{Specifications}

\section{Ranges :}

Model 6508b..... 0 to 5 meters ( $\pm 20 \mathrm{~mm}$ )

Model $6508 \mathrm{c} . . . .00$ to 10 meters ( $\pm 40 \mathrm{~mm}$ )

Temperature operating Range:

Model $6508 \mathrm{~b} / \mathrm{C} \ldots 0$ to $50^{\circ} \mathrm{C}$ 
APPENDIX B

RELIABILITY OF CHLORIDE PROBE 
During the chloride concentration laboratory analyses the chloride probe drifted. Drift means that the emv calibration values changed with each new electrode calibration, e.g., an initial calibration shows $1 \mathrm{ppm} \mathrm{Cl}^{-}$has an emV of 141, the next calibration shows $1 \mathrm{ppm}$ has an emv of 160. The emv values could drift either up or down. The problem that occurs is which calibration curve should be used for those samples tested between calibrations. Tables B-I and B-II present the calibration emv values used to predict sample chloride concentrations, and lists various statistics showing the amount of drift observed in the probe. As an example of the difficulty in determining which calibration curve to use to estimate the chloride concentration, compare calibrations 2 and 3 in Table B-I. The average drift was 14.28 units, see Table B-II, a sample tested towards the end of calibration run 2 having a emV of 140 could have a chloride concentration of $9.9 \mathrm{ppm}$ (curve 2) or $47 \mathrm{ppm}$ (curve 3). For this study, all samples were estimated from the calibration curve developed before the laboratory tests. 
TABLE B-I

OBSERVED EMV VALUES USED TO PREDICT

SAMPLE CHLORIDE CONCENTRATIONS

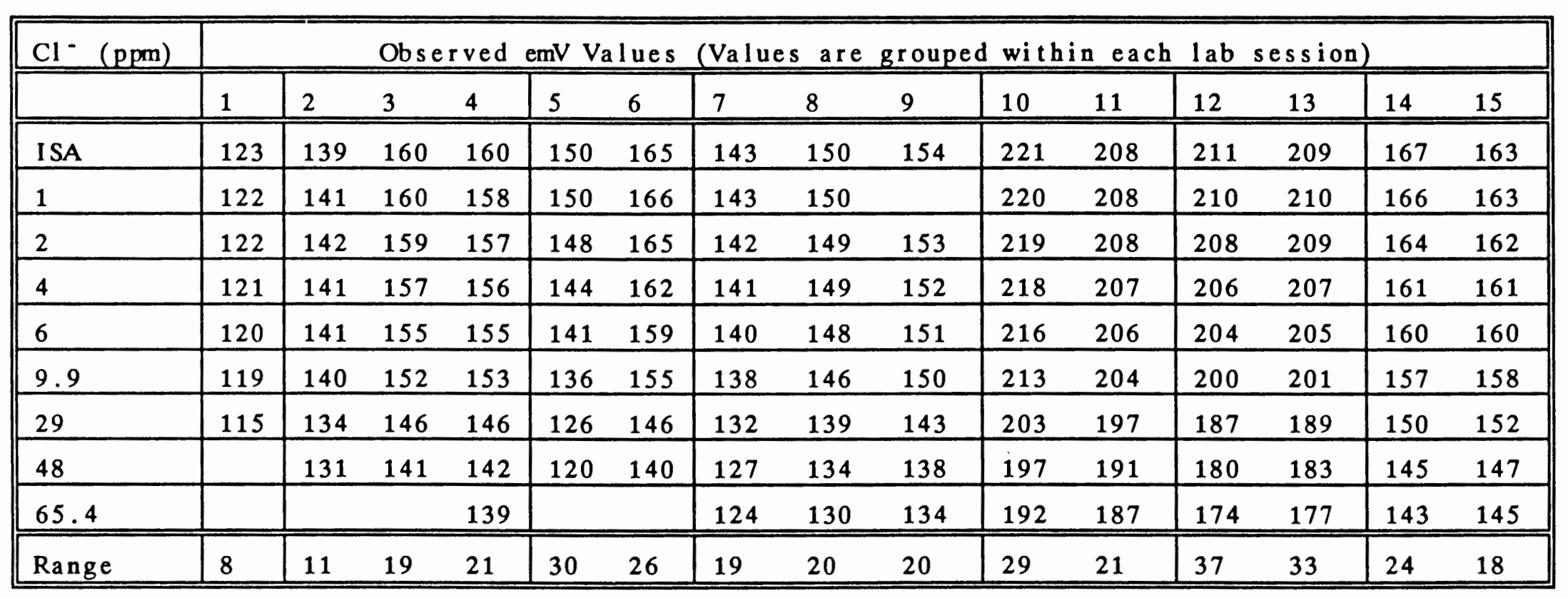


TABLE B-II

PROBE DRIFT BETWEEN CALIBRATION SETS SHOWN IN TABLE B-I (POSITIVE VALUES MEAN PROBE VALUES INCREASED)

\begin{tabular}{|c|c|c|c|c|c|c|c|c|}
\hline Calibrations & $2-1$ & $3-2$ & $5-4$ & $7-6$ & $8-7$ & $10-9$ & $12-11$ & $14-13$ \\
\hline & 21 & 0 & 15 & 7 & 4 & -13 & -2 & -4 \\
\hline & 19 & -2 & 16 & 7 & & -12 & 0 & -3 \\
\hline & 17 & -2 & 17 & 7 & 4 & -11 & 1 & -2 \\
\hline & 16 & -1 & 18 & 8 & 3 & -11 & 1 & 0 \\
\hline & 14 & 0 & 18 & 8 & 3 & -10 & 1 & 0 \\
\hline & 12 & 1 & 19 & 8 & 4 & -9 & 1 & 1 \\
\hline & 12 & 0 & 20 & 7 & 4 & -6 & 2 & 2 \\
\hline & 10 & 1 & 20 & 7 & 4 & -6 & 3 & 2 \\
\hline & & & & 6 & 4 & -5 & 3 & 2 \\
\hline Average & 14.28 & -.428 & 18.28 & 7.25 & 3.71 & -8.75 & 1.5 & .25 \\
\hline Std Dev & 3.20 & 1.27 & 1.50 & .707 & .487 & 2.71 & 1.07 & 1.91 \\
\hline
\end{tabular}




\section{APPENDIX C}

SHAPIRO - WILKS TEST ON REGRESSION RESIDUALS 
Below are the Shapiro-Wilks tests for the chloride linear

regress
Hell G1
RESIDUAL
-0.29246
-0.38788
0.262482
0.581834
-0.39832
0.471259
0.007594
0.145928
-0.60129
0.32128
0.090174
-0.2006

Hell G2

RESIDUAL

$-0.159$

$-0.44975$

$-0.90017$

0.523853

0.831826

0.337173

0.252908

0.278226

$-0.58005$

0.395189

0.222573

$-0.34871$

familian

RESIDUAL

0.204482

$-0.40691$

0.058294

0.205131

0.046181

$-0.06782$

$$
\begin{array}{rr} 
& x(i) \\
1 & -0.60129 \\
2 & -0.39832 \\
3 & -0.38788 \\
4 & -0.29246 \\
5 & -0.2006 \\
6 & 0.007594 \\
7 & 0.090174 \\
8 & 0.145928 \\
9 & 0.262482 \\
10 & 0.32128 \\
11 & 0.471259 \\
12 & 0.581834 \\
& \text { std dev }=
\end{array}
$$

$x(i)$

$-0.90017$

$-0.58005$

$-0.44975$

$-0.34871$

$-0.159$

0.222573

0.252908

0.278226

0.337173

0.395189

0.523853

0.831826

std dev =

$$
\begin{aligned}
& x(i) \\
& -0.40691 \\
& -0.06782 \\
& 0.046181 \\
& 0.058294 \\
& 0.204482 \\
& 0.205131
\end{aligned}
$$

std dev $=$

$$
\begin{aligned}
& x(n-i+1) \\
& 0.581834 \\
& 0.471259 \\
& 0.32128 \\
& 0.262482 \\
& 0.145928 \\
& 0.090174 \\
& 0.007594 \\
& -0.2006 \\
& -0.29246 \\
& -0.38788 \\
& -0.39832 \\
& -0.60129 \\
& 0.376425
\end{aligned}
$$

$x(n-i+1)$

\begin{tabular}{|c|c|c|c|}
\hline $\begin{array}{r}1.731993 \\
1.1039 \\
0.844939 \\
0.685887 \\
0.437229 \\
0.030335\end{array}$ & $\begin{array}{r}a(n-i+1) \\
0.5475 \\
0.3325 \\
0.2347 \\
0.1586 \\
0.0922 \\
0.0303 \\
\text { sum } b(i)=\end{array}$ & $\begin{array}{l}b(i) \\
0.948266 \\
0.367047 \\
0.198307 \\
0.108782 \\
0.040313 \\
0.000919 \\
1.663634\end{array}$ & \\
\hline $\begin{array}{l}\text { mputed } W= \\
\text { bulated } W\end{array}$ & & & $\begin{array}{r}0.95129 \\
0.859\end{array}$ \\
\hline
\end{tabular}

0.831826

0.523853

0.395189

0.337173

0.278226

0.252908

0.222573

$-0.159$

$-0.34871$

$-0.44975$

$-0.58005$

$-0.90017$

0.51429

$$
\begin{array}{r}
1.183123 \\
0.86958 \\
0.709162 \\
0.554939 \\
0.346531 \\
0.08258
\end{array}
$$

Computed $\boldsymbol{W}=$

$$
\begin{array}{rr}
a(n-i+1) & b(i) \\
0.5475 & 0.64776 \\
0.3325 & 0.289135 \\
0.2347 & 0.16644 \\
0.1586 & 0.088013 \\
0.0922 & 0.03195 \\
0.0303 & 0.002502 \\
\text { sun } b(i)= & 1.225801
\end{array}
$$

Tabulated $\mathbf{H}=$

0.964046

0.859

since the computed $U>$ Tabulated $U$

the residuals assume a normal distribution.

$x(n-i+1)$

0.205131

0.204482

0.058294

0.046181

$-0.06782$

$-0.40691$

0.227745

$\begin{array}{lrr} & a(n-i+1) & b(i) \\ 0.612041 & 0.5475 & 0.335093 \\ 0.272302 & 0.3325 & 0.09054 \\ 0.012113 & 0.2347 & 0.002843 \\ & \text { sum } b(i)= & 0.428476\end{array}$

Computed $\boldsymbol{H}=$ Sum $b(i)=0.428476$

Tabulated $\boldsymbol{W}=$

0.707899

0.788

The residuals DO NOT fit a normal dist.

$$
\begin{gathered}
x(i) \\
-1.82366 \\
-0.35637 \\
-0.33679 \\
-0.17478 \\
0.025235 \\
0.199062 \\
0.245704 \\
0.258041 \\
0.294718 \\
0.515638 \\
0.75947 \\
0.765755 \\
\text { std dev }=
\end{gathered}
$$

$$
\begin{gathered}
x(n-i+1) \\
0.765755 \\
0.75947 \\
0.515638 \\
0.294718 \\
0.258041 \\
0.245704 \\
0.199062 \\
0.025235 \\
-0.17478 \\
-0.33679 \\
-0.35637 \\
-1.82366 \\
0.692053
\end{gathered}
$$

$$
\begin{array}{rr}
a(n-i+1) & b(i) \\
0.5475 & 1 \\
0.3325 & 0 \\
0.2347 & 0 \\
0.1586 & 0 \\
0.0922 & 0 \\
0.0303 & 0
\end{array}
$$$$
\begin{array}{lr}
0.5475 & 1.417704 \\
0.3325 & 0.371018
\end{array}
$$$$
0.074462
$$$$
0.021465
$$

0.232805

sum $b(i)=$

0.001413

Computed $\mathbf{H}=$

Tabulated $\mathbf{H}=$

0.82607

0.859

The residuals DO NOT fit a normal dist. 
Well G5a RESIDUAL

$-0.39561$

$-0.60047$

$-0.65655$

0.7454

0.532815

0.98975

0.221381

0.135548

$-0.60987$

0.136453

$-0.09624$

$-0.40261$

Well G5b

RESIDUAL

0.473692

$-0.93151$

$-1.51648$

0.83196

0.569899

0.995981

0.213892

$-0.79824$

0.736484

0.070991

$-0.14162$

$-0.50505$

Well G6

RESIDUAL

$-0.51121$

$-1.01973$

$-0.12236$

0.800964

0.564989

0.46787

0.248575

0.31808

$-0.06302$

0.141316

0.371385

$-0.55217$

Well G7

RESIDUAL

$-0.35811$

0.068409

0.561475

0.96475

$-0.28337$

$-1.16534$

$-1.09767$

0.441442

0.311424

0.55699

$$
\begin{gathered}
x(i) \\
-0.65655 \\
-0.60987 \\
-0.60047 \\
-0.40261 \\
-0.39561 \\
-0.09624 \\
0.135548 \\
0.136453 \\
0.221381 \\
0.532815 \\
0.7454 \\
0.98975 \\
\text { std dev }=
\end{gathered}
$$

$$
\begin{gathered}
x(i) \\
-1.51648 \\
-0.93151 \\
-0.79824 \\
-0.50505 \\
-0.14162 \\
0.070991 \\
0.213892 \\
0.473692 \\
0.569899 \\
0.736484 \\
0.83196 \\
0.995981 \\
\text { std dev }=
\end{gathered}
$$

$$
\begin{gathered}
x(n-i+1) \\
0.995981 \\
0.83196 \\
0.736484 \\
0.569899 \\
0.473692 \\
0.213892 \\
0.070991 \\
-0.14162 \\
-0.50505 \\
-0.79824 \\
-0.93151 \\
-1.51648 \\
0.792363
\end{gathered}
$$

$x(i)$

$-1.01973$

$-0.55217$

$-0.51121$

$-0.12236$

$-0.06302$

0.141316

0.248575

0.31808

0.371385

0.46787

0.564989

0.800964

std $\operatorname{dev}=$

$x(n-i+1)$

0.800964

0.564989

0.46787

0.371385

0.31808

0.248575

0.141316

$-0.06302$

$-0.12236$

$-0.51121$

$-0.55217$

$-1.01973$

0.530086

$\begin{array}{lrr} & & \\ 1.820694 & (n-i+1) & b(i) \\ 1.117161 & 0.5475 & 0.99683 \\ 0.979078 & 0.3325 & 0.371456 \\ 0.493749 & 0.2347 & 0.22979 \\ 0.381096 & 0.1586 & 0.078309 \\ 0.107259 & 0.0922 & 0.035137 \\ & 0.0303 & 0.00325 \\ & \text { sum b(i)= } & 1.714771\end{array}$

Computed $W=$

0.951334

Tabulated $\omega=$

0.859

Since the computed $W>$ Tabulated $W$

the residuals assume a normal distribution.

$$
\begin{array}{r}
x(i) \\
-1.16534 \\
-1.09767 \\
-0.35811 \\
-0.28337 \\
0.068409 \\
0.311424 \\
0.441442 \\
0.55699 \\
0.561475 \\
0.96475
\end{array}
$$

std dev = $x(n-i+1)$

$$
0.96475
$$

0.561475

0.55699

0.441442

0.311424

0.068409

$-0.28337$

$-0.35811$

$-1.09767$

$-1.16534$

0.716799

$\begin{array}{lrr} & a(n-i+1) & b(i) \\ 2.130088 & 0.5739 & 1.222458 \\ 1.659143 & 0.3291 & 0.546024 \\ 0.915098 & 0.2141 & 0.195923 \\ 0.724817 & 0.1224 & 0.088718 \\ 0.243014 & 0.0399 & 0.009696 \\ & \text { sum b(i) }= & 2.062818\end{array}$

Computed $W=$

Tabulated $W=$

0.920206

0.842
Since the computed $W>$ Tabulated $W$ the residuals assume a normal distribution. 


Well G8a
RESIDUAL
0.186506
-0.66504
-1.2088
0.960082
0.448157
0.276971
0.11506
0.452497
-0.29996
0.119107
0.271926

Well G8b

RESIDUAL

$-0.26751$

0.73139

0.372823

0.394778

$-2.46146$

1.272076

$-0.28499$

0.405386

$-0.16447$

$-0.49223$

Hell GBC

RESIDUAL

0.090696

$-0.7357$

$-0.66718$

0.419677

0.468723

0.460807

0.268403

$-0.20651$

$-0.09712$

0.446726

0.486761

0.006875

Hell DIa

RESIDUAL

$-0.00734$

$-0.26596$

0.46437

$-0.05921$

$-0.17101$

0.684946

0.603378

$-0.46078$

$-1.17179$

$-0.6373$

0.249052

0.274091

0.497538

$\begin{array}{rr} & x(i) \\ 1 & -1.2088 \\ 2 & -0.66504 \\ 3 & -0.29996 \\ 4 & 0.11506 \\ 5 & 0.119107 \\ 6 & 0.186506 \\ 7 & 0.271926 \\ 8 & 0.276971 \\ 9 & 0.448157 \\ 10 & 0.452497 \\ 11 & 0.960082 \\ & \text { std dev }=\end{array}$
$x(n-i+1)$
0.960082
0.452497
0.448157
0.276971
0.271926
0.186506
0.119107
0.11506
$-0.29996$
$-0.66504$
$-1.2088$
0.591142

$\begin{array}{rrr} & a(n-i+1) & b(i) \\ 2.168882 & 0.5739 & 1.244721 \\ 1.117536 & 0.3291 & 0.367781 \\ 0.748113 & 0.2141 & 0.160171 \\ 0.161911 & 0.1224 & 0.019818 \\ 0.15282 & 0.0399 & 0.006098 \\ & \text { sum } b(i)= & 1.798589\end{array}$

Computed $W=$

Tabulated $\boldsymbol{H}=$

0.925708

0.842

Since the computed $W>$ Tabulated $W$

the residuals assume a normal distribution.

$$
\begin{gathered}
x(i) \\
-2.46146 \\
-0.49223 \\
-0.28499 \\
-0.26751 \\
-0.16447 \\
0.372823 \\
0.394778 \\
0.405386 \\
0.73139 \\
1.272076 \\
\text { std dev }=
\end{gathered}
$$

$x(n-i+1)$

1.272076

0.405386

0.394778

0.372823

$-0.16447$

$-0.26751$

$-0.28499$

$-0.49223$

$-2.46146$

1.003813

$\begin{array}{lrr} & a(n-i+1) & b(i) \\ 3.733533 & 0.5739 & 2.142675 \\ 1.223623 & 0.3291 & 0.402694 \\ 0.690377 & 0.2141 & 0.14781 \\ 0.662292 & 0.1224 & 0.081064 \\ 0.537293 & 0.0399 & 0.021438 \\ & \text { sum } b(i)= & 2.795681\end{array}$

Computed $W=$

Tabulated $\boldsymbol{H}=$

Since the computed $W>$ Tabulated $W$

the residuals assume a normal distribution.
0.861841

0.842 $x(i)$
-0.7357
-0.66718
-0.20651
-0.09712
0.006875
0.090696
0.268403
0.419677
0.446726
0.460807
0.468723
0.486761
std dev $=$ $x(n-i+1)$
0.486761
0.468723
0.460807
0.446726
0.419677
0.268403
0.090696
0.006875
-0.09712
-0.20651
-0.66718
-0.7357
0.435836

$\begin{array}{rrr} & a(n-i+1) & b(i) \\ 1.222466 & 0.5475 & 0.6693 \\ 1.135904 & 0.3325 & 0.377688 \\ 0.66732 & 0.2347 & 0.15662 \\ 0.543847 & 0.1586 & 0.086254 \\ 0.412801 & 0.0922 & 0.03806 \\ 0.1777707 & 0.0303 & 0.005385 \\ & \text { sum } b(i)= & 1.333307\end{array}$

Computed $\boldsymbol{H}=$

Tabulated $\boldsymbol{U}=$

0.850799

0.859 $x(i)$

$-1.17179$

$-0.6373$

$-0.46078$

$-0.26596$

$-0.17101$

$-0.05921$

$-0.00734$

0.249052

0.274091

0.46437

0.497538

0.603378

0.684946

std dev $=$
$x(n-i+1)$
0.684946
0.603378
0.497538
0.46437
0.274091
0.249052
$-0.00734$
$-0.05921$
$-0.17101$
$-0.26596$
$-0.46078$
$-0.6373$
$-1.17179$
0.542266

Computed $H=$

Tabulated $W=$

Since the computed $U>$ Tabulated $W$

the residuals assume a normal distribution.
0.938938

0.859 
Well D1C

RESIDUAL

$-1.20016$

$-1.08977$

0.192706

0.852631

0.684344

1.328551

0.51982

0.237871

$-0.44824$

0.227096

$-0.62897$

$-0.1624$

$-0.51348$

$$
\begin{array}{cc}
x(i) & x(n-i+1) \\
-1.20016 & 1.328551 \\
-1.08977 & 0.852631 \\
-0.62897 & 0.684344 \\
-0.51348 & 0.51982 \\
-0.44824 & 0.237871 \\
-0.1624 & 0.227096 \\
0.192706 & 0.192706 \\
0.227096 & -0.1624 \\
0.237871 & -0.44824 \\
0.51982 & -0.51348 \\
0.684344 & -0.62897 \\
0.852631 & -1.08977
\end{array}
$$

Computed $W=$

$a(n-i+1) \quad b(i)$

$\begin{array}{lrr}2.528716 & 0.5475 & 1.384472\end{array}$

1.942398

1.313316

0.3325

0.645847

1.033297

0.2347

0.308235

0.686114

0.1586

0.163881

0.389492

0.0922

0.06326

0.0303

0.011802

sum $b(i)=2.577497$

Below are the shaprio-wilks tests for the conductivity linear regression residuals.

$$
\begin{gathered}
\text { Well DIa } \\
\text { RESIDUAL } \\
-0.024 \\
0.0067 \\
0.0042 \\
0.003 \\
0.0166 \\
0.0064 \\
0.0134 \\
-0.01 \\
-0.004 \\
-0.008 \\
-0.017 \\
0.0118 \\
0.0015
\end{gathered}
$$

Well Familian

$$
\text { RESIDUAL }
$$

-0.267
0.113

0.0955

0.1006

0.1012

0.077

$-0.155$

Well D1C

RESIDUAL

$-0.022$

$-0.016$

0.0118

0.0166

0.0541

0.0416

$-0.035$

$-0.03$

$-0.028$

$-0.02$

$-0.02$

0.0252

0.0219

$$
\begin{array}{r}
x(i) \\
-0.024 \\
-0.017 \\
-0.01 \\
-0.008 \\
-0.004 \\
0.0015 \\
0.003 \\
0.0042 \\
0.0064 \\
0.0067 \\
0.0118 \\
0.0134 \\
0.0166 \\
0.0121
\end{array}
$$

std dev $=0.0121$

$$
\begin{aligned}
& \begin{array}{r}
x(n-i+1) \\
0.0166 \\
0.0134 \\
0.0118 \\
0.0067 \\
0.0064 \\
0.0042 \\
0.003 \\
0.0015 \\
-0.004 \\
-0.008 \\
-0.01 \\
-0.017 \\
-0.024 \\
\text { the resic }
\end{array} \\
& -0.024 \text { since the computed } W>\text { tabulated } W
\end{aligned}
$$$$
0.5350^{a(n-i+1)} b(i)
$$$$
0.5359 \quad 0.0215
$$$$
0.3325 \quad 0.0102
$$$$
0.2412 \quad 0.0053
$$$$
0.1707 \quad 0.0026
$$$$
0.1099 \quad 0.0012
$$$$
0.0539 \quad 0.0001
$$$$
\operatorname{sun} b(i)=
$$$$
0.0001
$$$$
0.0409
$$$$
\text { Computed } \mathrm{W}=
$$$$
\text { Tabulated } \boldsymbol{H}=
$$$$
0.9537
$$$$
0.866
$$

0.964166

0.859 the residuals assume a normal dist.

$\begin{array}{cc} & x(i) \\ 1 & -0.267 \\ 2 & -0.155 \\ 3 & 0.077 \\ 4 & 0.0955 \\ 5 & 0.1006 \\ 6 & 0.1012 \\ 7 & 0.113 \\ & \text { std dev }=\end{array}$

$$
\begin{array}{r}
x(n-i+1) \\
0.113 \\
0.1012 \\
0.1006 \\
0.0955 \\
0.077 \\
-0.155 \\
-0.267 \\
0.1544
\end{array}
$$

$$
\text { Tabulated } W=
$$

The residuals DO NOT fit a normal dist.
0.318

$$
\begin{array}{rr}
0.6233 & a(n-i+1) \\
0.3031 & 0.237 \\
0.1401 & 0.0776 \\
\text { sum } b(i)= & 0.0033
\end{array}
$$

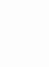

0.707
0.803




\begin{tabular}{|c|c|c|c|c|c|c|}
\hline $\begin{array}{c}\text { Hell G1 } \\
\text { RESIDUAL } \\
-0.02 \\
0.0028 \\
-0.002 \\
0.0016 \\
0.0138 \\
0.002 \\
0.0012 \\
0.002 \\
0.0088 \\
0.0105 \\
0.0185 \\
-0.033\end{array}$ & $\begin{array}{r}1 \\
2 \\
3 \\
4 \\
5 \\
6 \\
7 \\
8 \\
9 \\
10 \\
11 \\
12\end{array}$ & $\begin{array}{r}x(i) \\
-0.033 \\
-0.02 \\
-0.002 \\
0.0012 \\
0.0016 \\
0.002 \\
0.002 \\
0.0028 \\
0.0088 \\
0.0105 \\
0.0138 \\
0.0185 \\
\text { std dev }=\end{array}$ & $\begin{array}{c}x(n-i+1) \\
0.0185 \\
0.0138 \\
0.0105 \\
0.0088 \\
0.0028 \\
0.002 \\
0.002 \\
0.0016 \\
0.0012 \\
-0.002 \\
-0.02 \\
-0.033 \\
0.0142\end{array}$ & $\begin{array}{r}0.5475 \\
0.3325 \\
0.2347 \\
0.1586 \\
0.0922 \\
0.0303 \\
\text { sum b(i) }=\end{array}$ & $\begin{array}{r}B(n-j+1) \\
0.028 \\
0.0113 \\
0.0029 \\
0.0012 \\
0.0001 \\
5 e-07 \\
=\quad \\
W= \\
W=\end{array}$ & fit a normal dist. \\
\hline $\begin{array}{c}\text { Hell G2 } \\
\text { RESIDUAL } \\
0.0109 \\
-0.023 \\
-0.024 \\
0.0031 \\
0.0125 \\
0.0091 \\
0.0104 \\
0.0091 \\
0.0136 \\
0.0085 \\
0.0097 \\
-0.034\end{array}$ & $\begin{array}{r}1 \\
2 \\
3 \\
4 \\
5 \\
6 \\
7 \\
8 \\
9 \\
10 \\
11 \\
12\end{array}$ & $\begin{array}{r}x(i) \\
-0.034 \\
-0.024 \\
-0.023 \\
0.0031 \\
0.0085 \\
0.0091 \\
0.0091 \\
0.0097 \\
0.0104 \\
0.0109 \\
0.0125 \\
0.0136 \\
\text { std dev }=\end{array}$ & $\begin{array}{c}x(n-\mathrm{i}+1) \\
0.0136 \\
0.0125 \\
0.0109 \\
0.0104 \\
0.0097 \\
0.0091 \\
0.0091 \\
0.0085 \\
0.0031 \\
-0.023 \\
-0.024 \\
-0.034 \\
0.017\end{array}$ & $\begin{array}{l}0.5475 \\
0.3325 \\
0.2347 \\
0.1586 \\
0.0922 \\
0.0303 \\
\text { Sum b(i) = } \\
\text { Computed } \\
\text { Tabulated }\end{array}$ & $\begin{array}{l}a(n-i+1) \\
0.0261 \\
0.0123 \\
0.008 \\
0.0012 \\
0.0001 \\
2 e-06 \\
=\quad \\
W= \\
W=\end{array}$ & $\begin{array}{r}0.7099 \\
0.859 \\
\text { fit a normal dist. }\end{array}$ \\
\hline $\begin{array}{c}\text { Hell G3 } \\
\text { RESIDUAL } \\
0.1126 \\
-0.022 \\
-0.028 \\
-0.03 \\
-0.067 \\
-0.014 \\
-0.016 \\
-0.003 \\
0.005 \\
0.043 \\
0.0249 \\
-0.023\end{array}$ & $\begin{array}{r}1 \\
2 \\
3 \\
4 \\
5 \\
6 \\
7 \\
8 \\
9 \\
10 \\
11 \\
12\end{array}$ & $\begin{array}{r}x(i) \\
-0.067 \\
-0.03 \\
-0.028 \\
-0.023 \\
-0.022 \\
-0.016 \\
-0.014 \\
-0.003 \\
0.005 \\
0.0249 \\
0.043 \\
0.1126 \\
\text { std dev }=\end{array}$ & $\begin{array}{c}x(n-i+1) \\
0.1126 \\
0.043 \\
0.0249 \\
0.005 \\
-0.003 \\
-0.014 \\
-0.016 \\
-0.022 \\
-0.023 \\
-0.028 \\
-0.03 \\
-0.067 \\
0.0456\end{array}$ & $\begin{array}{l}0.5475 \\
0.3325 \\
0.2347 \\
0.1586 \\
0.0922 \\
0.0303 \\
\text { Sum b(i) }= \\
\text { Computed } \\
\text { Tabulated } \\
\text { Since the } \\
\text { the residu }\end{array}$ & $\begin{array}{c}(n-\mathrm{i}+1) \\
0.0984 \\
0.0244 \\
0.0124 \\
0.0044 \\
0.0018 \\
4 \mathrm{e}-05\end{array}$ & $\begin{array}{l}0.1414 \\
\quad 0.8764 \\
0.859 \\
\quad>\text { tabulated } W \\
\text { a normal dist. }\end{array}$ \\
\hline $\begin{array}{c}\text { Hell G5a } \\
\text { RESIDUAL } \\
-0.136 \\
-0.047 \\
0.0368 \\
0.0532 \\
0.0659 \\
0.116 \\
0.079 \\
-0.005 \\
-0.061 \\
-0.04 \\
-0.033 \\
-0.017 \\
-0.005\end{array}$ & $\begin{array}{r}1 \\
2 \\
3 \\
4 \\
5 \\
6 \\
7 \\
8 \\
9 \\
10 \\
11 \\
12 \\
13\end{array}$ & $\begin{array}{r}x(i) \\
-0.136 \\
-0.061 \\
-0.047 \\
-0.04 \\
-0.033 \\
-0.017 \\
-0.005 \\
-0.005 \\
0.0368 \\
0.0532 \\
0.0659 \\
0.071 \\
0.116 \\
\text { std dev }=\end{array}$ & $\begin{array}{c}x(n-i+1) \\
0.116 \\
0.071 \\
0.0659 \\
0.0532 \\
0.0368 \\
-0.005 \\
-0.005 \\
-0.017 \\
-0.033 \\
-0.04 \\
-0.047 \\
-0.061 \\
-0.136 \\
0.0673\end{array}$ & $\begin{array}{r}\text { a } \\
0.5359 \\
0.3325 \\
0.2412 \\
0.1707 \\
0.1099 \\
0.0539 \\
\text { Sum b(i) = } \\
\text { Computed } \\
\text { Tabulated }\end{array}$ & $\begin{array}{c}a(n-i+1) \\
0.1348 \\
0.0439 \\
0.0273 \\
0.0159 \\
0.0077 \\
0.0007 \\
=\end{array}$ & $\begin{array}{l}>\text { tabulated } W \\
\text { a normal dist. }\end{array}$ \\
\hline
\end{tabular}


Hel I G5b RESIDUAL

0.0025

0.0095

0.0103

$-0.008$

$-8 e-04$

$-0.02$

$-0.009$

0.0022

0.006

0.0036

0.0013

0.0021

Well G6

RESIDUAL

$-0.007$

$-0.011$

$-5 e-05$

0.0011

0.0093

0.0085

0.001

0.0076

0.0044

0.0035

$-0.004$

$-0.003$

Hell G7

RESIDUAL

0.0141

0.0204

2e-06

$-0.019$

$-0.054$

$-0.009$

0.0155

0.0132

0.0276

0.0102

$-0.019$

Hell G8a

RESIDUAL

0.0056

0.0221

$-0.369$

$-0.022$

$-0.419$

0.296

0.3681

0.4041

0.3262

0.2918

$-0.492$

$\begin{array}{rrr} & x(i) & x(n-i+1) \\ 1 & -0.02 & 0.0103 \\ 2 & -0.009 & 0.0095 \\ 3 & -0.008 & 0.006 \\ 4 & -8 e-04 & 0.0036 \\ 5 & 0.0013 & 0.0025 \\ 6 & 0.0021 & 0.0022 \\ 7 & 0.0022 & 0.0021 \\ 8 & 0.0025 & 0.0013 \\ 9 & 0.0036 & -8 e-04 \\ 10 & 0.006 & -0.008 \\ 11 & 0.0095 & -0.009 \\ 12 & 0.0103 & -0.02\end{array}$

$\begin{array}{lcc} & a(n-i+1) & b(i) \\ 0.5475 & 0.0163 & \\ 0.3325 & 0.0061 & \\ 0.2347 & 0.0033 & \\ 0.1586 & 0.0007 & \\ 0.0922 & 0.0001 & \\ 0.0303 & 4 e-06 & \\ \text { Sum } b(i)= & 0.0266 & \\ & & 0.8939 \\ \text { Computed } W= & 0.859 \\ \text { Tabulated } W= & \\ \text { Since the computed } W>\text { tabulated } W \\ \text { the residuals assume a normal dist. }\end{array}$

$x(i)$ $-0.011$

$-0.007$

$-0.004$

$-0.003$

$-5 e-05$

0.001

0.0011

0.0035

0.0044

0.0076

0.0085

0.0093

$x(n-i+1)$

0.0093

0.0085

0.0076

0.0044

0.0035

0.0011

0.001

$-5 e-05$

$-0.003$

$-0.004$

$-0.007$

std dev $=0.0062$

$\begin{array}{rrr} & x(i) & x(n-i+1) \\ 1 & -0.054 & 0.0276 \\ 2 & -0.019 & 0.0204 \\ 3 & -0.019 & 0.0155 \\ 4 & -0.009 & 0.0141 \\ 5 & 2 e-06 & 0.0132 \\ 6 & 0.0102 & 0.0102 \\ 7 & 0.0132 & 2 e-06 \\ 8 & 0.0141 & -0.009 \\ 9 & 0.0155 & -0.019 \\ 10 & 0.0204 & -0.019 \\ 11 & 0.0276 & -0.054 \\ & \text { std dev }=0.0238\end{array}$

$\begin{array}{lrr} & a(n-i+1) & b(i) \\ 0.5601 & 0.0458 & \\ 0.3315 & 0.0132 & \\ 0.226 & 0.0078 & \\ 0.1429 & 0.0033 & \\ 0.0695 & 0.0009 & \\ \text { Sum } b(i)= & & 0.0 \\ & \\ \text { Computed } H= \\ \text { Tabulated } \mathrm{H}=\end{array}$

0.0709

Tabulated $\mathbf{W}=$

Since the computed $W>$ tabulated $H$ the residuals assume a normal dist.

$\begin{array}{ccc} & x(i) & x(n-i+i) \\ 1 & -0.492 & 0.4041 \\ 2 & -0.419 & 0.3681 \\ 3 & -0.369 & 0.3262 \\ 4 & -0.022 & 0.296 \\ 5 & 0.0056 & 0.2918 \\ 6 & 0.0221 & 0.0221 \\ 7 & 0.2918 & 0.0056 \\ 8 & 0.296 & -0.022 \\ 9 & 0.3262 & -0.369 \\ 10 & 0.3681 & -0.419 \\ 11 & 0.4041 & -0.492 \\ & \text { std dev }=0.3342\end{array}$

$$
\begin{array}{lcc} 
& a(n-i+1) & b(i) \\
0.5601 & 0.5017 & \\
0.3315 & 0.261 & \\
0.226 & 0.1571 & \\
0.1429 & 0.0454 & \\
0.0695 & 0.0199 & \\
\text { sum } b(i)= & & 0.985 \\
& & \\
\text { Computed } W= \\
\text { Tabulated } W=
\end{array}
$$

\subsection{7}

0.85

Since the computed $W>$ tabulated $W$ the residuals assume a normal dist. 
Well G8b

RESIDUAL

$-0.006$

0.0873

0.0509

0.0582

$-0.071$

$-0.091$

$-0.094$

$-0.086$

$-0.023$

0.0207

0.0507

$\begin{array}{rr}x(i) & x(n-i+1) \\ -0.094 & 0.0873 \\ -0.091 & 0.0582 \\ -0.086 & 0.0509 \\ -0.071 & 0.0507 \\ -0.023 & 0.0207 \\ -0.006 & -0.006 \\ 0.0207 & -0.023 \\ 0.0507 & -0.071 \\ 0.0509 & -0.086 \\ 0.0582 & -0.091 \\ 0.0873 & -0.094 \\ \text { std dev }=0.0676\end{array}$

$\begin{array}{rrr} & a(n-i+1) & b(i) \\ 0.5601 & 0.1013 & \\ 0.3315 & 0.0494 & \\ 0.226 & 0.0309 & \\ 0.1429 & 0.0174 & \\ 0.0695 & 0.003 & \\ \text { Sum } b(i)= & & 0.202\end{array}$

$b(i)$

Tabulated $\hat{H}=$

since the computed $W>$ tabulated $W$

the residuals assume a normal dist.

Well GBC

RESIDUAL

$-0.023$

$-0.003$

0.0183

0.0336

0.0073

$-0.023$

$-0.014$

$-0.001$

$-0.002$

0.014

$x(i)$

$-0.023$

$x(n-i+1)$

$-0.023$

$-0.014$

$-0.003$

$-0.002$

$-0.001$

0.0073

0.0102

0.014

0.0336

0.0183

0.014

0.0102

0.0073

$-0.001$

$-0.002$

$-0.003$

$-0.014$

0.0183

$-0.023$

$0.0336 \quad-0.023$

$\begin{array}{lrl} & a(n-i+1) & b(i) \\ 0.5601 & 0.0318 & \\ 0.3315 & 0.0137 & \\ 0.226 & 0.0063 & \\ 0.1429 & 0.002 & \\ 0.0695 & 0.0006 & \\ \text { um } b(i)= & 0.0544 & \\ & & 0.9647 \\ \text { Computed } W= & 0.85 \\ \text { Tabulated } W= & \\ & & \\ \text { ince the computed } W>\text { tabulated } W\end{array}$

0.8947

.2021

0.85 
APPENDIX D

BAROMETRIC PRESSURE ANALYSIS 
The observed barometric pressure at the Portland International Airport for January through June 1993 is shown in Figure $D-1$ (a). Spectral analysis of the barometric time series, Figure $D-1$ (b), shows two primary spikes at 0.06 and 0.19 cycles/day ( 16.7 and 5.3 days respectively), and two lessor spikes at 1.0 and 2.0 cycles/day ( 1.0 and 0.5 days).

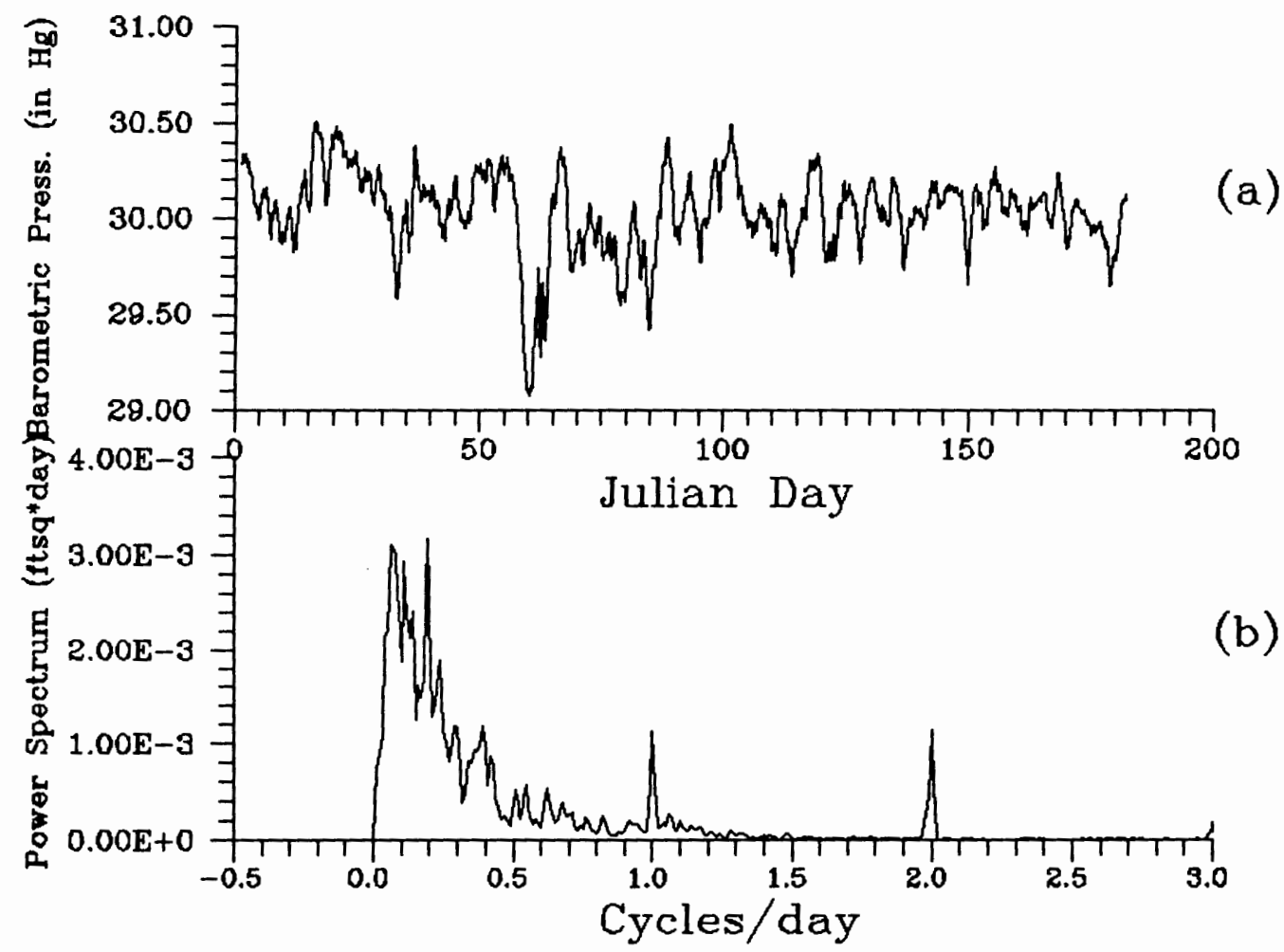

Figure $D-1$ observed barometric pressure time series January through June of 1991 (a). Power spectrum for the observed barometric time series (b). 
APPENDIX E

SHAPIRO - WILKS TEST ON IOG TRANSFORMED HYDRAULIC

CONDUCTIVITY 
Below is the sapiro-wilks test on the natural log transformed hydraulic conductivities (see Table E-I) for the perimeter dike and interior landfill soils.

\section{TABLE E-I}

OBSERVED HYDRAULIC CONDUCTIVITIES FOR THE ILANDFILL INTERIOR AND PERIMETER DIKE

\begin{tabular}{|c|c|c|c|}
\hline $\begin{array}{c}\text { Interior Hydraulic } \\
\text { Conductivity } \\
(\mathrm{ft} / \mathrm{s})\end{array}$ & Log Transformed & $\begin{array}{c}\text { Perimeter Dike } \\
\text { Hydraulic Conductivity } \\
(\mathrm{ft} / \mathrm{s})\end{array}$ & Log Transformed \\
\hline $3.06 \times 10^{-8}$ & -173023 & $1.97 \times 10^{-7}$ & -15.4401 \\
\hline $7.12 \times 10^{-8}$ & -18.7604 & $6.56 \times 10^{-9}$ & -18.8423 \\
\hline $8.76 \times 10^{-9}$ & -18.5531 & $1.97 \times 10^{-7}$ & -15.4401 \\
\hline $1.48 \times 10^{-8}$ & -18.0286 & $3.28 \times 10^{-8}$ & -17.2328 \\
\hline \multirow[t]{12}{*}{$1.15 \times 10^{-7}$} & -15.9783 & $1.31 \times 10^{-7}$ & -15.8481 \\
\hline & & $1.64 \times 10^{-7}$ & -15.6234 \\
\hline & & $9.84 \times 10^{-10}$ & -20.7394 \\
\hline & & $9.84 \times 10^{-8}$ & -16.1342 \\
\hline & & $1.31 \times 10^{-8}$ & -18.1507 \\
\hline & & $3.28 \times 10^{-\theta}$ & -19.5354 \\
\hline & & $3.28 \times 10^{-8}$ & -17.2328 \\
\hline & & $3.28 \times 10^{-7}$ & -14.9303 \\
\hline & & $6.56 \times 10^{-8}$ & -16.5397 \\
\hline & & $9.84 \times 10^{-9}$ & -18.4368 \\
\hline & & $1.64 \times 10^{-8}$ & -17.9260 \\
\hline & & $3.28 \times 10^{-7}$ & -14.9303 \\
\hline
\end{tabular}

PERIMETER DIKE

$\begin{array}{lrrrrl}x(i) & x(n-i+1) & a(n-i+1) & b(i) & \\ -20.7233 & -14.9141 & 0.5056 & 2.937103 & \\ -19.5193 & -14.9141 & 0.329 & 1.515101 & \text { Shapiro-Wilks Test } \\ -18.8261 & -15.4249 & 0.2521 & 0.857442 & W=0.936754 \\ -18.4207 & -15.4249 & 0.1939 & 0.580872 & & \\ -18.133 & -15.6073 & 0.1447 & 0.365473 & \text { Tabulated } W & \\ -17.9099 & -15.8304 & 0.1005 & 0.208984 & W= & 0.887 \\ -17.2167 & -16.1181 & 0.0593 & 0.065148 & \\ -17.2167 & -16.5236 & 0.0196 & 0.013586 & \\ -16.5236 & -17.2167 & \text { sum } b(i)= & 6.543708 & \\ -16.1181 & -17.2167 & & & \\ -15.8304 & -17.9099 & & & \\ -15.6073 & -18.133 & & & \\ -15.4249 & -18.4207 & & & \end{array}$




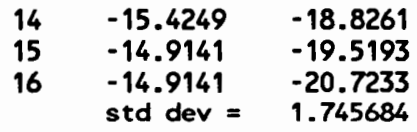

INTERIOR H-WELLS

$\begin{array}{rrrrrl}x(i) & x(n-i+1) & a(n-i+1) & b(i) & & \\ -18.7586 & -15.9743 & 0.6646 & 1.850455 & \\ -18.5558 & -17.2869 & 0.2413 & 0.306183 & \text { Shapiro-Wilks Test } \\ -18.0903 & -18.0903 & \text { Sum } b(i)= & 2.156637 & W= & 0.903358 \\ -17.2869 & -18.5558 & & & & \\ -15.9743 & -18.7586 & & & \text { Tabulated } W & \\ \text { std dev }= & 1.134533 & & & W= & 0.762\end{array}$

Testing for equality in variances at the $95 \%$ confidence level the null hypothesis being, $H_{n}: \sigma_{1}=\sigma_{2}$, and the alternative hypothesis being, $\mathrm{H}_{\mathrm{a}}: \sigma_{1} \neq \sigma_{2}$.

$$
\begin{aligned}
F_{c} & =\frac{S_{1}^{2}}{S_{2}^{2}}=\frac{3.04741}{1.28714} \\
F_{c} & =2.368 \\
F & =4.62(\text { at } \alpha=0.05)
\end{aligned}
$$

Since $F_{c}=2.368<F=4.62$ can not reject the null hypothesis. Test for equality in means at the 95\% confidence level the null hypothesis being, $\mathrm{H}_{\mathrm{n}}: \mu_{1}-\mu_{2}=0$, and the alternative hypothesis being, $\mathrm{H}_{\mathrm{a}}: \mu_{1}-\mu_{2} \neq 0$.

$$
\begin{aligned}
& T_{c}=\frac{\overline{x_{1}}-\overline{x_{2}}}{\left[\left(n_{1}+n_{2}\right)\left[\left(n_{1}-1\right) s_{1}^{2}+\left(n_{2}-1\right) s_{2}^{2}\right] /\left[n_{1} n_{2}\left(n_{1}+n_{2}-2\right)\right]\right]^{1 / 2}} \\
& T_{c}=\frac{17.0452-17.73318}{[(16+5)[(14)(3.04741)+(4)(1.28714)] /[(16)(5)} \\
& T_{c}=1.18 \\
& T=2.09(\text { at } \alpha=0.05)
\end{aligned}
$$


Since $\mathrm{T}_{c}=1.18<\mathrm{T}=2.09$ can not reject the null hypothesis. 
APPENDIX F

ESTIMATION OF VERTICAL SEEPAGE 
The time averaged vertical seepage at multi-completion wells Dlac, G5ab, and G8abc is presented below in Table F-I.

\section{TABLE F-I}

TIME AVERAGED VERTICAL SEEPAGE ESTIMATES AT MULTI-COMPLETION WELLS DIAC, G5AB, AND G8ABC

\begin{tabular}{|c|c|c|c|}
\hline Well & $\begin{array}{c}\text { Time Averaged } \\
\text { Vertical Gradient } \\
(\mathrm{ft} / \mathrm{ft})\end{array}$ & $\begin{array}{c}\text { Hydraulic Conductivity } \\
(\mathrm{ft} / \mathrm{s})\end{array}$ & $\begin{array}{c}\text { Vertical Seepage } \\
\left(\mathrm{ft}^{3} / \mathrm{ft}^{2} / \text { day }\right)\end{array}$ \\
\hline $\begin{array}{c}\text { G5ab } \\
\text { Sandy/Gravel }\end{array}$ & $1.726 \times 10^{-5}$ & 390 & $6.73 \times 10^{-3}$ \\
\hline $\begin{array}{c}\text { G8abc } \\
\text { Sandy/Gravel }\end{array}$ & $6.804 \times 10^{-4}$ & 390 & $2.65 \times 10^{-1}$ \\
\hline $\begin{array}{c}\text { D1ac } \\
\text { Clay }\end{array}$ & $-3.597 \times 10^{-3}$ & $10^{-4}$ & $3.6 \times 10^{-7}$ \\
\hline \multicolumn{1}{|c|}{$\begin{array}{c}\text { Average Vertical } \\
\text { Seepage }\end{array}$} & & $9.07 \times 10^{-2}$ \\
\hline
\end{tabular}

The average of the three wells could be used to approximate the vertical seepage within the landfill. However, assuming the groundwater mound within the landfill does not significantly influence groundwater levels in the sandy/gravel aquifer, a more representative method would be to estimate the hydraulic head below one of the interior monitoring wells (H1 through H5) interpolated from the hydraulic heads at monitoring wells Dlac, G5ab, G8abc. An estimated vertical gradient is then computed between the known head at one of the $\mathrm{H}$-wells and the estimated head below the H-well. Figure 3 of the thesis text shows that monitoring well H5 lies very close to a line drawn between monitoring wells G8abc and G5ab, therefore well H5 was used for the vertical gradient analysis. The hydraulic head in the sandy/gravel aquifer beneath 
monitoring well H5 was approximated by linear interpolation between the hydraulic head at monitoring wells G8abc and G5ab, see Figure F-1. Estimates for the hydraulic head were computed from equation $\mathrm{F}-1$.

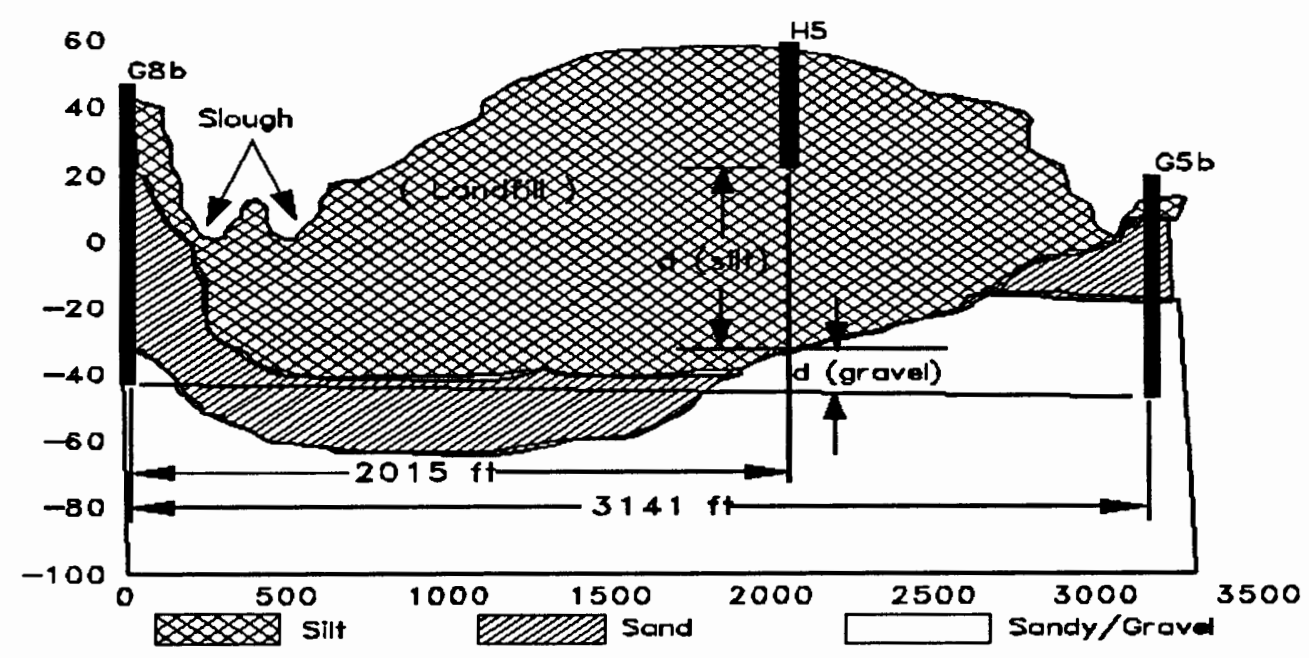

Figure $F-1$ Vertical soil profile from monitoring well G8abc to G5ab showing lengths and depths used to estimate groundwater levels beneath monitoring well H5.

$$
h_{H 5} \approx h_{G 5 b}+\left(h_{G 8 b}-h_{G 5 b}\right)\left(\frac{d-d^{\prime}}{d}\right)
$$

where: $d^{\prime}=2014 \mathrm{ft}$

$$
\mathrm{d}=3141 \mathrm{ft}
$$

The resultant hydraulic head time series is shown in Figure $\mathrm{F}-2$, also shown is the observed hydraulic head in monitoring well H5 (Parametrix Inc. and CH2MHill).

Also necessary for the vertical gradient analysis was the 
vertical elevation of the estimated hydraulic head. Estimates for the elevation were interpolated from monitoring well G8b and G5b elevations using equation $\mathrm{F}-1$.

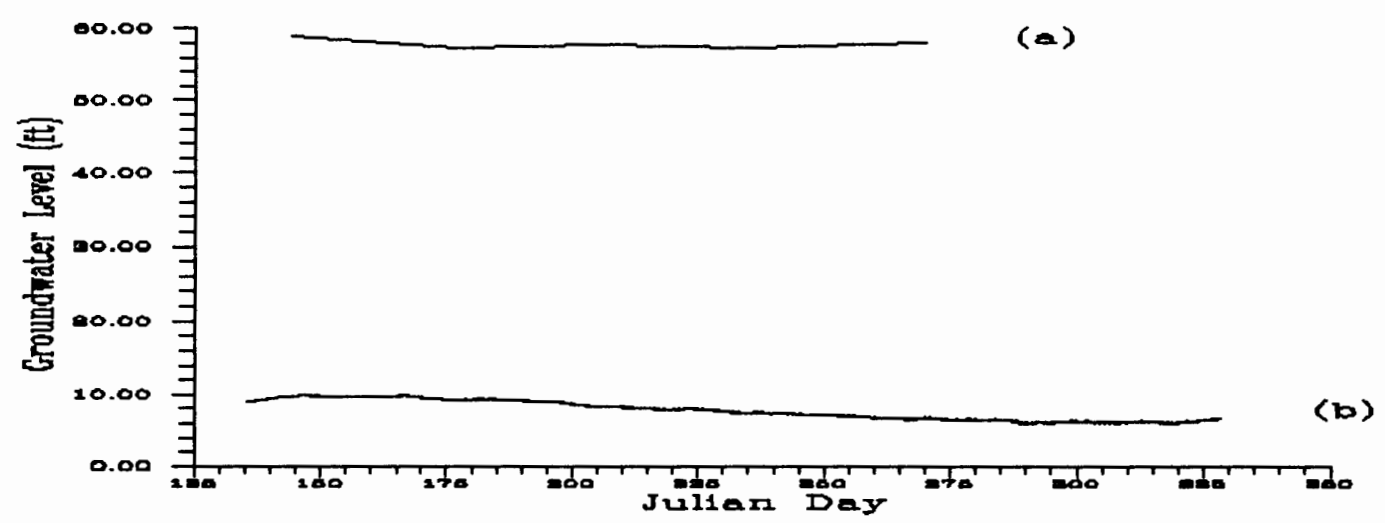

Figure F-2 Hydraulic head in monitoring well H5 (a), and estimated hydraulic head (b) beneath monitoring well H5, interpolated from hydraulic heads at monitoring wells Grabc and $G 5$.

To compute the vertical hydraulic gradient between the base of monitoring well $\mathrm{H} 5$ and the estimated hydraulic head in the sandy/gravel aquifer, the relative depth of each soil stratum must be known. Depths to the top of the sandy/gravel aquifer (-30 ft) were obtained from Fishman, (1986). Monitoring well H5 lies within the zone were silts are in direct contact with the sandy/gravel aquifer (i.e. there is no sandy aquifer between the two stratums, Fishman (1986)). Approximate depths for each soil stratum were:

$$
\begin{gathered}
d_{\text {(silt) }}=21.625-(-30)=51.6 \mathrm{ft} \\
d_{\text {(sandy/gravel) }}=-30-(-43.1)=13.1 \mathrm{ft}
\end{gathered}
$$


Estimates of the vertical hydraulic gradient below monitoring well $\mathrm{H} 5$ for the silt aquitard are summarized in Table F-II.

$$
\text { TABLE F-II }
$$

\section{ESTIMATED VERTICAL HYDRAULIC GRADIENT BELOW MONITORING WELL H5}

\begin{tabular}{||c|c|c|c|c||}
\hline Jul ian Day & $\begin{array}{c}\text { H5 Hydraul ic Head } \\
(\mathrm{ft})\end{array}$ & $\begin{array}{c}\text { Interpolated Head } \\
\text { Below H5 (ft) }\end{array}$ & $\begin{array}{c}\text { Hydraul ic Head at } \\
\text { Interface (ft) }\end{array}$ & $\begin{array}{c}\text { Vertical Hydraulic } \\
\text { Gradient in Silt (ft/ft) }\end{array}$ \\
\hline 144 & 58.83 & 9.71 & 9.7101 & 0.9515 \\
\hline 177 & 57.33 & 9.19 & 9.1901 & 0.9325 \\
\hline 205 & 57.88 & 8.35 & 8.3501 & 0.9594 \\
\hline 234 & 57.40 & 7.40 & 7.4001 & 0.9685 \\
\hline 270 & 57.90 & 6.71 & 6.7101 & 0.9916 \\
\hline \multicolumn{4}{|c|}{ Average Vertical Gradient } \\
\hline
\end{tabular}

The average vertical hydraulic gradient beneath monitoring well $\mathrm{H} 5$ was 0.9607 (ft/ft). Using an average hydraulic conductivity of $3.33 \times 10^{-8}(\mathrm{ft} / \mathrm{s})=2.88 \times 10^{-3}$ (ft/day), the estimated vertical seepage was,

$$
\begin{aligned}
q_{v} & \approx\left(2.88 \times 10^{-3}\right)(0.9607) \\
q_{v} & \approx 2.88 \times 10^{-3}\left(\mathrm{ft}^{3} / \mathrm{ft}^{2} \cdot \mathrm{day}\right) .
\end{aligned}
$$

Multiplying the vertical seepage by the landfill area of $\mathrm{A}=9.365 \times 10^{6}\left(\mathrm{ft}^{2}\right)$ the resultant vertical flow rate was,

$$
\begin{gathered}
Q_{v} \approx\left(2.88 \times 10^{-3}\right)\left(9.365 \times 10^{6}\right) \\
Q_{v} \approx 2.59 \times 10^{4}\left(\mathrm{ft}^{3} / \text { day }\right) .
\end{gathered}
$$

